\title{
BULLETIN
}

of the

\section{MEDICAL DEPARTMENT}

\author{
July 1, 1960
}

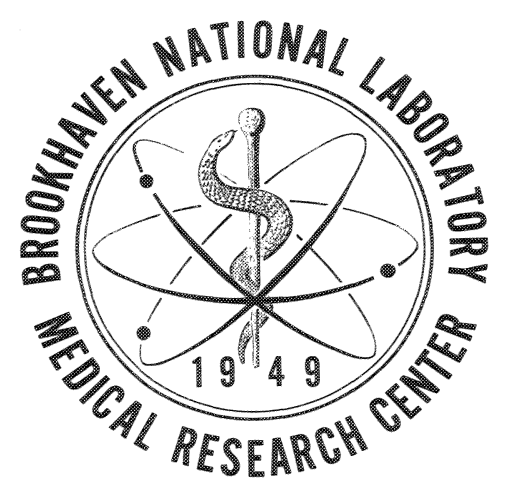

\section{BROOKHAVEN NATIONAL LABORATORY}

\author{
Associated Universities, Inc.
} under contract with the

United States Atomic Energy Commission 


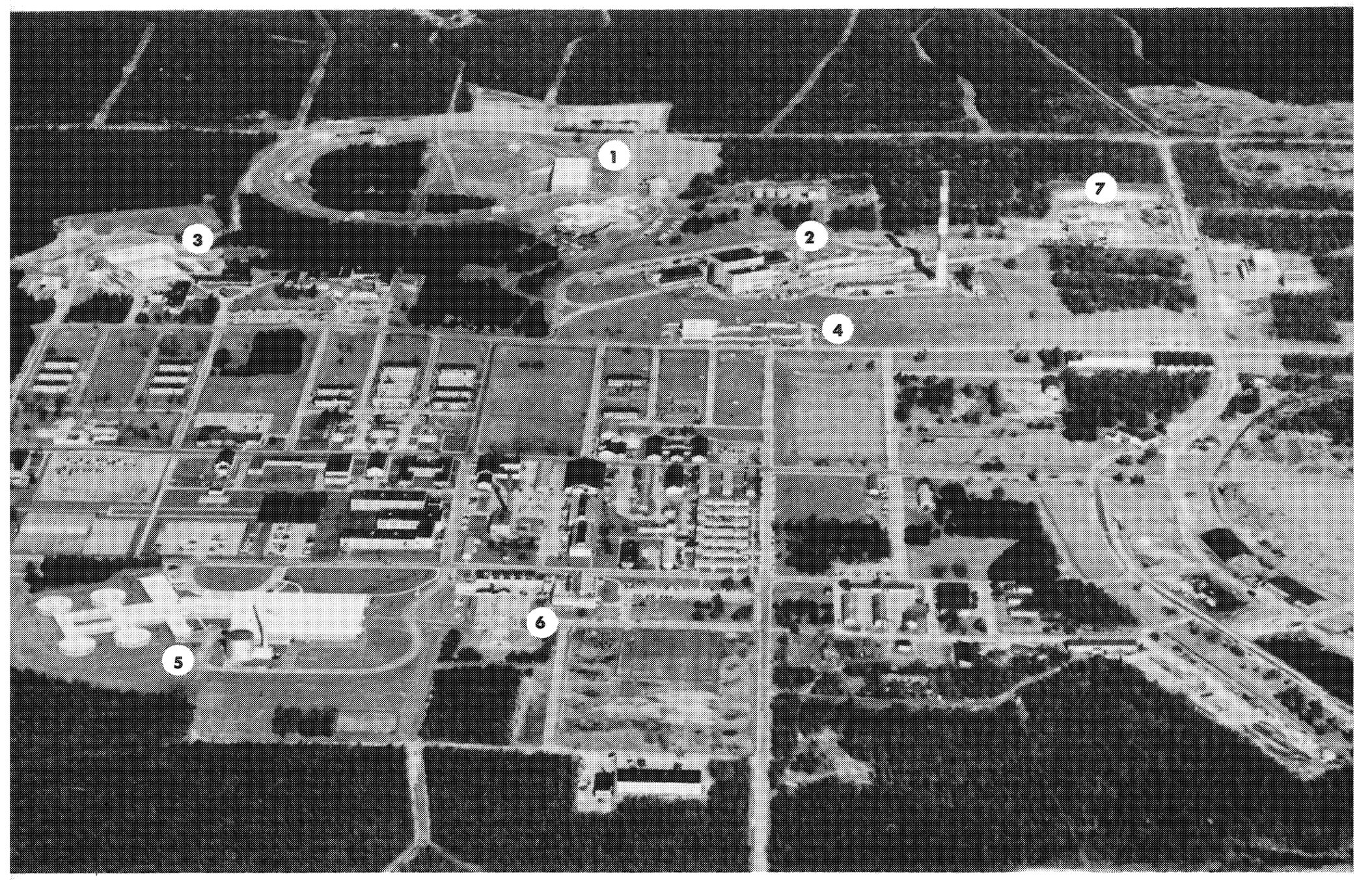

AERIAL VIEW OF THE LABORATORY SITE

1. Alternating Gradient Synchrotron.

2. Research Reactor and Hot Laboratory

3. Cosmotron

4. Cyclotron and Van de Graaff Building

5. Medical Research Center and Medical Reactor

6. Biology laboratories

7. Nuclear Engineering Building (under consfruction) 
Brookhaven National Laboratory is operated by Associated Universities, Inc., under contract with the United States Atomic Energy Commission. Nine northeastern universities sponsor Associated Universities, Inc. Two representatives from each university, one a principal administrative or corporate officer and the other a scientist, form the Board of Trustees of AUI. In addition, the Board itself selects three Trustees-at-Large. Their purpose is to insure adequate representation of any scientific discipline in which the corporation may undertake work and to provide general flexibility in methods of operation. The composition of the Board as of July 1960 is shown in the table below. AUI has appointed five visiting committees to Brookhaven National Laboratory to provide a continuing independent evaluation of the research program. These committees cover the fields of biology, chemistry, engineering, medicine, and physics, and report annually to the Board of Trustees.

\section{RALPH S. HALFORD}

TheOdORE P. WRIGHT

EDWARD REYNOLDS

P. Stewart Macaulay

Carl F. Floe

Joseph C. Elgin

Carl C. Chambers, Chairman

LAROY B. THOMPSON

C. Hamilton SAnford, JR.

\section{BOARD OF TRUSTEES \\ OF}

ASSOCIATED UNIVERSITIES, INC.

AS OF JULY 1,1960

Columbia University

Frank D. FAGKenthal (Honorary)

Cornell University

Harvard University

Johns Hopkins University

Massachusetts Institute of Technology

Princeton University

University of Pennsylvania

University of Rochester

Yale University

Trustees-at-Large

CARL K. Seyfert, * Vanderbilt University Leo Goldberg, University of Michigan

AlBERT E. WHITFORD, Lick Observatory

Ex Officio

Lloyd V. Berkner, President

*Deceased June 13, 1960

\section{OFFICERS OF ASSOCIATED UNIVERSITIES, INC.}

Chairman of the Board - Garl C. Ghambers

President - Lloyd V. BeRKNeR

Vice President - LeIAND J. HawORTH

Vice President - Otro Struve

Treasurer - JAMES S. AlEXANDER
Controller - LEWIS R. BURCHILI Secretary - CharLes F. DUNBAR Assistant Treasurer - JOSEPH F. LORD Assistant Secretary - Richard M. EMBERson 


\title{
VISITING COMMITTEE IN MEDICINE
}

VERnON W. Lippard, M.D., Chairman

Dean, Yale University School of Medicine

New Haven, Conn.

Term expires October 1960

Harold G. WolfF, M.D.

Professor of Neurology

Cornell University Medical College

525 East 68th St., New York 21, N.Y.

Term expires October 1960

JoHn C. Bugher, M.D.

Consultant in Nuclear Medicine

The Rockefeller Foundation, New York, N.Y.

Term expires October 1961

Thomas Francis, JR., M.D.

Professor and Chairman

Department of Epidemiology

University of Michigan School of Public Health

Ann Arbor, Mich.

Term expires October 1961
Robert A. Moore, M.D.

President, Downstate Medical Center

and Dean, School of Medicine

State University of New York at Brooklyn

450 Clarkson Ave., Brooklyn 3, N.Y.

Term expires October 1962

W.T.S. Thorp, D.V.M.

Dean, College of Veterinary Medicine

University of Minnesota, St. Paul 1, Minn.

Term expires October 1962

Joseph E. SMAdel, M.D.

Associate Director

National Institutes of Health, Bethesda $14, \mathrm{Md}$.

Term expires October 1963

Maxwell M. Wintrobe, M.D.

Professor and Head

Department of Internal Medicine

University of Utah School of Medicine

Salt Lake City, Utah

Term expires October 1963

\section{BROOKHAVEN NATIONAL LABORATORY OFFICERS AND CHAIRMEN OF SCIENTIFIC DEPARTMENTS}

\author{
Leland J. Haworth, Director \\ Gerald F. TAPE, Deputy Director
}

R. Christian Anderson, Assistant Director

Samuel M. Tucker, Assistant to Director

Charles E. FalK, Scientific Assistant to Director

G. Kenneth Green, Chairman, Accelerator Development Department

Howard J. Gurtis, Chairman, Biology Department

RICHARD W. Dodson, Chairman, Chemistry Department

J.B.H. Kuper, Chairman, Instrumentation and Health Physics Department LEE E. FARR, Medical Director and Chairman, Medical Department Ciarke Williams, Chairman, Nuclear Engineering Department

Maurice Goldhaber, Chairman, Physics Department

\section{REPRESENTATIVES OF THE}

\section{UNITED STATES ATOMIC ENERGY COMMISSION CONNECTED WITH THE MEDICAL DEPARTMENT AT BNL}

Charles L. Dunham, Director Division of Biology and Medicine U.S. Atomic Energy Commission Washington 25, D.C.
Emery L. Van Horn, Area Manager Brookhaven Area Office U.S. Atomic Energy Commission Upton, N.Y. 


\section{Laboratory Objectives and Program}

Brookhaven National Laboratory is a national research center in which the Laboratory staff and scientists from other institutions, especially those located in the northeastern United States, carry out fundamental and applied research in the nuclear sciences and related subjects as an integral part of the nation-wide program of the Atomic Energy Commission. It was established as a cooperative venture between nine leading northeastern universities (Columbia, Cornell, Harvard, Johns Hopkins, the Massachusetts Institute of Technology, the University of Pennsylvania, Princeton, the University of Rochester, and Yale) and the government in recognition of the need for large and expensive equipments, and concentrations of scientific manpower for the successful prosecution of nuclear research. The primary objectives of the Laboratory are:

1. To seek new knowledge in the nuclear sciences and related fields with emphasis on programs that require such large-scale research tools as nuclear reactors, accelerators, and special laboratories which are beyond the scope of most or all individual institutions.

2. To encourage appropriate use of its facilities by scientists of college, university, industrial, and other laboratories.

3. To assist the Atomic Energy Commission in the solution of specific problems by utilizing the Laboratory's unique facilities or the special talents of its staff.

4. To make use of the Laboratory as an important auxiliary in the training of scientists and engineers and otherwise to assist in the dissemination of scientific and technical knowledge.

The cooperative nature of the Brookhaven program is of paramount importance. A significant and increasing fraction of the scientists and engineers directly engaged in the scientific program is comprised of visitors from other institutions who take advantage of the special opportunities at Brookhaven to carry out specific research and to gain useful knowledge and experience.

These objectives, of pioneering in research fields requiring large and specialized equipment, of making the Laboratory's facilities available to visiting scientists, and of furthering the education and training of young scientists, exert a profound influence on the life of the Laboratory and on its planning with respect to both staff and facilities. Because of the constantly changing work and the rotation of the staff, a maximum degree of flexibility is demanded; the continuing presence of specially skilled groups and adequate and specialized laboratories and other facilities are required for the development, construction, and effective utilization of advanced scientific equipments; problems of housing, transportation, etc., are accentuated by the large number of scientists on temporary assignment, by the relative remoteness of the Laboratory from centers of population, and by the resort nature of the surrounding area. All these factors must be considered in the development of future plans.

The scientific program can be broadly divided into five general categories:

1. Fundamental studies of atomic nuclei, the particles which constitute them, and the forces involved in their structure.

2. Study and exploitation of the physical, chemical, and biological effects of nuclear radiation.

3. The use of nuclear tools such as neutrons, charged particles, gamma-rays, and isotopic tracers in all branches of scientific research.

4. Research and development not necessarily of a nuclear nature but useful in atomic energy development.

5. Useful applications of nuclear power.

The research is centered around, though not confined to, the use of several large equipments and other special facilities, which include a large, graphite-moderated, air-cooled nuclear reactor with accompanying laboratories suitable for work at low radiation levels; a small nuclear reactor for medical use; a hot chemistry laboratory for work at intermediate and high radiation levels; a proton synchrotron (the Cosmotron) which operates at approximately $3 \mathrm{Bev}$; a 60 -in. cyclotron capable of accelerating deuterons to somewhat in excess of $20 \mathrm{Mev}$; a $3.5-\mathrm{Mev}$ positive particle electrostatic accelerator; a 2-Mev electron electrostatic accelerator; and an 18-in. high-intensity cyclotron that 
accelerates protons to $3 \mathrm{Mev}$ and deuterons to 2 Mev. An Alternating Gradient Synchrotron for accelerating protons to approximately $30 \mathrm{Bev}$ is now undergoing final testing.

The scientific work is carried on by eight departments and three divisions: The Physics, Chemistry, Biology, Medical, Cosmotron, and Nuclear Engineering Departments, which conduct research and development in the indicated fields; the Accelerator Development Department, which is responsible for the design, construction, and operation of the large accelerators; the Instrumentation and Health Physics Department, which develops, constructs, and services nuclear instruments and is responsible for radiation protection throughout the Laboratory; the Reactor Division, which operates the Research Reactor; the Applied Mathematics Division; and the Mechanical Engineering Division.

\section{STAFFING}

The Laboratory scientific staff now includes approximately 310 "regular" members, 67 salaried and 14 nonsalaried postdoctoral research associates with tenure limited to two years, and 310 fulland part-time visitors from other institutions. Of the last group, approximately 200 spend a significant fraction of their time at the Laboratory, an average of about 100 actually being on site at any one time.

The Laboratory's mission of conducting research primarily in the more basic aspects of the atomic energy program, and in particular the objective of making its facilities available to visiting scientists including students, can be fully realized only by considerable expansion in the staff. In many of the activities in which Brookhaven engages, opportunities elsewhere are few in number or nonexistent. Implementation of existing budget requests should bring the continuing staff toward a well-rounded and effective size in many of the Laboratory's activities, as they provide for a staff in June 1961 of approximately 500 staff scientists, including 100 research associates, and 2000 supporting personnel. The average number of visiting scientists working on site will increase to 150 or more.

It is anticipated that with increased emphasis on basic research programs in the field of atomic energy and with the addition at Brookhaven of more advanced research tools and facilities, the scientific staff may double its present size in perhaps ten years. 


\title{
The Medical Department Program
}

\author{
Lee E. Farr, M.D. \\ Medical Director and Chairman, Medical Department
}

To distinguish certain efforts in the clinical and scientific practices of medicine peculiar to our times, the term "nuclear medicine" is becoming established in our lexicon. Nuclear medicine may be defined as that field of medicine which seeks to obtain diagnostic or therapeutic advantage through the utilization of the properties of particles resulting from nuclear transformation and from atomic transpositions resulting from nuclear changes. It is concerned, then, with the fundamental particles: the nucleus, the alpha particle, the neutron, the neutrino, the meson, the pion, and other identified high-energy particles. Beta and gamma emissions as manifestations of nuclear changes may be utilized. In these aspects nuclear medicine differs markedly on the one hand from radiology, which is concerned with electromagnetic and particle bombardment, and on the other hand from simple tracer techniques, which are applications or extensions of biochemistry and physiology. In many areas, however, a complete overlap may be seen. Another responsibility is to determine the effects of environmental radiological contamination upon man, to meet problems of decontamination of man, and to develop an understanding of such radiation effects in man as may need to be effectively combatted.

The research program of the Medical Department concerns itself with the biological effects of radiation and in particular with particle radiation of very short range. The researches thus must inherently be concerned with studies of precise isotope localization, kinetics of distribution and redistribution, metabolism of organic compounds, functions of inorganic compounds, and the effect of excited atoms on the stability of large molecules or complexes. We, as physicians, must always concern ourselves with ultimate effects upon intact mammalian organisms, even though the experimental observations may be carried out on isolated organ systems, tissue cells in culture, or chemical reactions which occur in the body. Ad- vantage is sought of special situations which may be applicable to medical therapy such as neutron capture therapy of glioblastoma multiforme. Isotopes used are largely those of short half-life - from a minute or less up to a few days - in order that progression through a metabolic complex can more satisfactorily be followed by judicious radioactive isotope selection and that radiation dose may be held to a minimum. Gamma and $\mathrm{x}$-radiation studies are also carried out in order that similarities and differences may be closely examined in the same fashion that effects are observed in single cells and in multicelled and highly organized species. Diagnostic studies in the widest sense are carried out on suitable disease states under study in the hospital. Such studies, however, are concerned primarily with elucidation of the nature of the disturbance and the proper selection of individuals in a general population for a uniform response rather than with specific diagnostic routines for use in a large general medical clinic. These studies have great significance in permitting us to predict effects of exposure of man to various radionuclides, both elemental and as organic compounds. The entire program of the Department is integrated with each scientist having awareness of, interest in, and, frequently, participation in his colleagues' investigations.

Many of the research problems confronting medical men today are so large and so complex that a group assault is necessary. However, in all circumstances a strenuous effort is made fully to preserve for the participating research scientist complete individual freedom to find his own path toward solution of some feature of the over-all problem. The scientist must not be denied the pleasure, privilege, or responsibility of doing his own thinking. Cooperative effort is maintained on an individual basis of voluntary associations among members of the Department and also with colleagues outside the Department. By careful preservation of the individual's choice of what 
FEDELD OF SPECIAL INTEREST ACTIVE SECONDARY INTEREST WIIID MAJOR ACTIVITY $\square$ PASSIVE ATTENTION ONLY

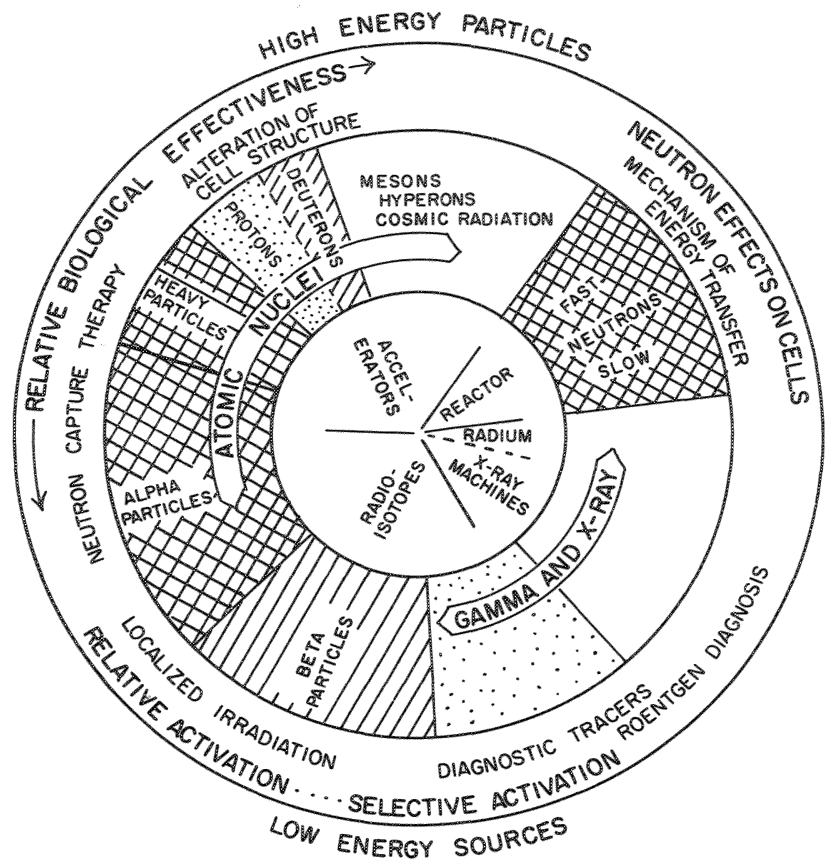

Fields of nuclear science at Brookhaven of interest to the Medical Department.

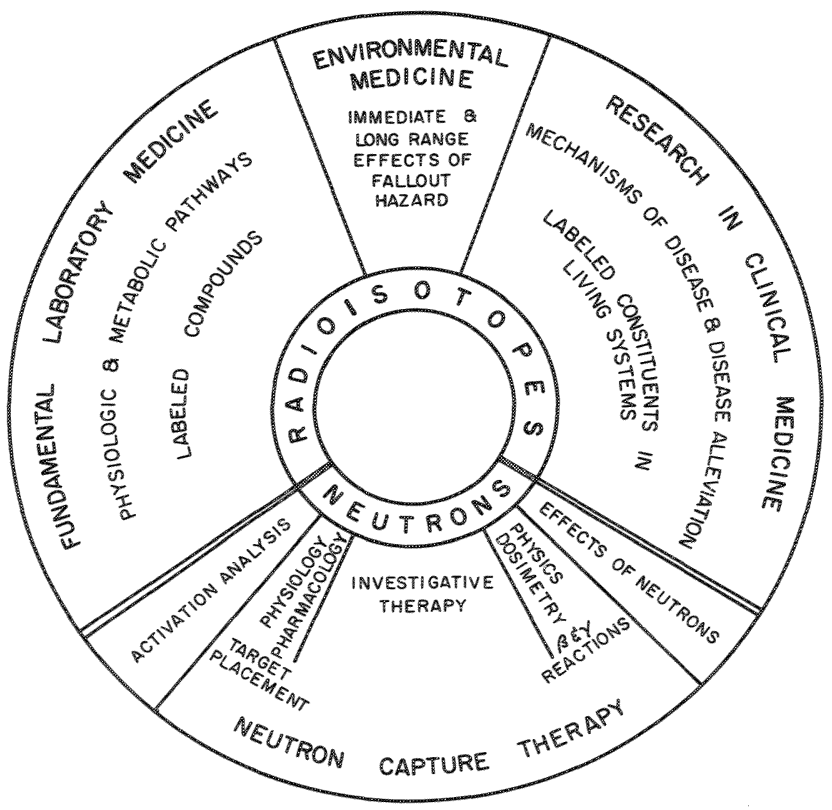

Distribution of investigative efforts of the Brookhaven Medical Department. appears to him to be the path leading to the most rewarding effort, there will emerge a program achieving the most productive employment of available knowledge, skills, and equipment. The new ideas for research must come from individuals, and in turn these will derive from experimental testing of hypotheses of each scientist within his own field of greatest competence.

Although research is the primary objective of the Medical Department, various aspects of education are inextricably blended into the framework of the investigative program. The special facilities of Brookhaven National Laboratory, the objective of Associated Universities, Inc., to assist other institutions by making these intricate and expensive devices available to qualified scientists, the responsibility of the Division of Biology and Medicine of the Atomic Energy Commission and the members of the staffs of its sponsored and supported laboratories in bringing before those concerned with medical education the present status and future areas of exploration in nuclear medicine - all these put further emphasis upon the role of the Medical Department in offering educational leadership in this new field of medical science.

\section{THE MEDICAL DEPARTMENT STAFF AND ITS ORGANIZATION}

The scientific staff of the Medical Department is limited in number by policy and design to fortyeight full-time, regular staff positions. A staff of this size is large enough to provoke stimulation within itself but not so large that each person may not be well acquainted with the work of his colleagues. It is large enough that necessary facets of medical and diagnostic services can be covered responsibly in the hospital but not so large as to require organization of several services. Although the Department is administratively organized into seven divisions - the Hospital, Biochemistry, Experimental Pathology, Physiology, Microbiology, Medical Physics, and Industrial Medicine functionally it operates as a single unit with no jurisdictional barriers impeding activities within the Department.

Since it is the policy of Associated Universities, Inc., that a large fraction of the staff shall be rotated in order that universities may benefit by having men on their faculties who have worked at Brookhaven and that Brookhaven may benefit 
by a constant infusion of new enthusiasm brought to it from universities and institutes, there is a general policy limiting the time a man may remain on the staff at Brookhaven in its several ranks of term appointments. On term appointments a man may, if reappointed, stay up to a maximum of ten years provided he begins his experience here as an assistant or associate scientist. A man beginning his appointment as a scientist or senior scientist is limited to three or five years depending upon his individual category. It is generally expected that most term appointees to the staff will spend approximately three to five years at Brookhaven becoming thoroughly qualified in the areas for which opportunities are provided here. It is anticipated that most appointments will be of junior men who come for education, training, and experience in the field of this Department and who will later return to university faculties.

Taking into account these policies, the scientific staff of the Medical Department is organized into three categories:

I. Full-time, Regular Staff.

A. Tenure scientists who hold their positions under terms comparable to professorial tenure in university faculties.

B. Indefinite appointment scientists who hold their positions indefinitely for performance of a necessary function in the Department or Laboratory organization.

C. Term scientists who hold appointments for specific terms.

II. Part-time, Temporary Staff. In a few special situations, part-time, temporary appointments are given for operational reasons to qualified persons.

III. Research Collaborator Staff.

The research collaborator staff is composed of those holding academic appointments in universities or equivalent appointments in hospitals or institutions who are given appointments to the staff of the Medical Department for terms renewable up to one year for intermittent work during those terms in collaboration, extension, or intensification of work of joint interest to the research collaborator and to a regular staff appointee in the Medical Department. Those holding fellowships from foundations or governmental agencies are generally given appointments as research collaborators in residence which permit them to be granted working privileges of the regular staff and to be integrated into the research, training, and education programs of the Department. Brookhaven does not award fellowships. On the other hand, the Department does have a limited number of one-year term appointments as Medical Associate renewable for two additional terms of one year. This appointment is available to persons of all ranks in universities or institutes, and it is available to persons on sabbatical or other leave from universities and institutes. In some instances in these on-leave categories, appointment as a research collaborator in residence may be more appropriate.

The categories of the scientific staff previously noted are further divided into four ranks: senior scientist, scientist, associate scientist, and assistant scientist. The title medical associate carries no specified rank, and persons holding this appointment may be given privileges and assigned responsibilities of any of the ranks depending upon their training and experience.

The medical staff of the hospital and the medical supporting staff of the hospital are separately designated groups of the Medical Department scientific staff which include those who by training and experience are qualified to meet the specific clinical responsibilities of this hospital. Likewise, the hospital staff includes a separately designated group of the technical staff trained to meet specific responsibilities. Rank of a person on the medical staff of the hospital and on the scientific staff is not always identical, being adjusted rather to specific interests, qualifications, and use. Inquires regarding staff appointments are welcomed and should be addressed to the Medical Director.

The technical staff of the Department is a career staff in the same manner as is the scientific staff. It is composed of technically qualified persons, individually selected for their interests and aptitudes, who bring a wide variety of skills and techniques to the Department's program. The technical staff is divided into several categories: scientist's assistants, technical assistants, laboratory services assistants, nursing staff to the hospital, clinical services staff to the hospital, and special services staff to the hospital. A scientist's assistant is a personal technical associate of a scientist holding a tenure appointment and is responsible directly to the scientist for performance of his duties. All other members of the technical staff are responsible to the Department as a whole through designated administrative channels to the 
Medical Director. A technical assistant may be assigned to specific duties and, although still retaining his general responsibility to the Department as a whole, will act as a technical associate of a specifically designated scientific staff member holding an indefinite appointment or, in special instances, a term appointment as scientist or higher. Other types of specialized professional training and skills are represented by the nursing staff, clinical services staff, and the other variously designated categories of the technical staff. At present there is a total of 147 positions in the various categories of the associated staffs.

The clerical and administrative staff furnishes those services to the Department as a whole. 


\section{REVIEW OF RESEARCH ACTIVITIES DURING THE FISCAL YEAR 1960}

\section{Outline of Report}

I. REACTOR RADIOLOGY

A. Reactor Devices (Graphite and Medical Research Reactors) .......................................... 11

B. Tissue Effects of Primary and Secondary Reactor Radiation......................................... 13

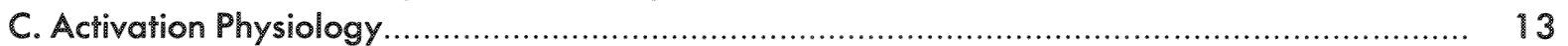

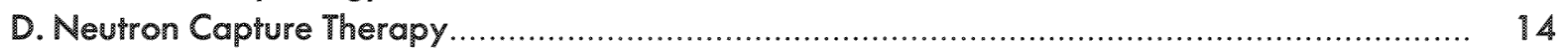

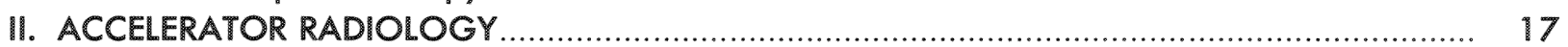

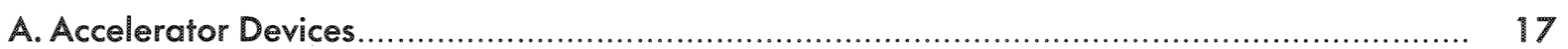

B. Tissue Effects of Primary and Secondary Accelerator Radiation................................ 17

C. Dosimetric Measurements (Physical equivalences) ..................................................... 18

D. Isotope Production for Other Medical Projects....................................................... 18

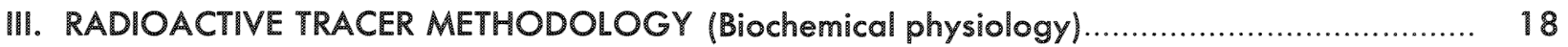

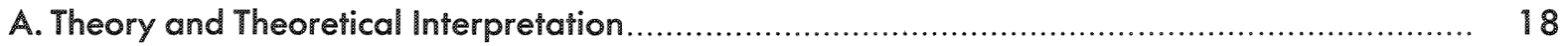

B. Kinetics (Studies on rates of movement observed by radioactive labeling) ........................ 19

C. Placement (Studies of uptake and position by radioactive detection) ................................. 21

D. Volumes of Distribution (Quantities of radioactive dilution) ........................................... 23

E. Metabolic Pathways (Study of sequential reactions by radioactive charting) ........................ 24

IV. CELLULAR REPRODUCTION, MIGRATION, AND TRANSFORMATION

(Radioactive badges affixed within cell unit components to give clues to the behavior of intact cell systems and heritable transmissions of marked components) ....................................... 32

A. Cell Identification (Selection and affixation of radioactive badges to cell components)........ 32

B. Cell Proliferation (Radioactive measurement of rates and routes) ........................................ 34

C. Cell Migration (Radioactive record of various cell positions within the body) ..................... 38

D. Differentiation, Transformation, and Maturation

(Radioactive proof of identity of differentiated, transformed, or matured cells)................. 39

V. ENVIRONMENTAL MEDICINE AND RADIATION EFFECTS ......................................... 41

A. Radioactive Operational Hazards and Control.................................................... 41

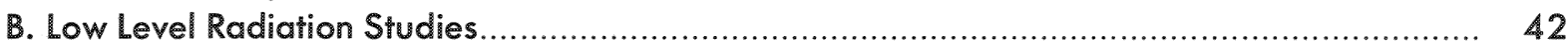

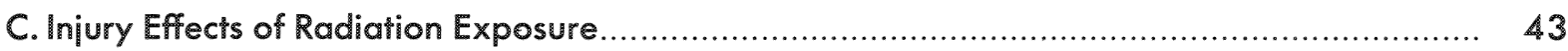

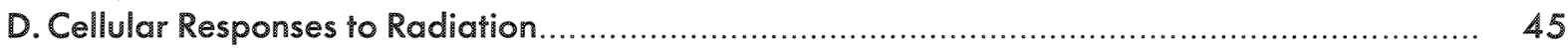

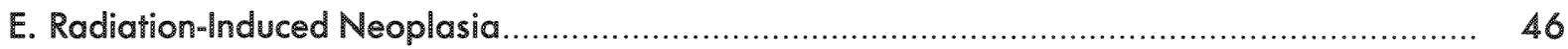

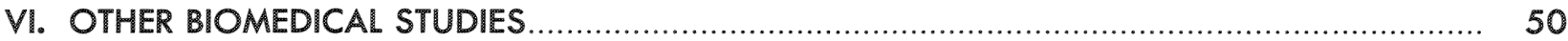

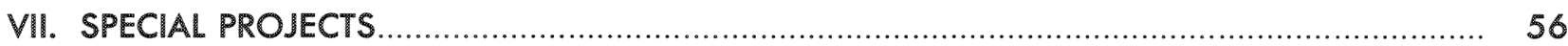

A. Medical Studies of the People of the Marshall Islands.................................................. 56

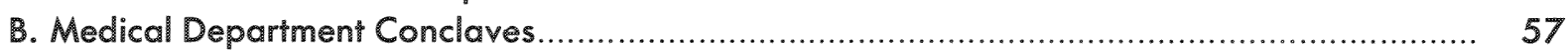

C. The Medical Student Institute of Nuclear Medicine ....................................................... 58

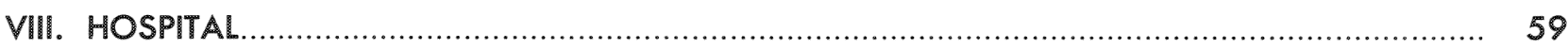

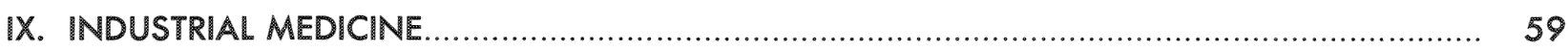

X. GENERAL ACTIVITIES OF THE MEDICAL DEPARTMENT ............................................... 59 
During fiscal 1960 the research activities reached a new high since the Department was organized in 1949. The soundness of adhering to an integrated plan of research operations is now demonstrated in both the quality and the versatility of approach to researches. The interrelationships of the various scientific members of the staff provoke new ideas in regard to the problem under attack by each. The texture of activities in basic medical research, applied research, and technological development has now become so closely interwoven in most instances that only arbitrary classifications in the above categories can be made. The adherence to a limited and yet self-selected field of endeavor of deep interest and concern both to medicine and nuclear science is developing a group of senior investigators skilled in the art of medicine and increasingly sophisticated in the nuances of nuclear physics with applications or implications in the field of medicine. The present report is concerned only with work completed during the year or very clearly defined. It is in no wise a complete and detailed report of all research activities and yet the picture presented is valid. Trends and more significant observations have in general been emphasized. It must be noted that the report does not deal with future research plans but only with accomplishments of this past fiscal year. Inevitably, though, past endeavors give rather clear indications of what may be forthcoming.

For greater ease in grasping the general scope of the Department's activities, the major outlines of its program are given herewith. Cancer work, medical research utilizing special devices and products of nuclear physics, and researches on control and better understanding of radiation effects will each be found under each of the main headings listed. More work has been done on cancer patients during the past year, for, as better instrumentation has become available for radioisotope studies, more and more advantage is being taken of the enormous documented knowledge of metabolism both normal and abnormal in cancer. Within this framework, observations may be susceptible of much firmer interpretation than in other circumstances and in particular in that great ill-defined group of our population often classed as "normal" but perhaps better designated as insufficiently studied to develop a sound diagnosis of existing abnormalities. It is anticipated that increasing study of cancer pa- tients will continue with very considerable benefits to both the investigator and the patient with cancer.

\section{Reactor Radiology}

For medical purposes, the reactor is being used at present either as a primary source of neutrons or for the production of secondary reactions through neutron interaction. The development of design criteria and necessary modifications of the basic reactor components must be a continuing effort to permit advantageous exploitation for medical interest.

\section{A. REACTOR DEVICES \\ (Graphite and Medical Research Reactors)}

1. Operational characterization (Purity of neutron emissions; power levels; efc.)

a. Neutron energy spectrum by foil measurements. 060602. Drs. Stickley, Robertson; Res. Col.* Amato, Mr. Meinhold, ** Mr. Powell ***

For the Medical Research Reactor (MRR) a comprehensive project was begun using gold, cobalt, copper, enriched $U^{235}$, depleted $U^{238}$, aluminum, and sulfur radioactivants to define the emergent neutron cloud spectra at a point in free air. Fifteen different geometries are being used, and the cadmium difference technique is being applied whenever applicable. The half-life of each radioactivant end product is being followed. Gamma emitters are checked in a 100-channel analyzer. This comprehensive program evolved from a much simpler initial effort found to be inadequate. Half of the samples are being checked for the Department by Oak Ridge National Laboratory. Gamma intensities are estimated with a lithiumshielded Victoreen condenser r-meter and photoluminescent glass needle dosimeters. Presumably the latter are relatively neutron insensitive and energy independent. Five basic geometries of bismuth, heavy water, and polyethylene reflectors appear to give widely different spectra in terms of suitability for neutron capture therapy. Further combinations will be tested in efforts to develop

\footnotetext{
*Res. Col. = Research Collaborator. **Member of the Health Physics Division.

***Head, Reactor Division.
} 
better information on the lowest gamma-producing geometry with maximum efficiency in use of core emergent neutrons. Suitable check studies have also been done on the medical facility at the Graphite Research Reactor. Completion of the present massive effort to characterize the neutron cloud and the development of a suitable and simplified procedure for further testing of this type are expected to be effected within the coming fiscal year. Preliminary results suggest that one geometry, a considerable improvement over the original one, will be suitable for final patient testing.

b. MRR output in relation to power level. 060602. Dr. Stickley, Mr. Powell

The MRR was carefully tested at various power levels up to and including 5 megawatts. On the basis of these test reports permission to operate was obtained from the Atomic Energy Commission. The neutron output appeared to correlate well with power levels attained, and a semipulsed type of operation was tested to permit later use of this technique to shorten patient exposures.

2. Design and criteria modifications (Reflector moderator, field-defining aperture materials and biological shields). 060601. Drs. Stickley, Robertson, Fine, Farr; Res. Col. Amato, Mr. Powell

In conjunction with the work on characterization of the energy spectrum of emergent neutron cloud and gamma contamination, careful studies were begun on the influence on quantity of induced gamma radiation from reactor moderating and reflector components as well as gamma shielding. By altering the moderating and filtering materials in the shutter and reflector of the reactor, more than a dozen different configurations can be made available for study. Since the amount of heavy water can also be varied, at least twice this number of configurations can readily be attained. In the course of these efforts, which must continue for at least two more years, it was ascertained that for the present a practical arrangement for patient testing could be effected by using an 8-in. barrier of heavy water in the shutter rather than within the shield and with a more peripheral position of the bismuth gamma-ray shield.

For local shielding problems both phantom and animal studies suggested that for the present only $\mathrm{Li}^{6}$ metal in sheets of 1.0 and $1.5-\mathrm{mm}$ thickness be used as a neutron field limiting material. The flexible sheets permit application to a rigid or nonrigid field geometry with rapid adaptation. The local shielding afforded by such $\mathrm{Li}^{6}$ sheets to patients has been tested and is the best yet attained.

Changes in the geometry of the components both within the shield and in the shutter base resulted in an inadequacy of the heavy shielding to meet current operating practices. Efforts to determine the best and most practical type of biological shielding to be added have not been completed. A closed circuit television unit has been added to permit the experimenter to make observations in safety. The higher exposures encountered at the operating console have temporarily been reduced to acceptable levels.

\section{Dosimetry (Physical equivalences)}

a. Estimation of capture gamma dose in patients. 060601. Drs. Robertson, Cohn, Yamamoto, Stickley, Forr

Concern during the past year with better characterization of the neutron and gamma spectra has led to a closer scrutiny of the information upon which physical dosimetry in these efforts has been based and in particular to a specific effort to develop a better calculation of probable captureinduced gamma emissions in patients. The problem has become increasingly complex as better information was sought. For a reasonable approximation in a geometry of an actual head it is clear that a computer must be used. An attempt is being made in collaboration with the Applied Mathematics Division to evolve suitable formulation of the problem for computer solutions.

\section{Isotope production}

a. Graphite Research Reactor

Radioactive isotopes of use to the Medical Department that can be more economically produced in the Graphite Research Reactor continue to be obtained from the Reactor Division. In addition, derived isotopes such as $\mathrm{I}^{132}$ are obtained from the Hot Laboratory for a further extension in the number of radioactive and stable isotopes used in the medical research program.

\section{b. Medical Research Reactor}

During the year special beam tube devices were developed for production of short half-life activities. These include a simple pneumatic tube installation and a 1-liter tank, usable also as a loop, for gases and liquid media, which was designed and built by Mr. M. Zukas of the Reactor Division. The extensive calibration work at the treatment ports requiring very long, continuous runs and numerous repetitions thereof has not permitted any exploitation of this unit this year. 


\section{B. TISSUE EFFECTS OF PRIMARY AND SECONDARY REACTOR RADIATION \\ Drs. Farr, Lippincott, Yamamoto, Calvo, Easterday, Stickley, Robertson}

Because of marked inconsistencies noted when physical equivalences of neutron doses and $\mathrm{B}^{10}$ derived alpha-particles are applied to predictions of tissue changes, an extensive program of direct observation under controlled conditions has been initiated.

1. Particle radiation (Fast neutrons, slow neutrons, derived particles)

a. Clinical observations (physiological) of neutron effects on special senses. 060101

It has been repeatedly observed on previous patients that exposure of the retina to significant neutron dosage during neutron capture therapy does not produce retinal hemorrhage or exudate. Functional studies carried out on patients capable of cooperating detected no changes in visual capacity for field, motion, or color. Hearing was unaffected. Motor areas showed no adverse effects of exposure.

b. Clinical observations (histological) of neutron

effects on neuronal structures

Serial sections of brains of 16 patients who were given neutron capture therapy from 1951 to 1953 have been received from the special processing laboratory and have been scanned in a preliminary fashion. No gross cellular abnormalities were noted even in regions of most intense neutron exposure. Quantitation of combined neutron and boron doses and topographic distribution of effective exposure will be completed in the coming year.

c. Effects of thermal neutron exposure on central nervous system of rabbits. 060101

The heads were exposed to high doses of thermal neutrons up to a surface exposure of $10^{13}$ thermal neutrons $/ \mathrm{cm}^{2}$ with a concomitant gamma dose of $<100 \mathrm{r}$. No abnormal behavior of the animals was seen initially. Vision, smell, taste, appetite, and the like appeared to be unaffected, and no muscle abnormalities were noted.

d. Effects of thermal neutron exposure on striated muscle in the mouse. 060101

Several thousand mice were exposed to intense thermal neutron dose with and without accompanying infusion of $\mathrm{B}^{10}$ compounds. The exposure was limited to one hind leg, and no observable difficulty has thus far ensued. A few mice are under long-term observation for delayed effects. e. Effects of thermal neutron exposure on the elec" trophysiology of the eye. 060101. With Res. Col. Jacobsen, Najac, Kiebel, Krohn

Ocular radiation effects from 250-kvp x-radiation in doses of 4000 to $9000 \mathrm{r}$ have been studied at the New York Eye and Ear Infirmary. The present studies are concerned with a similar approach to thermal neutron effects. The electrophysiological effects studied to date include threshold sensitivity and conformation of the electroretinogram (ERG). With $\mathrm{x}$-ray it was found that $7000 \mathrm{r}$ diminished the ERG to the point of extinction. At this dose respiratory enzyme activity is also lost. Thus far this has not been duplicated with thermal neutron exposures.

f. Effects of thermal neutron exposure in histological structures of various systems. 060101

Studies of muscle tissues, vascular tissues, cardiac muscle, and preliminary studies of lung specimens have been carried out after thermal neutron exposure to determine if any unusual sensitivity can be demonstrated with special histochemical techniques. Enzyme mapping has not yet been started. A more comprehensive study on rabbits and the mouse is under way to determine if any specific or nonspecific changes in the central nervous system structures can be induced by exposure to thermal neutrons.

\section{Electromagnetic radiation. 060101}

Until further advancement is reached in the measurement of capture gamma production in a mixed neutron field, efforts in this endeavor will continue to be delayed.

\section{ACTIVATION PHYSIOLOGY}

A considerable program in physiologic activation analysis has been envisaged, but the necessity of establishing the operating characteristics of the reactor and installing necessary appurtenances for specimen activation has retarded the effort.

\section{Instrumentation design and development}

a. Beta-gamma coincidence system. 060602. Drs. Cotzias, Borg

A system requiring coincidence between signals from one gamma and two beta detectors has been developed and used in the detection of radioactive manganese in tissues. The gamma detector is a $4 \times 5$-in. NaI crystal with a plastic shield to eliminate counts due to energetic betas and to brehmsstrahlung. One of the beta detectors is a thin 
(0.015-in.) plastic scintillator which is relatively insensitive to gamma radiation. The second is a thicker $(0.25$ or 0.5 -in.) plastic scintillator giving essentially total absorption of the beta energy. These detectors are seen by photomultiplier tubes from which the signals pass through the necessary preamplifiers to the coincidence control circuit, where each enters separately a fast $\left(10^{-7}\right.$-sec $)$ coincidence circuit. The two beta signals also enter a slow $\left(5 \times 10^{-6}\right.$-sec) single-channel analyzer. The gamma signal is analyzed with a 100-channel pulse-height analyzer, its gating being controlled by the coincidence requirements. Requiring the beta and gamma energies to match the $\mathrm{Mn}^{56}$ spectrum favors counting the manganese in the presence of relatively much larger levels of $\mathrm{Na}^{24}$, the principal competitor. A system using a fourth detector for the Compton backscatter gamma-rays has also been used and gives even better discrimination under some conditions, depending upon the geometry that it is possible to use.

b. Slow neutron filter for selective activation. 060602. Drs. Cotzias, Borg

Another approach to the problem of activation analysis of trace constituents of tissue involves selective activation. A device used for this is a container so designed that the sample can be completely surrounded by cadmium and boron. The cadmium and boron cut out the thermal neutrons but permit sufficient penetration by more energetic neutrons for manganese to be activated by the 337-ev neutrons for which it has a resonance capture peak.

2. In vitro measurement of manganese in human blood, plasma or serum. 060601 . Drs. Cotzias, Papavasiliou

A method was developed which permits the harvesting of uncontaminated blood, plasma or serum samples, neutron activation, the chemical separation of the ensuing $\mathrm{Mn}^{56}$, the elimination of contaminating radionuclides, and the accurate comparison to standards. It employs $0.05 \mathrm{ml}$ to 0.1 $\mathrm{ml}$ of sample (blood, serum or plasma). Samples contained on the average $1 \times 10^{-10} \mathrm{~g}$ manganese $(0.3 \mu \mathrm{g} / 100 \mathrm{ml})$; the measurement was precise within $\pm 2.9 \%$. Its accuracy was close to $100 \%$ (within the limits of the precision) in plasma and serum. Blood gives slightly higher results due to some conversion of $\mathrm{Fe}^{56}$ to $\mathrm{Mn}^{56}$.

Because the plasma manganese values so obtained are significantly lower than those previously reported by other methods, a comparison with a standard spectroscopy method was begun in collaboration with Mr. J. Forrest of the Hot Laboratory Division. Thus far careful and meticulous spectroscopy confirms the results for manganese by activation analysis as noted above.

\section{NEUTRON CAPTURE THERAPY}

Drs. Farr, Robertson, Stickley, Yamamoto, Lippincott, Easterday, Fine, Cohn, Usenik

Work continues on application of the interaction between thermal neutrons and $\mathrm{B}^{10}$ to produce a cytocidal effect capable of controlling neoplasms deep within vital body structures. Promising leads have been developed which indicate that the procedure is capable of meeting expectations in the case of animal tumors in certain positions, and progress is also being made in applications to patients.

\section{Clinical procedures (current). 0609}

During the past year clinical activities were absolutely minimal as all efforts were directed toward improvement of the Medical Research Reactor to prevent recurrences of the ocular complication seen in the first month of the fiscal year. By May sufficient characterization of the beam was available to warrant cautious resumption of patient treatments. Four patients in far advanced stages of their disease were treated. A standard $\mathbf{B}^{10}$ administration of $35 \mathrm{mg} / \mathrm{kg}$ body weight was used. A postinjection interval of $28 \mathrm{~min}$ was adopted for the present. Thermal neutron exposure duration ranged from 100 to $200 \mathrm{sec}$. This is on the basis of animal tumor data. In the four patients treated, skin flaps were turned back and a thermal neutron exposure of the brain cortex from $1.73 \times 10^{12}$ to $1.21 \times 10^{13}$ neutrons $/ \mathrm{cm}^{2}$ was obtained. No immediate adverse effects were noted from the marked increase in neutron exposure in this group of patients as compared with those treated previously. Significant practical advantages were gained by using a semipulsed type of operation of the Medical Research Reactor for these treatments.

Patients previously treated were observed and studied so that procedures might be further improved. For the first time phenomena of multiple tumors, both contra- and ipselateral, began to be observed. Until pathological studies are completed the significance of this finding cannot be evaluated. One patient survived for 18 months with minimum impairment and maximum effectiveness 
following a single treatment. This is the maximum longevity attained thus far for glioblastoma multiforme.

\section{Clinical evaluation. 0609}

The evaluation of neutron capture therapy at present is based primarily upon histological studies from which the effect of the treatment can be determined on both neoplastic and nonneoplastic cells. The study procedure which seems best has now been established and provides serial sections of whole brain and tumor in situ relative to each other. Appropriate staining and histochemical techniques can be used to map topographically the items of interest. The first sixteen cases are now being studied in conjunction with Dr. Webb Haymaker and Dr. Otto Stockdorph, Research Collaborators from the Armed Forces Institute of Pathology. No enzyme topography has yet been done. Definite tumor effects are now obtained. A tissue laboratory is being established in the Department to process samples in this way, so that the material being studied in the future will be current, after the backlog is eliminated. In a study of a sarcoma of vascular origin in the cerebellum, extensive destruction of tumor was demonstrated. Nonneoplastic structures of the brain stem are still being studied to determine if any treatment-induced changes occurred.

\section{Studies on mechanisms of action. 060101}

In evaluation of blood curves of boron in patients undergoing treatment, boron dosage in relation to effects indicates that the mechanism of action in the cell may be due to kinetic differences that boron exhibits in different cells. Selectivity thus rests on time differences and is truly founded on kinetics rather than on unique distribution or uptake. Sharp boundaries of effectiveness strongly suggest that a threshold for neutron exposure exists in provocation of the cytocidal reaction. The present series at 27 to $28 \mathrm{~min}$ post boron injection for neutron exposure indicates better effects than those previously obtained with exposures 8 to 15 min after completion of boron injection.

Counting of gamma-induced radioactivity in the head by using the whole-body counter is being developed to measure effective thermal neutron penetration en masse. The gamma spectra were measured in two patients over a 5-day period following neutron capture therapy with the Medical Research Reactor. An attempt is being made to correlate induced $\mathrm{Na}^{24}, \mathrm{Cl}^{38}$, and $\mathrm{Ca}^{49}$ activities with the effective thermal neutron dose received.

\section{Pharmacology. 0607}

The synthesis of organic boron compounds for possible use in neutron capture therapy is being left to others until a further exploration of inorganic compounds has been completed. Preparatory to final testing, pharmacological studies are in progress on lithium-containing compounds and on salts containing both lithium and boron. Acute toxicity studies and observation on the amelioration of toxicity by glucose are under way. The relative potency estimates for lithium tetraborate trihydrate and sodium tetraborate decahydrate are in the process of computation. Similarly, computation of relative potency of several organic boron compounds is in progress.

Studies conducted at Consolidated Edison and Technicon Research Laboratories indicated the feasibility of using the Autoanalyzer for boron samples. A device was purchased and an analytical development program is in progress. This should materially improve the capacity to conduct certain boron studies.

\section{Control of experimental, transplantable, and spon-} taneous animal neoplasms

a. Neutron exposure required for control of transplantable mouse sarcoma. 0609

The exceedingly fruitful and informative studies on control of the transplantable mouse tumor by the neutron capture procedure have been continued with particular emphasis on two aspects. On the one hand, certain runs have been made at the Brookhaven Graphite Research Reactor and the Medical Research Reactor that are comparable and duplicate each other as nearly as possible, in order to obtain sufficient data with standardized procedures to allow interpretation of studies made for several years at the Graphite Research Reactor in terms of studies now being made at the Medical Research Reactor. In this project exposures were intended to produce clearcut control of the tumor to a known degree. Certain consistent differences have been observed in the results. The causes for these differences are not clear, and further study is indicated. However, the latest data suggest that conditions can be established in the Medical Research Reactor studies such that it will no longer be necessary to continue the projects at the medical facility of the Brookhaven Graphite Research Reactor.

The other study has dealt with an effort better to delimit the conditions of a cytocidal reaction in relation to tumor size. For this study a standard 
dose of boron was used in all animals, namely, 35 $\mathrm{mg} \mathrm{B}^{10}$ per $\mathrm{kg}$ observed body weight. The boron was injected as a solution of sodium pentaborate administered rapidly into the tail vein of the animal. Twenty-six to $30 \mathrm{~min}$ later the tumor region was exposed to thermal neutrons in varying number but at an essentially constant rate of delivery. The Medical Research Reactor was not operated at a power level exceeding $1 \mathrm{Mw}$ in these procedures. Tumors ranging in diameter from 8 to $17 \mathrm{~mm}$ were observed. A surface neutron dose, i.e., skin exposure, of thermal neutrons ranging from 1.61 to $3.2 \times 10^{12}$ neutrons $/ \mathrm{cm}^{2}$ was capable of complete control of these tumors. Animals "cured" have been observed up to two years subsequently. No recurrences were noted, and no induction of other neoplasms was observed. In one study comprising 730 animals a measure of effectiveness termed tumor growth index was calculated. At the same time a careful check was made of possible partial shielding of the proximal edge of the tumor to protect the animal. In every instance the tumor growth index showed a significant negative value, which indicated a regression of the tumor. When neutron exposure was less than the limits previously mentioned the tumor ultimately regrew and eventually killed the animal. Four percent of the animals in which the tumor apparently disappeared completely showed a recurrence within 60 days. It appears at this writing, however, that in almost every instance in which this occurred there was partial shielding of a small tumor segment. This is being further explored.

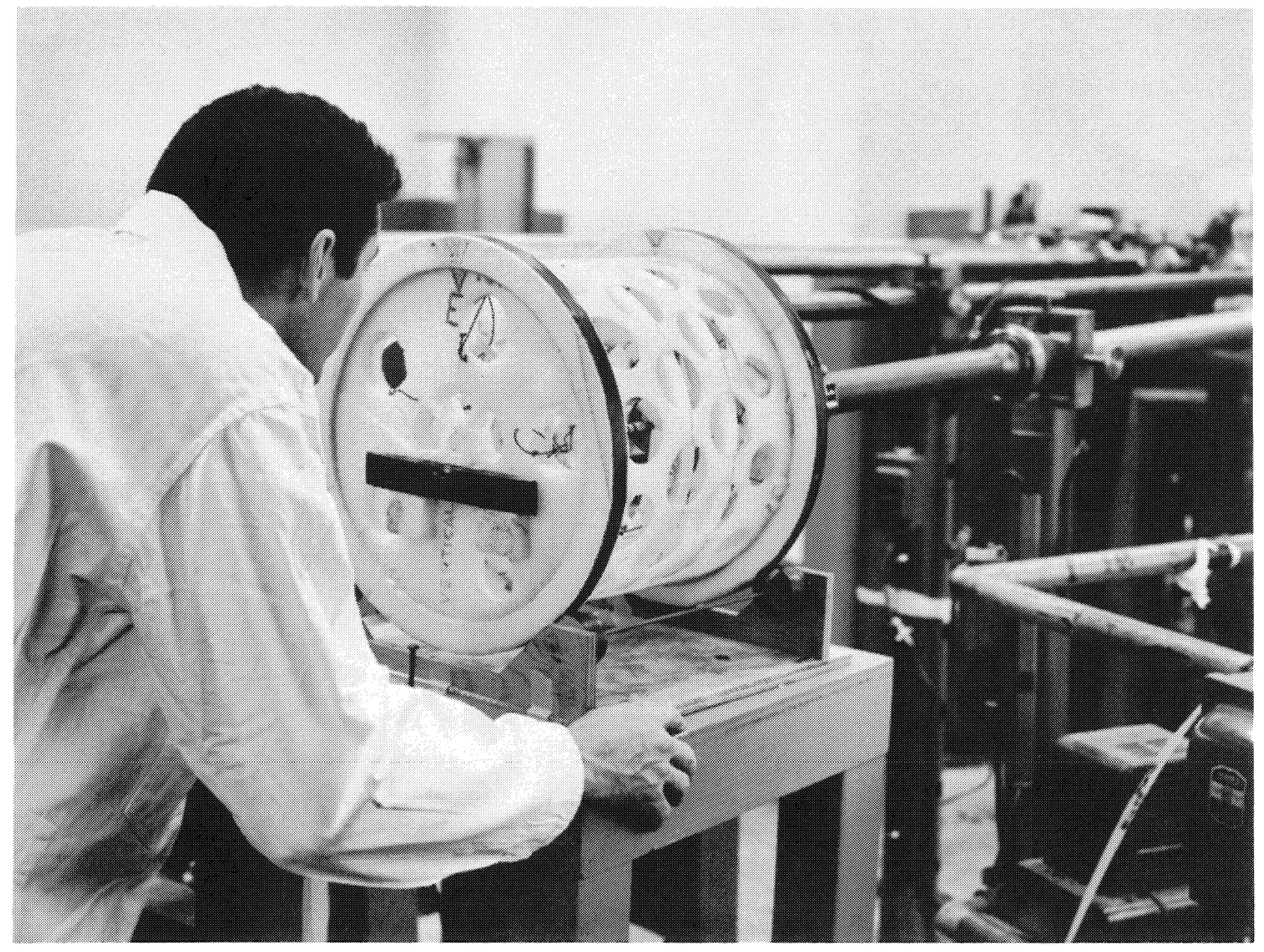

Alignment of mouse exposure cage with beam pipe of 3-Mev Van de Graaff generator (for monoenergetic neutron rbe studies). 
b. Treatment of a spontaneous canine osteogenic sarcoma. 0609

A great Dane with a spontaneous osteogenic sarcoma was referred for treatment. On admission the dog appeared to be moribund. Weight loss had been extensive, weakness was so great the animal could not stand, and a semicomatose condition prevailed. The animal's temperature and physical examination indicated a septicemia. Intravenous and antibiotic therapy were instituted, a skin flap was turned back, and the tumor was treated by neutron capture therapy. The procedure followed the rationale developed for localized irradiation, and a higher level of exposure was achieved because of the accessible location of the tumor. It presented on the medial aspect of the distal end of the left tibia and was a mass $10 \times 12$ $\times 15 \mathrm{~cm}$ in size.

Subsequent to treatment, the primary tumor grossly decreased in size. The clinical picture of this $60-\mathrm{kg}$ dog changed dramatically. Appetite returned, and with it strength and vigor. The animal resumed normal activity hampered by surgical restriction of the leg. The infection was eliminated, and for several weeks a reversal in the course of the disease was clearly effected. However, seven weeks postirradiation, metastases to the lung became evident, together with renewal of growth at the edge of the original tumor site. Although the bone shaft was eroded extensively when first seen, no fracture occurred. Rarefaction did not increase following treatment. No blood changes specifically attributable to radiation were found. Examination of the tumor site indicated that the original tumor was destroyed. The recurrence apparently was due to a nearby proximal extension that had been shielded during the treatment procedure. No histological changes in bone, muscle, or tendon were observed to follow the treatment.

\section{Accelerator Radiology}

\section{Drs. Bond, Bateman, Stickley, Johnson, Krueger; Res. Col. Rossi, Rose, Malis}

The study of particle effects that are or may be of medical significance is not limited to reactor radiology. Accelerators can provide "pure" energy spectra of a variety of particles and hence are used as devices by the Medical Department to extend and diversify its program.

\section{A. ACCELERATOR DEVICES}

The Van de Graaff accelerator and the 18 and 60-in. cyclotrons are the devices used at present. It is hoped that ultimately the Cosmotron and Alternating Gradient Synchrotron (AGS) will also be utilized.

\section{Adaptive equipment design and development. 060602}

While the fundamental problem of mammal accessibility to an accelerator is partially solved by externalizing the beam of accelerated particles, to turn this raw material into useful studies further instruments and adapters must be devised and built. The 2.8-Mev proton beam of the Van de Graaff striking on a tritium target provides a spectrum of neutrons with energies varying with the angle of emission from the target. A suitable target system was constructed which permitted selection of exposure positions at various angles so that essentially monoenergetic beams could be selected in the range from 0.1 to $2 \mathrm{Mev}$. The animal holders engineered and built allow very accurate placement of large numbers of specimens for short or prolonged exposure.

2. Operational characterization of machine output. 060601

Foil measurements, ionization chambers giving continuous readings, and tissue-equivalent plastic ionization chambers were used to determine beam energy and dose at various positions in the holding system. The distances from target to mouse were selected to assure uniform dose rates for exposure at different energies, and ranged from 10 to $20 \mathrm{~cm}$. The maximum fall-off of dose in traversing the thickness of a mouse was $\approx 30 \%$.

\section{B. TISSUE EFFECTS OF PRIMARY AND SECONDARY ACCELERATOR RADIATION}

Particles of varying mass and energy impinging on tissue constituent atoms are capable of exerting both direct and indirect effects. Various cytological parameters are selected to demonstrate these effects.

\section{Spleen and thymus weight loss as a measure of exposure. 060101}

Monoenergetic neutron beams ranging from 0.1 to $2.0 \mathrm{Mev}$ in energy were used to irradiate mice. The animals were so positioned as to receive es- 
sentially monoenergetic beam exposures. Comparisons were made of spleen and thymus weight loss in relation to total energy deposition and in relation to energy of the beam used. These data were compared with similar effects produced by neutrons of energies $>2.0 \mathrm{Mev}$. The lower energy neutrons appeared to result in greater weight loss of these tissues than those of higher energy per rad of total energy delivered. The relative biological effectiveness was found to be as high as 4.5. A consistent inverse correlation was noted of effectiveness and presenting energy. The most sensitive biological indicator appears to be spermatogonia depletion. Dose rate effect studies requisite for adequate interpretation of the relative effectiveness have been made.

2. Effects of monoenergetic deuterons of $\approx 20 \mathrm{Mev}$ on neural growth. 060101

The 60-in. cyclotron was used in a study of the effects on tissue of penetration of the cerebral cortex by a deuteron beam. A laminar (sharply delimited narrow zone in which all nerve cells have been destroyed) lesion was produced with peak doses of 15,000 to $45,000 \mathrm{rad}$. The corresponding surface and average doses are $\approx 3000$ to 9000 and 5000 to $15,000 \mathrm{rad}$ respectively. Deuteron intensity ranged from 4.0 to $12.0 \times 10^{9}$ deuterons $/ \mathrm{cm}^{2}$. By appropriate maneuver the procedure can be used to isolate a strip of cortical tissue but a few neurons thick. Doses above 45,000 rad produced necrotic foci, and at 75,000 rad complete necrosis of the irradiated region was observed.

\section{DOSIMETRIC MEASUREMENTS (Physical Equivalences)}

1. Utilization of tissue-equivalent ionization chambers to physical-equivalent doses. 060601

For appropriate response correlations it was found necessary to construct ionization chambers of tissue-equivalent plastic material. For other aspects of physical dosimetry continuously recording ionization chambers containing tissue-equivalent gas were used. Both devices were designed by Dr. H.H. Rossi. Appropriate placement of the various ionization chambers permitted characterization of individual ionization events which could simultaneously be correlated with animal experiments. Studies using a tissue-equivalent plastic mouse phantom indicated that energy deposition throughout the mouse, with the conditions of bilateral exposure used, was uniform to at least $\pm 10 \%$.

\section{ISOTOPE PRODUCTION FOR OTHER MEDICAL PROJECTS}

During the year two accelerator-produced radioactive isotopes were used in other medical studies. One was $\mathrm{I}^{124}$. It was used as a label for a globulin fraction in the study of protein metabolism of cancer and was selected to obtain different information from that obtained with the $I^{131}$ label.

The other radioactive isotope obtained from the cyclotron was $\mathrm{Cu}^{67}$. It was used in a study of metal binding in mammals.

\section{Radioactive Tracer Methodology}

(Biochemical Physiology)

The use of radioactive elements as tracers to give information on rates of movement and fate of the studied constituent in a mixture largely or almost entirely nonlabeled is the field of widest general application of radioactive isotopes in medicine. In this subsection the description of the use of radioactive isotopes is restricted to elements, elemental salts, or elements incorporated within a molecule (hence biochemistry) for observation of molecular behavior, and not as a badge of large cellular structural components.

\section{A. THEORY AND THEORETICAL INTERPRETATION}

In principle it is possible to deduce the kinetic properties of steady-state systems by mathematical analysis of families of curves chosen as representative of the behavior of the exchangeable substances in the systems. In practice, however, this pure mathematical reasoning must be combined with analysis of experimental data to determine the best fits. Computers both analogue and digital thus come into play for data analysis long before the definitive mathematical relationship has been completely clarified.

1. An analogue computer for analysis of tracer kinetics in steady-state biological systems. 060601. Dr. Robertson

For the rapid analysis and comparison of data obtained in study of biological systems, analogue computers have an immediate and most practical application. Specifically, analogue computers designed to solve linear differential equations may 
be used in the analysis of such systems. When the rate of flow of unlabeled material between any two given compartments is equal in the two opposing directions, however, it is simpler to use a more direct analogy with only resistance and capacitance circuits. An instrument relying chiefly on such circuits was constructed with provision for "injection" of constant initial charge or constant initial voltage or for continuous injection of charge, and with provision for changing the various parameters up to ten times per cycle. As many as four curves may be displayed simultaneously. Another feature is an electronic data display which is independent of, but displayed on, the same oscilloscope as are the analogue curves. Applications to studies of electrolyte exchange in human beings as well as studies of other kinds of biological systems are immediate.

2. Analogue computer analysis of studies using $\left.\right|^{131 .}$ labeled protein. 060601. Dr. Robertson

Data obtained by Dr. Lippincott and Dr. Cohn on the degradation of intravenously injected $\mathrm{I}^{131}$ labeled proteins have been subjected to analysis on the analogue computer leading to a mathematical model explaining the principle kinetic features of the data. On the basis of this computer analysis, it appears that a substantial part of the degradation occurs within the circulation, which thereby settles a speculative point not otherwise readily treated.

\section{B. KINETICS \\ (Studies on Rates of Movement Observed by Radioactive Labeling)}

1. Kinetics of strontium and calcium metabolism. 060102 . Dr. Cohn, Res. Col. Spencer

The kinetics of parenterally and orally administered $\mathrm{Sr}^{85}$ have been studied in nine patients over periods ranging up to five months. The patients were selected to illustrate fundamental disturbances in $\mathrm{Ca}$ metabolism under differing clinical conditions. Turnover rates of $\mathrm{Zn}^{65}$ and $\mathrm{Cs}^{137}$ are also being studied in four patients over a long period of time.

In addition, Ca metabolism in two patients with multiple myeloma was studied by using the tracer $\mathrm{Ca}^{47}$. By an appropriate isotope technique, combining measurement of plasma clearance and whole-body retention, it has been possible to measure the exchangeable $\mathrm{Ca}$ and the accretion rate of labeled $\mathrm{Ca}$ in the skeleton of the patients with this disease.

2. Extrathyroidal metabolism of halides. 060102. Drs. Robertson, Cranny

$\mathrm{I}^{131}, \mathrm{I}^{132}$, and $\mathrm{Cl}^{38}$ were injected into rats in a continuation of studies of the secretion of halides by the stomach and other features of the extrathyroidal metabolism of the halides. The rates of secretion of iodine and chlorine by the gastric mucosa have been shown to be higher in fed animals than in fasted ones.

With the use of in vivo gamma-ray counting, $\mathbb{I}^{132}$ was also used in a preliminary series of three patients to explore the possibilities of using iodine secretion as an index of gastric physiology. The relative rate of secretion of iodine by the stomach in these patients was less than had been expected from the animal studies, but the feasibility of the approach has been demonstrated.

\section{Competition of strontium isotopes for rat bone.} 0605. Dr. Cohn, Res. Col. Sobel

The dietary administration of stable strontium was found to decrease significantly (by 70\%) the retention of injected radiostrontium by rat skeletal tissue. This decreased uptake of radiostrontium was reflected by a decrease of both the strontium exchange capacity and the strontium accretion rate of the skeleton. The experimental procedure was based on the hypothesis that a monolayer of strontium salts is bound to the surface of the apatite bone crystal with a greater force than will a subsequent layer of strontium salts.

\section{General chemical dynamics of bone. 0605 . Dr. Cohn}

Studies on the kinetics of uptake and distribution of fission products in animals are being continued on a limited scale. Since the deposition of rare earth elements in bone is little understood, an experiment was undertaken to compare both the exchange capacity of the skeleton for $\mathrm{Y}^{89}$ and its rate of accretion in bone with that of previously studied $\mathrm{Sr}^{85}$. The two isotopes were studied simultaneously in rats, and their incorporation into the exchangeable and nonexchangeable compartments of bone was measured in both normal and irradiated bones. Although some rare earth elements form colloids and nonionized complexes in plasma, the uptake by the skeleton from these complexes is active and similar to that of the alkaline earths $\left(\mathrm{Sr}^{85}\right)$. 
5. Kinetics of intravenously administered $\mathrm{CO}^{60}$. labeled $B_{12} .060102 . \quad$ Drs. Cronkite, Rubini, Wolins; Res. Col. L. Meyer, Henley

Studies of kinetics of vitamin $\mathbf{B}_{12}$ administered intravenously indicate that plasma clearance and mixing of vitamin $B_{12}$ go on simultaneously. The clearance curve is of the two-component type showing a half-time of a few minutes and a few hours. Fecal and urinary excretion is also two component, with half-times of $\approx 1$ and 300 days, respectively. The tissue concentration of detectable label varies widely. Further study on the nature and dissociation of primary and secondary binding sites of $B_{12}$ in plasma and various tissues is needed. The kinetics of labeled vitamin $B_{12}$ and thus the turnover of whole-body $B_{12}$ can only be satisfactorily established by using true tracer doses and a whole-body counter to ascertain the normal picture and whether there are aberrations in diseased states.

6. A transport mechanism of manganese in plasma. 060102. Drs. Cotzias, Borg, Bertinchamps, E.R. Hughes, Papavasiliou

The facts that Parkinsonism may be induced in normal humans by (a) inhalation of manganese ore dusts and (b) the use of some tranquilizing drugs have been stressed earlier. There exists a paradoxical dichotomy relative to the effect of phenothiazine tranquilizers on persons suffering from Parkinsonism versus those who are not: the first may be helped by some phenothiazines, the latter may be induced to develop Parkinsonism. Recent information reveals that (1) spontaneous Parkinsonism has some hereditary tendencies, (2) phenothiazine-induced Parkinsonism occurs in persons whose families are prone to develop spontaneous Parkinsonism, and (3) the manganese ore inhalations result in Parkinsonism more often among blood relatives than among the miners as a whole.

This evidence indicates (1) a familial defect in Parkinsonism, and (2) a familial basis for the interrelation of the drug-induced, the industrial, and the spontaneous Parkinsonisms.

Evidence exists from studies of Wilson's disease and of blood dysfunctions indicating that familial defects tend to be reflected in the defective synthesis of a protein. In the course of studies at BNL on kinetics of manganese a human plasma protein that binds manganese in vitro has been discovered, and evidence has been obtained suggesting that the same protein transports manganese in vivo. This protein of plasma, tentatively called transmanganin, shows both similarities and dissimilarities with the iron-carrying one, transferrin. This protein is being studied with both $\mathrm{Mn}^{54}$ and $\mathrm{Mn}^{56}$ and the use of ultrafiltration and electrophoresis. This work is greatly aided by the observation that the physiologically transported manganese is trivalent. Trivalent manganese is markedly unstable when free in water, but is stabilized by the protein. At present the effort is to determine the role of transmanganin in Parkinson's disease.

Since Wilson's disease is in some respects similar to Parkinsonism and also involves an abnormality of metal metabolism (copper), it has been of interest. Dr. I.H. Scheinberg, Research Collaborator from the Albert Einstein College of Medicine, Bronx, N.Y., has introduced for the first time the isotope $\mathrm{Cu}^{67}$ (half-life $61 \mathrm{hr}$ ) in the study of this disease. The point of immediate interest is to ascertain whether ceruloplasmin, the copper-containing protein of plasma, is instrumental in copper transport. This work was impossible with the earlier isotope $\mathrm{Cu}^{64}$ because of its short half-life.

7. Effects of adrenal steroids on manganese and cadmium turnover in mice. 060102. Drs. Cotzias, E.R. Hughes

Studies with intact mice: $\mathrm{Mn}^{54}$ shows a characteristic total-body turnover rate. Furthermore, this turnover rate is sensitive to the level of stable manganese existing in the diet of these animals. Likewise it is sensitive to parenterally administered loads of stable manganese. $\mathrm{Cd}^{109}$ on the other hand shows almost no total-body turnover rate, and almost none can be induced by feeding or injecting stable cadmium salts. Thus $\mathrm{Cd}^{109}$, as opposed to manganese, does not obey homeostatic "signals." In an effort to reconcile these differences adrenal steroids were given. Glucocorticoids had only slight effects on the turnover rate of $\mathrm{Mn}^{54}$ in mice, while mineralocorticoids had none.

8. Studies of manganese movements. 060102. Drs. Cotzias, Borg, Papavasiliou, E.R. Hughes

The manganese pathway through the body has been studied further. Data previously published had confirmed for man the model of manganese tissue uptake first explored in animals. At present the emphasis is on long-term studies following administration of carrier-free $\mathrm{Mn}^{54}$ (300-day halflife). The specificity of the manganese pathway seen in animals is being verified in man, and al- 
terations in radiomanganese content and distribution in different parts of the body are being studied in various disease states and in response to certain hormones and drugs.

9. $\mathrm{Mg}^{28}$ turnover studies in man. 0605. Drs. Dahl, Robertson, Silver.

Ten adults were studied with $\mathrm{Mg}^{28}$ of low specific activity to determine turnover times and other pertinent data. The magnesium was given both orally and intravenously. These studies suggest that gastrointestinal absorption of magnesium is very limited. On the other hand, following intravenous administration the isotope rapidly appears in the urine but only insignificant amounts appear in the stool. Equilibration of the administered isotope with body stores is slow, reaching only onethird equilibrium at $90 \mathrm{hr}$. Graphical analysis of urinary $\mathrm{Mg}^{28}$ curves in terms of exponential components demonstrated a slow component with a half-time of 14 to $35 \mathrm{hr}$ accounting for 10 to $15 \%$ of the injected dose, and two more rapid components with half-times of 1 and $3 \mathrm{hr}$, each accounting for 15 to $25 \%$ of the injected dose. The large fraction remaining, $\approx 25$ to $50 \%$ of the body's total, has a turnover rate of $<2 \%$ per day. These turnover values must be interpreted with caution because of possible effects from the significant amounts of dietary magnesium in addition to the effect of that administered with low specific gravity $\mathrm{Mg}^{28}$.

\section{PLACEMENT}

(Studies of Uptake and Position by Radioactive Detection)

The use of radioactive labels incorporated into active molecules permits detection of the site of action of active molecules. Hormones, in particular, are elusive in their placement both biochemically and anatomically.

1. Localization of labeled hormones. 060601. Drs. Schwartz, Cronkite, Debons, Silver, Johnson; Res. Col. Brecher

The glucostatic theory of appetite regulation rests heavily on the assumption that gold thioglucose produces lesions in the "satiety center" of the ventromedial hypothalamus. It is contended that the toxic gold moiety of this compound destroys the satiety-integrating neurones after being selectively accumulated by virtue of the special affinity of these cells for glucose. Critical evidence in support of this hypothesis has been obtained at $\mathrm{BNL}$ by activation with thermal neutrons of $\mathrm{Au}^{19 i}$ and $S^{32}$. These activation products were identified by $\beta$ and $\gamma$ spectrometry and radioautography. The radioautographs show that the gold and probably the sulfur moieties of gold thioglucose are accumulated in well-defined areas of the ventromedial hypothalamus in all animals that developed hyperphagia and obesity, but in none of the control animals. The technique of neutron radioactivation, as employed in this study, constitutes a new and unique method for the combined functional and anatomical localization of a neuronal integrating center.

2. Studies on vasopressin labeled with tritium and iodine. $060102 . \quad$ Drs. Schwartz, Silver, Debons; Res. Col. Fong

Lysine vasopressin and arginine vasopressin were purified from partially processed mixed hog and beef pituitary powder by countercurrent distribution and ion exchange chromatography. Both hormones were labeled with $\mathrm{H}^{3}$ by the Wilzbach procedure, freed of exchangeable tritum, repurified from the mixture of radiation degradation products, and shown to have retained biological activity.

By using the preparation of $\mathrm{H}^{3}$-labeled vasopressin which proved to have the highest specific activity $(0.32 \mathrm{mC} / \mathrm{mg})$, evidence was obtained suggesting that this hormone is attached at its renal receptor site by coulombic forces, hydrogen bonds, and a covalent (disulfide) bond probably formed by a disulfide displacement reaction involving the hormone disulfide bridge and thiol groups on the receptor protein.

$I^{131}$-labeled vasopressin has been prepared and recovered as a chromatographically and electrophoretically homogeneous and biologically active component. The final $\mathrm{I}^{131}-\mathrm{ADH}$ appears to have about $1 / 1000$ the biological activity of the cold ADH (antidiuretic hormone) and tritiated ADH.

It now appears possible to use this labeled, biologically active material to study the rate of degradation of the hormone in isotopic dilution procedures to observe changes in $\mathrm{ADH}$ production in association with other parameters such as salt intake, serum osmolality, and blood pressure.

3. Relationship between antidiuretic hormone of the pituitary and human hypertension studied with labeled hormone. 060102. Drs. Schwartz, Dahl, Silver; Res. Col. Fong 
Since the discovery of the ADH of the posterior pituitary gland, it has been known that this substance is a potent agent for raising blood pressure in mammals including man. Subsequently it was recognized that this hormone was intimately involved in regulation of the salt and water content of the body. For these reasons this hormone has been of great interest to students of hypertension. It has been shown that restriction of salt intake leads to serum dilution as well as fall in blood pressure. Serum dilution will automatically lead to inhibition of $\mathrm{ADH}$ secretion. It is possible that this inhibition of $\mathrm{ADH}$ secretion is related to the concomitant fall in blood pressure. However, specific and sensitive techniques for measuring $\mathrm{ADH}$ concentration and turnover in man have not existed. Such methods have been developed at BNL by the use of $\mathrm{ADH}$ labeled with radioactive isotopes. Studies of the turnover of both $\mathrm{H}^{3}$ and ${ }^{131}$-labeled hormone have been started in animals and man, with and without hypertension, under various salt loads. This work is still in progress and no interpretation of the data would be warranted at this time.

\section{Histologic site of binding of labeled vasopressin} and chemical nature of attachment in the rat nephron. 060102. Drs. Schwartz, Silver, Debons, Christman (Chemistry Dept.); Res. Col. Fong

$\mathrm{H}^{3}$-arginine vasopressin $\left(\mathrm{H}^{3}\right.$-AVP) of increased specific activity $(0.4 \mathrm{mC} / \mathrm{mg})$ was prepared by exposing the hormone to tritium in a special chamber in which high voltage discharges were passed through the hormone-tritium gas reaction mixture. The hormone was freed of exchangeable tritium, repurified from the mixture of radiation degradation products and shown to have retained the biological activity of highly purified natural arginine vasopressin ( 400 pressor units $/ \mathrm{mg}$ ).

This preparation of $\mathrm{H}^{3}$-labeled arginine vasopressin was used in extension of experiments similar to those begun last year with $\mathrm{H}^{3}$-labeled lysine vasopressin. The results confirmed the earlier finding that the hormone is attached at its receptor site in the mammalian kidney by a covalent (disulfide) bond in addition to electrovalent forces. Evidence that the formation of a hormone-receptor disulfide bond is involved in the mechanism of action of the hormone was obtained in experiments on the mammalian kidney and on vasopressin-sensitive amphibian membranes. With both experimental systems it was possible to show that, following exposure of the rat kidney or toad bladder to $\mathrm{H}^{3}$-arginine vasopressin, $>50 \%$ of the attached radioactivity was linked to that target organ through disulfide bonds; however, when sufficient time had been allowed for hormonal activity to disappear, it was no longer possible to demonstrate disulfide bonding of hormone to target tissue. In other experiments employing $\mathrm{SH}$ blocking compounds ( $n$-ethyl maleimide, $p$-chloromercuribenzoate, methyl mercury bromide), it was found that pretreatment of the target organ with these reagents blocked both the biologic activity of the hormone and the formation of hormone-receptor disulfide bonds. To our knowledge, these findings represent the first clue to the nature of a chemical (covalent) bond formed between a hormone and the target organ and suggest that the formation of this bond is directly involved in the mechanism of action of vasopressin on membrane permeability.

Experiments to determine the nature of the binding of $\mathrm{I}^{131}$-labeled insulin to its receptors in rat diaphragm and adipose tissue (epididymal fat pad) also resulted in a significant release of label following procedures which specifically disrupted disulfide bonds. These results suggest that what has been found true for vasopressin may be a general phenomenon applicable to other disulfide peptide hormones which act on cell membrane permeability.

Microdissections of individual nephrons of the rat kidney have been carried out successfully, and $\mathbb{I}^{131}$-arginine vasopressin has been localized autoradiographically, principally in the distal convoluted tubule and collecting duct. In similar studies, $I^{131}$-labeled insulin was localized in the first part of the proximal convoluted tubule. The effect of irradiation on beta and gamma-emitting isotope derivatives of vasopressin was studied by following the change with time in potency of natural vasopressin as compared with $\mathrm{H}^{3}$-vasopressin and $\mathbb{I}^{131}$-vasopressin. Lysine vasopressin- $\mathrm{H}^{3}$ (specific activity $0.32 \mu \mathrm{C} / \mathrm{mg}$ ) sustained $\approx 10 \%$ loss of hormonal potency over a 1-year period of storage at $-30^{\circ} \mathrm{C}$. On the other hand, $\mathrm{I}^{131}$-arginine vasopressin did not lose potency during the period required for the $\mathbb{I}^{131}$ to decay to levels of $<0.1 \%$ of the original radioactivity. In fact, the hormonal potency of the $\mathbb{I}^{131}$-AVP increased during storage. This finding is probably due to the fact that the decay of $I^{131}$ results in the formation of a chemically inert gas $\left(\mathbb{I}^{131} \rightarrow \mathrm{Xe}^{131}\right)$ which frees 
the hormone of the markedly inhibitory influence of its attached iodine and restores the native form of its tyrosyl residue. Whatever the explanation, the phenomenon constitutes an interesting, if not unique, instance of enhanced physiological activity as a consequence of isotope decay.

In collaboration with Dr. Howard Rasmussen of the Rockefeller Institute, we have employed the bladder of the toad, Bufo marinus, as a model for the vasopressin-receptive zone of the mammalian kidney. This vasopressin-sensitive living membrane consists of a single layer of mucosal cells and is well suited for continuation and extension of the studies of hormone-receptor interaction and of the effects of radiation on receptor function and structure. During the past nine months the response of the toad bladder to vasopressin has been standardized and characterized. It has been found that the striking action of vasopressin on its permeability is independent of oxidative metabolism and of metabolic processes coupled to active transport of sodium. This finding is consistent with the suggestion that a hormone-receptor thiol-disulfide exchange reaction underlies the critical change, i.e., partial disruption of cross-linking in the tertiary structure of a receptor protein, which enlarges the membrane area available for free diffusion and hydrodynamic flow of water. This finding also suggests that in the course of study of the effect of radiation on the functional integrity of $A D H-r e-$ ceptor systems of this tissue, a dosage range can be found which will affect differentially its structural and metabolic properties.

\section{Manganese fraction of human heme identified with $\mathrm{Mn}^{54}$. 0603. Drs. Cotzias, Borg}

The fast disappearance from the bloodstream and the later incorporation into erythrocytes of injected $\mathrm{Mn}^{54}$ has been discussed earlier. The incorporation of the tag into red cells had been ascribed to the synthesis of a heme containing iron instead of manganese. An attempt is now being made to separate the iron-containing from the manganese-containing fraction of human heme.

\section{Studies of internal distribution of $\mathrm{Mn}^{54}$ in mice as affected by adrenal steroids. 060102 . Drs. Cotzias, E.R. Hughes}

Surprisingly, while glucocorticoids had only a small effect on the total body turnover rate of $\mathrm{Mn}^{54}$, they had a marked effect on the isotope's internal distribution. The liver became depleted of $\mathrm{Mn}^{54}$ and the carcass was simultaneously en- riched. The entire liver cell seemed to participate in this phenomenon since the relative intracellular partition of the isotope remained remarkably constant on treatment of the animals with glucocorticoids. As opposed to the sensitivity of the liver to the treatment, the kidney, heart, brain, pancreas, gonads, and gastrointestinal tract seemed unaffected. The mineralocorticoids again showed no effect whatsoever.

\section{Studies of in vitro binding by $\mathrm{Mn}^{54}$. 060102 .} Drs. Cotzias, E.R. Hughes

Coordination or chelation of manganese by steroid hormones is possible on the basis of their respective chemical properties. Therefore, this was studied in vitro with two sets of end points: (1) competition for binding of $\mathrm{Mn}^{54}$ between a resin and the hormones, and (2) competition for binding of $\mathrm{Mn}^{54}$ between plasma and hormones as indicated by electrophoresis, ultrafiltration and equilibrium dialysis.

These latter studies are not completed. The sum total of the experience at hand indicates that cortisol behaves relative to these binding sites in a fashion parallel to that of salicylaldehyde, a wellknown manganese chelator.

\section{VOLUMES OF DISTRIBUTION (Quantities of Radioactive Dilution)}

Dilution of a known dose of administered radioactive isotopes can be used to determine either specific pool size, total exchangeable fraction, or volume of body concerned in which this may be a variable. Appropriate physiological parameters permit specific medical interpretation of results in patients.

1. Kinetics of sodium in patients with essential hypertension. 060102. Drs. Dahl, Gordon, Silver, Spraragen, Smilay

The phenomenon of exaggerated natriuresis following infusions of hypertonic saline in hypertensive patients is well established. The influence of variation in salt intake on this response has been studied, and the possibility that individuals with and without hypertension call upon different body pools of sodium after this stimulus has been explored. Eleven hypertensive and six nonhypertensive adult subjects were studied for two or more periods during each of which the daily salt intake was held constant at $0.3,4.3,8.3$ or $12.3 \mathrm{~g}$. After small infusions of $5 \% \mathrm{Na}^{24} \mathrm{Cl}$, measurements of 
$\mathrm{Na}^{23}$ and $\mathrm{Na}^{24}$ in plasma and urine were made for the next $24 \mathrm{hr}$. This study, begun in 1959, has now been completed with the following results: (1) On equivalent salt intakes, hypertensives during the first $3 \mathrm{hr}$ following the infusion usually excreted more urinary sodium than nonhypertensives. (2) The magnitude of this natriuretic response was changed drastically by antecedent variations in salt intake; the higher the salt intake, the greater the response, and vice versa. (3) The specific activity of urine and blood was similar in hypertensive and nonhypertensive, which suggests that the sodium was probably mixed in similar fashion in the body.

Studies have begun on factors affecting sodium turnover in the human. With the aid of the wholebody counter the biological half-life of $\mathrm{Na}^{22}$ in patients with and without hypertension is being explored. This extensive time-consuming program is still in progress and no single parameter has been fully explored. The following preliminary observations have been made: (1) By appropriate increases in the $\mathrm{NaCl}$ intake, the biological halflife of $\mathrm{Na}^{22}$ was changed from $>200$ days to $<8$ days. (2) With the sodium intake constant, increments in the potassium intake materially shortened the biological half-life of $\mathrm{Na}^{22}$.

2. Sodium turnover in experimental hypertension in rats. 060102. Drs. Dahl, Gordon, Silver, Spraragen, Smilay

This work, begun in 1959 prior to the inception of similar work on humans here, has been largely confined to development of satisfactory counting techniques for whole rats, using $\mathrm{Na}^{22}$. These technical problems have now been overcome, so that the factors affecting sodium metabolism during and after the development of experimental hypertension can be studied actively.

3. $\mathrm{Sr}^{90}, \mathrm{Cs}^{137}$, and $\mathrm{K}^{40}$ content of body-fluid specimens from Marshall Islanders. 060401. Dr. Cohn

Further data on levels of internal contamination in the exposed Marshallese are being obtained by the radiochemical analysis of their urine. The radiobiochemical laboratory is concerned with the development and standardization of procedures for low level counting of $\mathrm{Sr}^{90}, \mathrm{Cs}^{137}$, and $\mathrm{K}^{40}$. One hundred urine samples were analyzed, as were samples of food collected for the Marshall Islands survey in 1959. Additional urine samples were collected for the survey in 1960 and are being analyzed. A multidetector, low level, anticoincidence beta counter for these and other studies was constructed and is in operation.

\section{E. METABOLIC PATHWAYS \\ (Study of Sequential Reactions by Radioactive Charting)}

Appropriate use of labeled precursors or products and intermediates with observation of intermediate and end products permits selection of most likely reaction sequences in complex metabolic oxidations and syntheses of carbohydrates, proteins and fats.

\section{Utilization of $C^{14}$ label in carbohydrate metabolism studies}

a. Formation of ketone bodies in diabetic man. 060102. Dr. Shreeve

Studies have continued on the analyses of $\mathrm{C}^{14}$ content and distribution in urinary beta-hydroxybutyric acid (BHBA) after the administration of $1-\mathrm{C}^{14}$-acetic acid to diabetic patients. It has been further established that the $\mathrm{C}^{14}$ is distributed evenly between the carboxyl and the carbonyl carbons in mildly or severely diabetic patients when the ketone body in the urine of the first $2 \mathrm{hr}$ is analyzed. This appears to be true also when the patient has received prednisone prior to the $\mathrm{C}^{14}$ study. In juvenile, acutely diabetic patients the ratio of carbonyl $\mathrm{C}^{14}$ : carboxyl $\mathrm{C}^{14}$ remains $\approx 1.0$ in BHBA of the urine up to $6 \mathrm{hr}$ after $\mathrm{C}^{14}$-acetate injection; in mildly diabetic patients the ratio appears to be decreased to $\approx 0.75$ in $\mathrm{BHBA}$ of $6-\mathrm{hr}$ urine. This finding of a ratio different from 1.0 provides some support to the theory of Lynen that ketone bodies are formed via 6-carbon, branchedchain intermediates. According to this theory, differences in isotopic content of the two-carbon moieties of ketone bodies may be expected.

The average specific $\mathrm{C}^{14}$ activity of carbons of BHBA from 6-hr urine has been generally found to be $\approx^{1 / 4}$ to $1 / 6$ that of the $\mathrm{C}^{14}$ activity of $\mathrm{BHBA}$ from 2 -hr urine. In one patient, the activity in the BHBA of 6 -hr urine had fallen to $<1 / 2$ that of the BHBA in earlier urine.

Chromatograms of urine obtained in the process of purification of BHBA have indicated the presence of a number of organic acids in the urine in addition to BHBA. One of these has been identified as pyruvic acid. These acids (including pyruvic acid) are much less prominent in urine of severely diabetic patients than in urine of mildly diabetic subjects. Also the prior administration of 
prednisone generally depresses these acids in the urine of the mildly diabetic patient.

b. The formation of blood glucose in man. 060102. Drs. Shreeve, De Meutter

This study has been extended by the inclusion of other labeled compounds (pyruvic acid and glycine) in addition to acetic and lactic acids as precursors of glucose formation. Also the study has explored gluconeogenesis in metabolic conditions other than fasting diabetes with or without insulin or tolbutamide (oral hypoglycemic drug). The report may be divided into two phases:

(1) Extent of formation and hepatic output of glucose. About the same percentage (20 to 30\%) of intravenously injected 2- or 3- $\mathrm{C}^{14}$-pyruvate is calculated to be present in free extracellular glucose at peak incorporation ( 30 to $60 \mathrm{~min}$ ) as when the labeled precursor is $\mathrm{C}^{14}$-DL-lactate in fasting, untreated diabetic patients. With $2-\mathrm{C}^{14}$-glycine in one study with an insulin-treated diabetic the incorporation at 30 min was $15 \%$.

Among a current series of seven untreated, fasting diabetic patients and one nondiabetic patient (cyclic edema) studied with trace amounts of $\mathrm{C}^{14}$ pyruvate or $\mathrm{C}^{14}$-lactate, the nondiabetic subject showed the lowest incorporation of $\mathrm{C}^{14}$ into glucose $(13 \%$ at peak time of $30 \mathrm{~min})$. The more severely diabetic subjects in general showed the higher amounts of incorporation. Comparisons between the 2 and 3 carbons of pyruvate and lactate in the same individual will be made pending results from studies recently performed.

In a further attempt to assay the effect of treatment on the process of gluconeogenesis, a patient was studied in an acute, uncontrolled diabetic state, and then in a controlled condition plus intravenous infusion of insulin. With this patient the 2- $\mathrm{C}^{14}$-lactate was infused with a load of Na-lactate. The apparent minimal uptake of $\mathrm{C}^{14}$ into glucose was (as with trace quantities of lactate) about 25\% of the injected dose in the diabetic state and only about one-third this much in the insulin-treated state.

Since it has been claimed that a glucose load diminishes or completely inhibits glucose production by the liver, the nondiabetic patient (vide supra) was retested for conversion of $2-\mathrm{C}^{14}$-lactate to glucose shortly after intravenous injection of a glucose load. There was relatively little decrease in the incorporation of $\mathrm{C}^{14}$ into glucose compared to that in the fasting state. Glucagon, which breaks down liver glycogen to free glucose, was given to this patient $2 \mathrm{hr}$ after the $\mathrm{C}^{14}$-lactate. Subsequent analyses of blood glucose suggested that much more glycogen had been deposited from newly formed $\mathrm{C}^{14}$-glucose when a glucose load was given than when the patient was fasting.

(2) Pathways of formation of glucose. Further studies have been conducted in diabetic and nondiabetic patients of the distribution of $\mathrm{C}^{14}$ in the glucose molecule after the injection of $2-$ or $3-\mathrm{C}^{14}$ lactate or 2 - or $3-\mathrm{C}^{14}$-pyruvate. The previous finding of marked lack of symmetry between the two halves of glucose (greater randomization in carbons 1 and 2 than carbons 5 and 6 ) has been substantiated not only in other diabetic patients but in a nondiabetic patient as well. One diabetic patient given $3-\mathrm{C}^{14}$-pyruvate is an exception to this general finding. The nondiabetic and the diabetic patients given insulin appear to show less randomization between carbons 5 and 6 than the untreated diabetics. The distribution of $\mathrm{C}^{14}$ in glucose after $2-\mathrm{C}^{14}$-glycine administration is qualitatively like that after $2-\mathrm{C}^{14}$-pyruvate or $2-\mathrm{C}^{14}$-lactate. These studies form a basis for evaluation in the human of intermediary metabolic pathways, which appear to involve more than reactions of the Krebs cycle and glycolysis in gluconeogenesis from small molecular precursors.

c. Dynamics of bicarbonate movement and iurnover in diabetic man. 060102. Drs. Shreeve, De Meutter; Res. Col. R. Schwartz

In studies of venous and arterial differences in specific activity of $\mathrm{C}^{14} \mathrm{O}_{2}$ after $\mathrm{NaHC}^{14} \mathrm{O}_{3}$ injection into diabetic humans concomitantly, $\mathrm{Na}^{24} \mathrm{Cl}$ and Evans blue dye (T-1824) have been included as tracers. This permits reference points for $\mathrm{C}^{14}$ bicarbonate distribution in that T-1824 measures essentially plasma mixing and distribution, while $\mathrm{Na}^{24} \mathrm{Cl}$ measures (in the early time period) extracellular fluid mixing and distribution. According to these studies bicarbonate definitely mixes in a larger space, and with a larger pool, than is contained in the extracellular compartment of the peripheral tissues (forearm). The magnitude of this pool and kinetics of mixing have not yet been clearly defined.

$\mathrm{d}$. The conversion of $\mathrm{C}^{14}$-lactate and $\mathrm{C}^{14}$-pyruvate to respired carbon dioxide in diabetic man. 060102 . Drs. Shreeve, De Meutter

Studies of $\mathrm{C}^{14} \mathrm{O}_{2}$ production from labeled lactate and pyruvate were commenced this year to estimate the oxidative fate of these componds in relation to their conversion to glucose in diabetic 


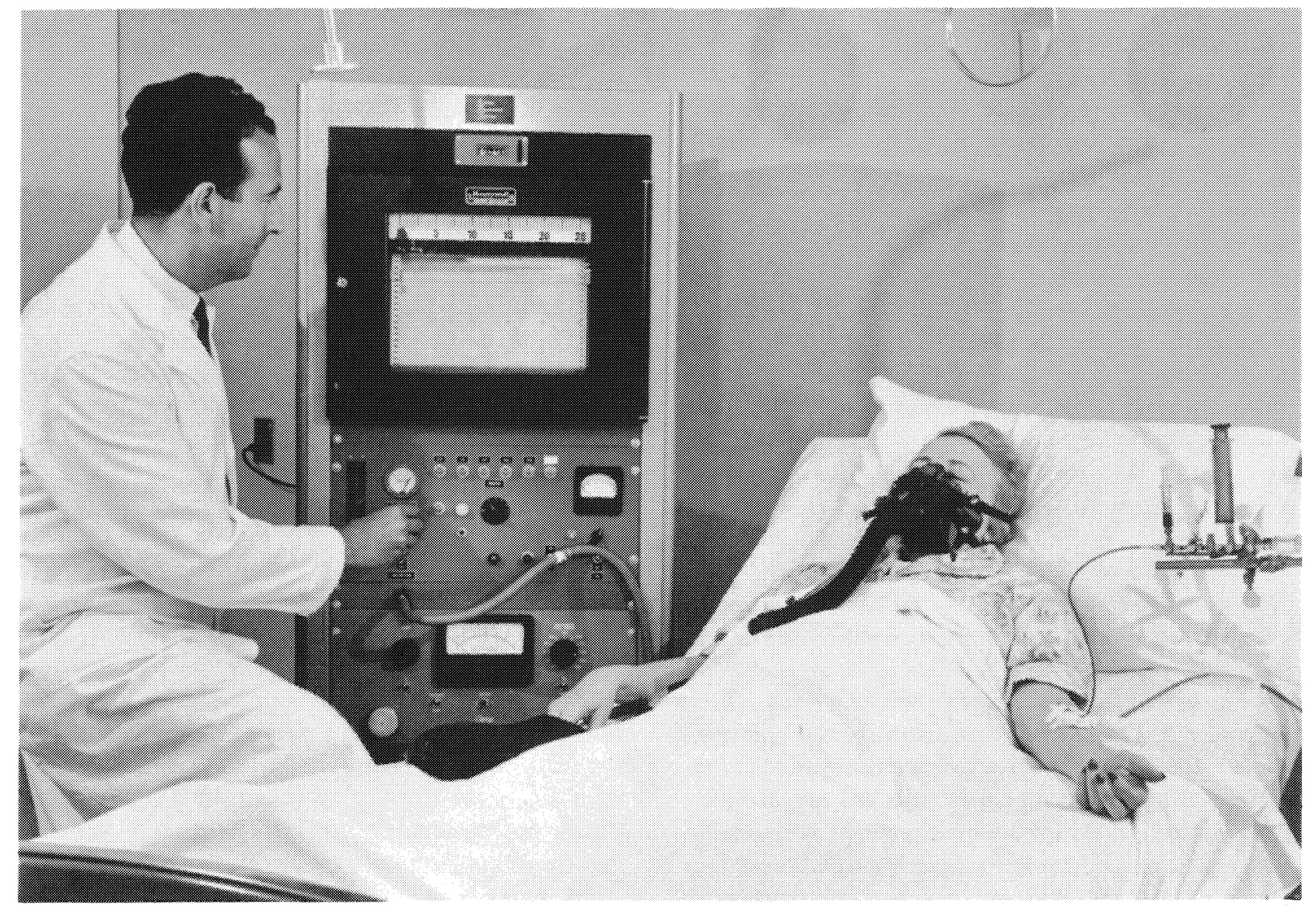

Collection and measurement of respired $\mathrm{C}^{14} \mathrm{O}_{2}$ in studies of carbohydrate oxidation in diabetic patients.

patients. Changes in rate of $\mathrm{C}^{14} \mathrm{O}_{2}$ appearance have been found to occur in conjunction with insulin and glucose administration. $\mathrm{C}^{14} \mathrm{O}_{2}$ is produced at approximately twice the rate from lactate when the patient is acutely diabetic and untreated. In another study insulin administration was accompanied by faster output of $\mathrm{C}^{14} \mathrm{O}_{2}$ than when tolbutamide was given. After a glucose load the appearance of $\mathrm{C}^{14} \mathrm{O}_{2}$ from lactate also was greater in the early time period than in the fasting state. Concomitant decreases in $\mathrm{C}^{14}$ appearance in glucose suggest a diversion of lactate to oxidative pathways and away from gluconeogenesis as an effect of insulin. However, changes in rate of dis-appearance of labeled lactate from the blood should be considered and investigated.

e. Production of $\mathrm{C}^{14} \mathrm{O}_{2}$ from 1 - and 2-C ${ }^{14}$-acetate in man. 060102. Dr. Shreeve; Res. Col.R. Schwartz, Hennes

The rate of appearance of $\mathrm{C}^{14} \mathrm{O}_{2}$ in the breath of human subjects under diverse metabolic condi- tions has been determined after a single intravenous injection of 1 - or $2-\mathrm{C}^{14}$-acetate ( 40 to 200 $\mu \mathrm{C}$ in $0.75 \mathrm{mM}$ ). Three patients with pulmonary carcinoma and four patients with diabetes were employed in 13 individual studies.

Patients in general excreted $\approx 60$ to $70 \%$ of the $\mathrm{C}^{14}$ from $1-\mathrm{C}^{14}$-acetate as $\mathrm{C}^{14} \mathrm{O}_{2}$ within the first 24 $\mathrm{hr}$, and $\approx 55 \%$ from $2-\mathrm{C}^{14}$-acetate. $\mathrm{C}^{14} \mathrm{O}_{2}$ from 1- $\mathrm{C}^{14}$-acetate was excreted with an earlier and twofold higher peak activity, a steeper decline of activity from 2 to $8 \mathrm{hr}$ after injection, and at a somewhat more rapid cumulative rate than that from $2-\mathrm{C}^{14}$-acetate.

Stable, elderly diabetics (without insulin but normoglycemic) showed no difference from nondiabetic (carcinomatous) subjects in excretion of $\mathrm{C}^{14} \mathrm{O}_{2}$ from $1-\mathrm{C}^{14}$-acetate. In the stable diabetics, fasting for $40 \mathrm{hr}$, which produced mild ketosis, did not noticeably change $1-\mathrm{C}^{14}$-acetate oxidation. In stable, juvenile, or lipoatrophic diabetics, $\mathrm{C}^{14} \mathrm{O}_{2}$ excretion after $2-\mathrm{C}^{14}$-acetate was apparently identical. 
In paired experiments in the same individual, with and without prior acute dosage with prednisone, there was in each case (three studies with 1- $\mathrm{C}^{14}$-acetate, one with $2-\mathrm{C}^{14}$-acetate) a significant decrease averaging 10 to $20 \%$ in $\mathrm{C}^{14} \mathrm{O}_{2}$ excretion.

In one patient analyses of peripheral venous and arterial $\mathrm{C}^{14} \mathrm{O}_{2}$ at the same times as breath $\mathrm{C}^{14} \mathrm{O}_{2}$ during the first $40 \mathrm{~min}$ after injection of 2- $\mathrm{C}^{14}$-acetate showed that, while arterial and respiratory $\mathrm{C}^{14} \mathrm{O}_{2}$ were essentially parallel, the specific activity of peripheral venous $\mathrm{C}^{14} \mathrm{O}_{2}$ rose much more slowly.

\section{Utilization of labeled proteins and amino acids in protein metabolism studies}

a. In vitro metabolism of tryptophan-2- $\mathrm{C}^{14}$ and glycine-2- $\mathrm{C}^{14}$ by Trichinella spiralis larvae. 060102. Drs. Hankes, Stoner

Active metabolism of well-encapsulated Trichinella spiralis larvae was demonstrated by administering diets containing $\mathrm{C}^{14}$-labeled glycine, alanine, tyrosine, or tryptophan to mice with infections of two and six months' duration. The larvae also exhibited a progressive uptake of $\mathrm{C}^{14}$ when isolated from host tissues by pepsin digest and cultured in vitro in chemically defined media containing these $\mathrm{C}^{14}$-labeled amino acids. A significant amount of the $\mathrm{C}^{14}$ was found in larval protein.

These studies have been extended to include the metabolism of DL-tryptophan-2- $\mathrm{C}^{14}$ and glycine2- $\mathrm{C}^{14}$ into various chemical components of Trichinella larvae. Mice with Trichinella infections of nine months' duration were injected intraperitoneally with $\mathrm{C}^{14}$-labeled amino acids. The animals received a total dose of $4.62 \mu \mathrm{C}$ DL-tryptophan-2- $\mathrm{C}^{14}$ and $4.63 \mu \mathrm{C}$ glycine-2- $\mathrm{C}^{14}$ daily for six days. Muscle larvae were isolated by pepsin digest, washed, and cultured at $37.5^{\circ} \mathrm{C}$ in sterile KrebsRinger solution. At intervals of $0,3,6,12$, and 24 $\mathrm{hr}$, viable larvae were recovered from the media and processed for $\mathrm{C}^{14}$ analysis. Weighed samples from each group were fractionated into carbohydrate, lipid, protein, and nonprotein material (NPM - not precipitated by tungstic acid). $\mathrm{C}^{14}$ analyses of these fractions were conducted with the Van Slyke, Steele, and Plazin gas counting method. The percent of $\mathrm{C}^{14}$ activity in the glycogen and the NPM of the larvae previously labeled with tryptophan-2- $\mathrm{C}^{14}$ decreased during the 24-hr period of culture. An increase in $\mathrm{C}^{14}$ activity was obtained in the protein and lipid fractions. In the glycine-2-
$\mathrm{C}^{14}$-labeled larvae the percent of $\mathrm{C}^{14}$ activity decreased in the glycogen and lipid fractions. The percent of $\mathrm{C}^{14}$ activity increased in the protein and NPM fractions of the larvae cultured for a period of $24 \mathrm{hr}$.

b. Metabolism of 3-hydroxyanthranilic acid in neoplastic mice. 0609. Dr. Hankes

Earlier experiments with carboxyl-labeled 3hydroxyanthranilic acid have shown that it was rapidly metabolized to carbon dioxide via acetate and that it was converted to quinolinic acid and the vitamin niacin (nicotinic acid).

Clinical studies reported in the literature indicate that in some neoplastic diseases there are elevated levels of urinary 3-hydroxyanthranilic acid, anthranilic acid, kynurenine and 3-hydroxykynurenine. In addition, two of these compounds, 3-hydroxyanthranilic acid and 3-hydroxykynurenine, have exhibited tumor-producing qualities in mice. In view of these findings, it has become more important to establish the normal metabolic pathway for these compounds.

Carboxyl-labeled 3-hydroxyanthranilic acid was injected intraperitoneally into normal mice and into mice with spontaneous mammary tumor, ascites tumor, or transplantable brain tumor to study the effects of the tumors on the metabolism of this compound. It was injected in a dose of $0.0011 \mathrm{mM}$ containing $0.024 \mu \mathrm{C}$ activity per gram body weight. The respired $\mathrm{CO}_{2}$ collected for the first $12 \mathrm{hr}$ indicated that the animals with mammary tumor metabolize the 3-hydroxyanthranilic acid at a rate similar to that in normal mice. Slightly lower rates of metabolism in the mice with brain tumor and those with ascites tumor may have been the result of rapid tumor development in these animals. The $\mathrm{C}^{14}$ contents of the urines of animals with tumors were slightly lower than those of the normal animals, and much smaller quantities of quinolinic acid appeared in the urines of the tumor-bearing animals. The ratios of the specific activity of the urinary quinolinic acid to that of the administered 3-hydroxyanthranilic acid show that almost all the quinolinic acid that appeared in the urine of the tumor-bearing mice came from the injected 3-hydroxyanthranilic acid. The lower quinolinic acid values in the tumor-bearing mice could be due in part to the accelerated activity of enzyme II, which is responsible for the decarboxylation of 1-amino-4-formyl-1,3-butadiene-1,2dicarboxylic acid (the compound formed when the 3-hydroxyanthranilic acid ring is split) in position 
2 to form picolinic acid. However, the total urinary $\mathrm{C}^{14}$ activity in quinolinic acid, picolinic acid, and nicotinic acid does not account for all the activity in the urines. The lower levels of total $\mathrm{C}^{14}$ activity in the urine of the tumor-bearing animal and the high percent of urinary $\mathrm{C}^{14}$ in unidentified compounds suggest that the metabolism of 1 amino-4-formyl-1,3-butadiene-1,2-dicarboxylic acid may be shifting into other pathways producing components retained or utilized in the animal body. For example, labeled 3-hydroxyanthranilic acid has been shown to be converted into labeled glutamic acid.

c. Beta alanine-2-C $\mathrm{C}^{14}$ as a precursor of quinolinic acid. 060102 . Dr. Hankes

In an effort to account for all the $\mathrm{C}^{14}$-labeled components present in the urine of the tumorbearing mice, other possible pathways related to 3 -hydroxyanthranilic acid were explored. The ability of tobacco-root cultures to incorporate $\mathrm{C}^{14}$ from beta-alanine-2- $\mathrm{C}^{14}$ into the pyridine ring structure of nicotine suggested that some new scheme for nicotinic acid synthesis existed or that the proposed scheme of converting 3-hydroxyanthranilic acid to $\mathrm{CO}_{2}$ via glutaric acid and acetic acid may be reversible.

Mice, rats, and guinea pigs were injected with beta-alanine-2- $\mathrm{C}^{14}$ in doses of $1.78 \mathrm{mg}$ per mouse, $4 \mathrm{mg}$ per rat, and $4 \mathrm{mg}$ per guinea pig. The mice metabolized the beta-alanine at the fastest rate as indicated by $\mathrm{C}^{14} \mathrm{O}_{2}$ excretion, and they also excreted a larger percentage of the administered $\mathrm{C}^{14}$ activity in the urine than either the rat or guinea pig. Quinolinic acid isolated from each urine contained $\mathrm{C}^{14}$ activity. Failure to obtain $\mathrm{C}^{14} \mathrm{O}_{2}$ by decarboxylation of quinolinic acid in the 2 position showed that the $\mathrm{C}^{14}$ activity was either in the 3 position carboxyl group or in the pyridine ring of the quinolinic acid isolated from the urines.

The conversion of labeled 3-hydroxyanthranilic acid to labeled glutaric acid and labeled acetate indicated this as the pathway for the metabolism of 3-hydroxyanthranilic acid to acetate via 1 amino-4-formyl-1,3-butadiene-1,2-dicarboxylic acid. The observation in another laboratory that $\mathrm{C}^{14}$-labeled beta-alanine is converted into $\mathrm{C}^{14}$ labeled acetate, coupled with our observation that beta-alanine is converted to quinolinic acid, suggests that the pathway for the formation of acetate from 3-hydroxyanthranilic acid via cisglutaconic acid is reversible, at least as far as 1 amino-4-formyl-1,3-butadiene-1,2-dicarboxylic acid. These findings show that there are other pathways for the synthesis of small quantities of quinolinic acid.

The depression of quinolinic acid synthesis in the tumor-bearing mice discussed above could be the result of an acceleration of the metabolism of 3-hydroxyanthranilic acid into cis-glutaconic acid, glutaric acid, and acetate.

d. Synthesis of 3-hydroxykynurenine-4-C'14. 0607.

Dr. Hankes; Res. Col. Brown; Tech. Col. Kawashima

The recent evidence that 3-hydroxykynurenine exhibits carcinogenic activity in producing a mouse bladder tumor has made it more important to establish the function of 3-hydroxykynurenine in the metabolism of tryptophan to quinolinic acid and niacin. Such a study requires the preparation of labeled 3-hydroxykynurenine.

Work has been completed on the synthesis of a large quantity of carboxyl- $\mathrm{C}^{14}$-labeled 3-methoxy2-nitrobenzoic acid, the starting material for the synthesis of 3-hydroxykynurenine-4- $\mathrm{C}^{14}$. A small quantity of the labeled acid has already been converted into sufficient 3-hydroxykynurenine-4- $\mathrm{C}^{14}$ for preliminary work with animals.

e. Incorporation of $\mathrm{H}^{3}$-labeled tryptophan by Trichinella spiralis larvae. 060102. Drs. Stoner, Hankes

Active metabolism of tryptophan by Trichinella spiralis larvae was previously shown by feeding DLtryptophan-2- $\mathrm{C}^{14}$-labeled diets to infected mice and by in vitro culture of the larvae in chemically defined media. In the work described here, tritium-labeled tryptophan $\left(\mathrm{H}^{3}\right.$-tryptophan) with a high specific activity was administered parenterally to infected mice in order to study incorporation of this compound into muscle larvae, saline extracts of larvae, and serum. L-Tryptophan was labeled with tritium by means of the Wilzbach gas exposure method and recrystallized several times from $50 \%$ ethanol. Daily intraperitoneal injection of 7.4 $\mu \mathrm{C} \mathrm{H}^{3}$-tryptophan was started on the 17 th day of infection and continued for 10 or 24 days. Noninfected control animals of the same age were also maintained on the same schedule. Muscle larvae were isolated by pepsin digest, separated from undigested materials, and washed to remove soluble digestion products. The washed larvae were lyophilized and vacuum-dried, and weighed samples were analyzed for tritium with the gas counting procedures of Christman and Wilzbach. Saline extracts of the larvae and $0.1-\mathrm{ml}$ serum samples were dried in zinc boats and analyzed for tritium. 
The results show progressive incorporation of tritium into Trichinella larvae with time.

f. The direct whole-body counting technique for determining protein turnover. 060601. Drs. Lippincott, Robertson, Farr, Cohn, Fine

In clinical studies of the metabolic behavior of radioactively labeled proteins, the turnover or degradation rate is usually determined from serum (or plasma) concentration curves which entail multiple blood sampling. The amounts of retained isotope are customarily inferred (by difference) from the analyses of excreta obtained from complete 24-hr samples collected for several successive days. In the present experiments the turnover of $I^{131}$-labeled proteins prepared by ethanol fractionation was determined not only by the conventional method of blood and urine sampling but also by a new technique utilizing the wholebody gamma spectrometer. This device permits in vivo measurement of very low levels of an internally deposited gamma emitter (in this case, $\mathbb{I}^{131}$ ). The procedure provides an excellent method for measuring retention of labeled albumin and globulins over long periods of time following administration of very low levels of isotopes. It also eliminates the tedious radiochemical analyses of excreta.

g. Turnover rates of $\mathrm{Co}^{60}$ and $\mathrm{Co}^{58}$-labeled vita$\min B_{12}$ in man. 060102. Drs. Cohn, Reizenstein

The rates of turnover of labeled vitamin $B_{12}$ are being studied in two patients over a 1 -yr period. Both patients received $\mathrm{Co}^{60}$-labeled vitamin $\mathrm{B}_{12}$ parenterally and simultaneously received $\mathrm{Co}^{58}$ labeled vitamin $\mathrm{B}_{12}$ orally. In addition, eight patients who had received $3 \mu \mathrm{C} \mathrm{Co}{ }^{60}$-labeled vita$\min \mathrm{B}_{12}$ up to $3 \mathrm{yr}$ before are being followed in the whole-body counter with a high degree of precision, in order to determine the long-term biological half-time of vitamin $B_{12}$.

h. Turnover of labeled normal gamma globulin in multiple myeloma. 0609. Drs. Lippincott, W.L. Hughes, Stickley, Wolins; Res. Col. Korman, Fong

Aberrations of protein metabolism in multiple myeloma have been studied by a number of investigators to ascertain whether the globulins in the blood consist of excesses of normal globulins, of chemically abnormal globulins, or both. Such research has been directed toward determining whether "characteristic protein abnormalities" could be distinguished by (1) separation of the serum proteins with identification of their physiochemical properties by using the Tiselius electrophoresis apparatus and the analytical ultracen- trifuge, (2) certain structural relationships indicated by the amino end-group method, (3) immunochemical procedures, and (4) detection of formation of abnormal protein by administering to the patient isotopically labeled amino acids, the tracers being the stable isotopes $\mathrm{N}^{15}$ and $\mathrm{C}^{13}$ or radioactive carbon, $\mathrm{C}^{14}$. By use of such experimental methods it has been reported that at least some, if not all, of the quantitatively excess globulins produced in this disease are abnormal.

In the present investigation of certain fundamental aspects of protein metabolism in this disease, concern has been with the patient's turnover of globulins. The turnover of $\mathbf{I}^{131}$-labeled normal gamma globulin was determined in ten patients with multiple myeloma and correlated with the serum globulin distribution as established by paper electrophoresis. In four patients with the predominant peak in the beta region, the mean of the fast component was $12.24 \pm 0.47 \mathrm{hr}$, while in the six patients with the predominant peak in the gamma region the mean was $10.95 \pm 0.59 \mathrm{hr}$. For the slow component in the beta type individual the mean was $16.12 \pm 1.15$ days, and in the gamma type, $7.14 \pm 0.28$ days. The rate of degradation for normal gamma globulin indicated by the slow component is far more rapid for the patient with excessive gamma globulin in his serum protein distribution than for the individual with excessive beta globulin.

i. Turnover of autologous and homologous labeled gamma globulin in multiple myeloma. 0609. Drs. Lippincott, W.L. Hughes; Res. Col. Korman

The turnover was determined for $\mathrm{I}^{131}$-labeled gamma globulins prepared by ethanol fractionation from the sera of patients with multiple myeloma. The three donor patients whose sera were used for fractionation of the globulin had gamma-type paper serum electrophoretic patterns. The fractionated gamma globulin was considered by free (Tiselius) electrophoresis to be at least $95 \%$ homogeneous, and the ultracentrifuge patterns also indicated a high degree of homogeneity. Both autologous and homologous turnover studies were made. The mean of the halflives of the three labeled gamma globulins was 15.5 days in the hyper-beta-globulinemic patients, while in the hyper-gamma-globulinemic patients it was 6.3 days. When gamma globulin prepared from normal healthy individuals was labeled and the turnover was determined in some of these and in other multiple myeloma patients, the mean of 
the half-lives in five instances for the hyper-betaglobulinemic group was 17.1 days and in eight instances for the hyper-gamma-globulinemic group 7.4 days. The determining factor in difference of degradation rate was not the donor source of the gamma globulin but the recipient multiple myeloma patient's type of serum protein distribution as indicated by the serum electrophoretic patterns.

i. Radioactive tracers and immunological procedures, electrophoresis and ultracentrifugation in studies of protein metabolism in cancer. 0609. Dr. Lippincott

The present researches are an extension of clinical-pathological investigations that originated eslewhere several years ago. The original and still current objective is a study of certain of the properties and functions of the serum proteins in neoplastic diseases. Should any characteristic(s) exist for a given protein fraction distinguishing it from a similar fraction in normal subjects or those with various nonneoplastic diseases, a basis might be established for a diagnostic test for cancer. The principal approach in this long-range study has been detailed investigation of the physicochemical nature of human crystalline albumin and of human globulins utilizing techniques involving immunochemical procedures, electrophoresis, ultracentrifugation, and infrared spectroscopy. These measurements did not yield results useful in the diagnosis of cancer or in prognosis for the patient with known cancer. For this reason attention has been centered on approaching this problem through observation of the turnover of radioactively labeled proteins in neoplasic diseases.

k. RNA and DNA metabolism in human tissue culture cells studied with tritiated cytidine. 0603.

Drs. Bond, Shreeve, Feinendegen, Painter

The autoradiographic technique combined with biochemical methods was employed to study aspects of ribonucleic acid (RNA) and desoxyribonucleic acid (DNA) metabolism in human tissue culture cells incubated with tritiated cytidine. Tritiated cytidine was incorporated within minutes into all intact nuclei of HeLa S3 cells and Osgood leukemic cells. The label subsequently increased over the nucleoli and over the cytoplasm. This sequence of labeling was defined and quantitatively observed in turnover studies, in which the cultures were incubated with the labeled nucleoside for a short time only, followed by growth in carrier cytidine supplemented medium.
While nuclear label decreased, cytoplasmic label became visible, and most nucleoli temporarily accumulated label with a maximum at $1 \mathrm{hr}$ after cessation of incubation with tritiated cytidine.

Desoxycytidine as carrier in the new medium failed to prevent further uptake of tritiated cytidine, which was apparently not removed by washing of the cultures. It is concluded, therefore, that the cytidine incorporation depends on enzyme systems different from that of desoxycytidine. Preparatory steps for autoradiography of the cells extracted an appreciable amount of activity, which declined after cessation of the incubation with tritiated cytidine. Some label was probably also extracted from the chromatin portion of the nucleus.

RNA synthesis stops while the cell is in mitosis, as evidenced by the lack of incorporation of tritiated cytidine into dividing cells.

Evidence is presented indicating that the tissue culture cells synthesize RNA also during the DNA synthesis period.

Tritiated cytidine is incorporated into DNA during DNA synthesis. Compounds not previously incorporated into DNA during short-term incubation with tritiated cytidine were found to be utilized at a later time for DNA synthesis.

The majority of the incorporated cytidine is recovered in the RNA. The label in the acidsoluble pool declines steadily with time after cessation of incorporation of the labeled cytidine, while the nonacid-soluble RNA label remains constant.

It is confirmed for HeLa cells that cytidine is in part converted to thymidine for DNA synthesis.

The experimental results lend support to the hypothesis that RNA synthesis begins in the chromatin portion of the nucleus. The fate of the incorporated cytidine apparently is decided in the nucleus, where it is first linked specifically and from where it progresses to the building blocks of nucleolar and cytoplasmic RNA or DNA.

1. The metabolism and fate of tritiated thymidine in man. 060102 . Drs. Cronkite, Bond, Rubini, Fliedner

The metabolism and fate of tritiated thymidine were studied in two patients in hemopoietic equilibrium. Plasma clearance of $\mathrm{H}^{3}$-thymidine commences in the first circulation time and becomes exponential following apparent equilibrium with total body water. Two components with half-times of 0.2 and $1.0 \mathrm{~min}$ were identified. The rapid 
plasma clearance of $\mathrm{H}^{3}$-thymidine was associated with incorporation of this compound into newly formed DNA of proliferating cells as early as 1 min after injection. Labeling of proliferative cells of the bone marrow was nearly complete within $10 \mathrm{~min}$ after injection, and thereafter the label appeared to remain in these cells or their progeny for their life span, diluted only by successive mitoses. This short availability time of intravenous $\mathrm{H}^{3}$ thymidine simplifies the analyses of the time parameters of labeled proliferating cell populations. About one-third of the $\mathrm{H}^{3}$-thymidine was catabolized to THO within a few hours after injection. Small amounts of urine nonvolatile $\mathrm{H}^{3}$ activity were excreted in the urine during the first day after injection. $\mathrm{H}^{3}$-beta-aminoisobutyric acid was identified in these urines as a catabolic product of $\mathrm{H}^{3}$-thymidine. Severe malnutrition resulted in greater degradation of $\mathrm{H}^{3}$-thymidine to $\mathrm{THO}$ and urine nonvolatile $\mathrm{H}^{3}$ activity.

$\mathrm{m}$. Acquired immune folerance in mice to crystalline bovine serum albumin. 0605 . Drs. W.L. Hughes, Terres

Mice exposed soon after birth to crystalline bovine serum albumin acquire an immune tolerance for this antigen, which lasts for several weeks. This tolerance is demonstrated by the lack of anaphylactic response to a challenge following suitable sensitizing injections. The sensitizing procedure was one that produced a high incidence of anaphylaxis in normal (neonatally not exposed) litter mates. Tolerance is also demonstrated by an almost complete lack of circulating antibodies as measured by the Farr technique (ammonium sulfate precipitation of labeled antigen in immune serum). The acquired tolerance diminishes with time and is succeeded by a state of hypersensitivity. The mechanism for the establishment of tolerance and immunity in mice may therefore coexist during the first two weeks of life. The degree and duration of the tolerant state is related to the amount of antigen given during the early postnatal period. An interpretation of these results has been presented based on the assumption that antigen is retained at intracellular sites.

$\mathrm{n}$. Enhanced sensitization in mice by simultaneous injection of antigen and specific rabbit antiserum. 0605. Drs. Terres, Wolins

Mice were injected intravenously with a solution of serum albumin (human and bovine) plus specific rabbit antiserum in antigen excess. The antibody response to serum albumin was tested and compared to that obtained in mice injected intravenously with serum albumin alone or with albumin and normal rabbit serum. The results show that the antibody response elicited with serum albumin plus specific rabbit antiserum is significantly greater than that elicited by using serum albumin alone or with normal rabbit serum.

o. Whole-body measurement in vivo of radioactivity as a means for following the degradation of $1^{13}$-labeled proteins in mice. 060601. Drs. W.L. Hughes, Terres, Wolins

Whole-body radioactivity has been measured at intervals following the intravenous administration of $I^{131}$-labeled human serum albumin and bovine serum albumin. The loss in trichloroacetic acid-precipitable activity with time parallels the rate of loss of radioactivity as determined by whole-body counting; the latter parallels the loss of radioactivity in the serum. Less than $1 \%$ of radioactivity in the urine is trichloroacetic acid precipitable. The influence of thyroidal uptake of radioactive iodide on whole-body count has been investigated and the effect of $\mathrm{NaI}$ on this determined. It is concluded that with prior or concomitant administration of iodide (0.01 to $1.0 \%)$ in the drinking water, whole-body counting is an accurate method for following the degradation of radioiodine-labeled proteins.

p. Immune degradation in passively sensitized mice. 0605. Drs. Terres, Wolins

Whole-body counting was used to study the degradation of $\mathrm{I}^{131}$-labeled antigen in passively sensitized mice. In such mice, antigen is degraded at an accelerated rate. ADAR (antigen degraded at the accelerated rate) is the difference at any time between the residual antigen in the passively sensitized mice and that in normal mice, expressed as a percent of residual antigen in the latter. Ninety-seven to $99 \%$ of the antigen was degraded at an accelerated rate in mice injected with antigen-antibody ratios that correspond to equivalence or antibody excess in vitro. Antigen is degraded at an accelerated rate in mice injected with ratios of antigen to antibody that are in antigen excess in vitro, and are associated with little or no precipitation. The ADAR is inversely related to the amount of antigen used if the amount of antibody is held constant and if the antigen-antibody ratios are in antigen excess in vitro. In mice injected with antigen-antibody ratios which are in antigen excess in vitro, the amount of antigen degraded at 
the accelerated rate is estimated to be greater than the amount precipitated at equivalence. The accelerated degradation of the antigen in passively sensitized mice is completed 6 to $10 \mathrm{hr}$ after the antigen is injected, and the half-time of the accelerated degradation is independent of the antigen-antibody ratios used. The ADAR (determined at $24 \mathrm{hr}$ ) is a function of the amount of antibody used when the amount of antigen injected is held constant.

3. The use of $\mathrm{C}^{14}$-labeled compounds in studies on fat metabolism. 060102. Drs. Schwartz, Debons, Silver, Dahl, Shreeve, De Meutter; Res. Col. Gidez, Dreiling

a. Hormonal regulation of lipid and cholesterol absorption, transport in blood, and mobilization from tissues

The mechanism by which thyroid hormone elevates the concentration of nonesterified fatty acids (NEFA) in plasma was studied in dogs by comparing the clearance of $\mathrm{C}^{14}$-labeled palmitic acid before and after the administration of $l$-triiodothyronine. Within $5 \mathrm{hr}$ after an intravenous injection of $l$-triiodothyronine $(1 \mathrm{mg})$, the rate of disappearance from the plasma of palmitic acid-1$\mathrm{C}^{14}$ was increased although the total concentration of NEFA in the plasma had doubled, which confirmed and extended our previous observation in man. When a steady concentration of labeled NEFA was maintained by a constant infusion, the administration of $l$-triiodothyronine was followed in $5 \mathrm{hr}$ by a significant decrease in specific activity. It is therefore concluded that, although the thyroid hormone increases the rate of removal of NEFA from the blood, its predominant effect is to enhance the release of fatty acids from tissue stores.

b. Thyroid hormone and $\mathrm{C}^{14}$-labeled cholesterol content of rat lymph. 060102

Preliminary experiments were done to investigate the nature of the hypocholesterolemic effect of thyroid hormone, a most obscure aspect of which is the nature of the hormone influence on cholesterol absorption. Rats with lymph fistulas were prepared and given $\approx 50 \mathrm{mg}$ cholesterol-4$\mathrm{C}^{14}$ by stomach tube. The total amount and specific activity of cholesterol absorbed into the lymph over a $24-\mathrm{hr}$ period were determined in normal controls and in two groups of animals, one chronically pretreated with $l$-triiodothyronine, and the other with $d$-triiodothyronine. In the normal animals the peak of absorption was sharp and occurred at $6 \mathrm{hr}$. The specific activity of the lymph cholesterol was strikingly lower than that of the administered cholesterol-4- $\mathrm{C}^{14}$, which showed that there had been an endogenous dilution of the administered labeled cholesterol which can be explained either by the existence of a large endogenous pool of cholesterol in the intestinal wall or by reabsorption of unlabeled endogenous cholesterol that had entered the intestine via the bile.

In contrast, in the thyroid-treated animals, the ratio of the specific activity of the lymph cholesterol to that of the administered cholesterol was very much higher than in the controls, which suggests that the thyroid hormone acts in some manner to reduce the endogenous intestinal mucosal pool of cholesterol and/or to lessen the biliary secretion of cholesterol. The former effect would appear to be more significant in view of the finding that the total amount of cholesterol absorbed is reduced by $50 \%$ or more in the thyroid-treated animals as compared with the controls.

\section{Cellular Reproduction, Migration and Transformation}

(Radioactive Badges Affixed

Within Cell Unit Components

to Clue Behavior of Intact Cell Systems

and Heritable Transmission of Marked Components)

\author{
A. CELL IDENTIFICATION \\ (Selection and Affixation \\ of Radioactive Badges to Cell Components)
}

1. Resolution and image spread in autoradiographs of tritium-labeled cells. 060601. Drs. Robertson, Bond, Cronkite

Calculations of the radiation dose rate about point sources of tritium have been extended to explain the variations in image spread seen in autoradiographs of cells labeled with tritiated thymidine. The resolution attainable with tritium sources in contact with the sensitive emulsion is much sharper $(0.2 \mu \mathrm{C})$ than that attainable with $\mathrm{C}^{14}(2 \mu \mathrm{C})$. With sources at a depth of $1 \mu$ or more, however, the effect of the very low energy tritium $\beta^{-}$ particles on improving the resolution is lost, and the resolution deteriorates. As the depth of a tritium-labeled cell nucleus in the tissue section increases, the grain density decreases, the resolution becomes poorer, and the image spread increases. 
2. The use of gamma-emitting badge in DNA for cell identification. 0603. Drs. W.L. Hughes, Commerford, Krueger; Res. Col. Gitlin

The purpose of this study is to develop a diagnostic procedure using $\mathbb{I}^{131}$-deoxyuridine (I*DU) for the estimation of cell proliferation in the human by external measurement of radioactivity. Such a procedure should be a useful tool for gauging the effects of $x$-rays either at a diagnostic or at a therapeutic level or, in fact, for quantitating any treatment based on inhibiting new cell formation. If sufficient resolution in whole-body scanning can be achieved, differential estimation in several proliferating tissues, including neoplasms, may be possible.

The results thus far obtained with mice appear to demonstrate the practicability of the above goal. Mice maintained on $\mathrm{NaI}$ in drinking water were injected with trace amounts of $I^{*} D U$ labeled with $\mathrm{I}^{131}(<0.1 \mathrm{mM}$ per mouse). Within $1 \mathrm{hr}$ following injection essentially all the radioactivity was converted to iodide or incorporated into DNA. As radioiodide is rapidly excreted, the residual radioactivity after $24 \mathrm{hr}$ was all found in DNA. At this time the concentration of radioactivity in several organs varied 50 -fold and decreased in the order thymus, gut, spleen, skin, bones, liver, muscle, in accord with their proliferative activity. The radioactivity of all organs except skin declined during the following days. This decline presumably measures cell turnover, since the skin radioactivity remained constant throughout the period of observation (one week). Double tracer experiments with both $\mathrm{I}^{*} \mathrm{DU}$ and $\mathrm{H}^{3}$ thymidine showed thymidine to be utilized 3 to 4 times as efficiently as I*DU. Both the $I^{131}$ and the $\mathrm{H}^{3}$ radioactivity of the DNA of intestine remained constant for $36 \mathrm{hr}$. Subsequently, both activities declined rapidly, as would be expected in the renewal of intestinal epithelium. Moreover, the $\mathrm{I}^{131}$ activity declined more rapidly than $\mathrm{H}^{3}$ activity (from $\mathrm{H}^{3}$-thymidine), which indicates either that thymidine is measurably reutilized in this process or possibly that some of the $I^{131}$ tag is removed.

$X$-radiation was found to decrease $I * D U$ incorporation if irradiation preceded the injection of I*DU. Marked inhibition appeared within $1 \mathrm{hr}$ after irradiation, while maximum inhibition was reached when I*DU was injected 6 to $12 \mathrm{hr}$ after irradiation. Recovery from this inhibitory effect was observed 24 or more hours after irradiation, the extent of recovery depending upon the size of the $\mathrm{x}$-ray dose and the tissue. Inhibition of $\mathrm{I} * \mathrm{DU}$ incorporation decreased as the x-ray dose decreased, but significant inhibition was observed after x-ray doses as low as $10 \mathrm{r}$. Exposure to x-rays later than $2 \mathrm{hr}$ after I*DU injection failed to inhibit I*DU incorporation or to remove I*DU already incorporated.

Incorporation of $I * D U$ was also markedly depressed by prior administration of cortisone, and the maximum depression, as with $\mathrm{x}$-rays, was obtained when I*DU was given $\approx 6 \mathrm{hr}$ posttreatment. At this time inhibition was noted after an injection of as little as $40 \mu \mathrm{g}$ cortisone acetate. Cortisol also inhibited, but to a lesser degree and with more transient effect.

\section{In vitro studies on tissues obtained at surgery and using tritiated thymidine. 0609. Drs. Bond, Cronkite, Rubini, Fliedner}

Incubation of hematopoietic and other tissues with $\mathrm{H}^{3}$-thymidine in vitro results in incorporation of the labeled material into the nucleus of the cell in the process of DNA synthesis, detectable by means of stripping-film autoradiography. This technique allows estimation of the proliferative potential of individual cell types without the necessity of giving $\mathrm{H}^{3}$-thymidine to the patient or animal.

The striking differences observed in the degree of labeling in different blood dyscrasias has been reported previously. Serial determinations of the number of labeled cells have been carried out on the blood of patients receiving chemotherapy, or $\mathrm{x}$-ray therapy, to the spleen. The decrease in the number of labeled cells has in general paralleled the decrease in total cell count, which indicates that these therapeutic agents do not selectively prevent cells from entering the DNA synthesis phase of the cell cycle, or kill cells in this phase. Previous studies with tritiated thymidine have shown that most neoplastic tissues have slower turnover rates than do many normal tissues. The findings indicate that these therapeutic agents, useful in the temporary control of neoplastic processes, do not effect control of the process either by virtue of a selective effect on the more rapidly dividing cells, or by preventing cells from entering DNA synthesis.

In vitro uptake studies have been performed on various tissues obtained at surgery, and the results are being evaluated. 


\section{B. CELL PROLIFERATION \\ (Radioactive Measurement of Rates and Routes)}

1. Study of interrelationship of RNA and DNA synthesis and metabolism of HeLa cells. 0609. Drs. Bond, Feinendegen

Previously reported studies on nucleic acid metabolism in human tissue culture cells and bone marrow cells were continued. $\mathrm{H}^{3}$-cytidine, $\mathrm{H}^{3}$ uridine and $\mathrm{H}^{3}$-thymidine were used as the labeled precursors. The measurements were obtained through autoradiographic histochemical and biochemical methods.

Macromolecular RNA, as well as DNA in the HeLa cells, retained $\mathrm{H}^{3}$ activity from once-incorporated $\mathrm{H}^{3}$-uridine. Carrier cytidine or uridine in great excess did not significantly liberate the bound $\mathrm{H}^{3}$-nucleoside. The tritium distribution of cytosine and uracil in the macromolecular RNA was relatively stable, observed up to $48 \mathrm{hr}$ after short-term labeling with $\mathrm{H}^{3}$-cytidine. This suggests that an internal RNA turnover and conversion with random utilization of the metabolic products had not occurred. These findings indicate that the previously reported autoradiographically observed sequence of labeling from the nucleus (mainly chromatin portion) to cytoplasm means a true shift of RNA. In whatever form nuclear RNA had contributed to the cytoplasmic RNA, it was not brought into equilibrium with the nucleoside carrier. In addition, independent RNA synthesis in the cytoplasm was not excluded.

By far the majority of the acid-soluble pool tritium turned over rapidly within one generation time. Examination of the distribution of tritium to uracil and cytosine within the acid-soluble pool indicated that cytidine is rapidly de-aminated to uridine. The decline of the total acid-soluble tritium paralleled the appearance of tritium in the culture medium. A small fraction of the acidsoluble tritium continued to contribute to DNA and also to macromolecular RNA, despite the presence of nucleoside carrier. Experiments with $\mathrm{H}^{3}$-thymidine failed as expected to demonstrate continuous "late incorporation" of tritium into DNA after short-term feeding of the cells.

The continuous incorporation of tritiated precursors into DNA decreased with time and was observed even up to $48 \mathrm{hr}$ after short-term labeling of the cells with $\mathrm{H}^{3}$-cytidine. This late incorporation was inhibited only partially by nonradioactive cytidine, and to a still lesser degree by uridine. No significant difference was observed in the competitive effect of thymidine and deoxycytidine as carrier. On the other hand, direct $\mathrm{H}^{3}$ cytidine incorporation into DNA in the presence of thymidine carrier was reduced to $\approx 37 \%$ of that of the control, while deoxycytidine as carrier did not reduce direct incorporation of $\mathrm{H}^{3}$-cytidine into DNA. It enhanced it, rather, by a factor of 0.29 , which indicates different mechanisms of cytidine and deoxycytidine utilization for DNA synthesis in the HeLa cell.

A study of the distribution of the tritium to cytosine and thymidine of the DNA revealed that the continued rise of the tritium content of the DNA after short-term incubation with $\mathrm{H}^{3}$-cytidine and the maintained growth of the cultures in the presence of excess carrier cytidine, involves an increase of thymine-tritium as well as cytosinetritium at an approximately equal rate. Addition of carrier thymidine to carrier cytidine reduced the rise of the total DNA tritium by the amount expected when the thymine-tritium rise was selectively blocked.

The "availability time" of the "late DNA precursor" was calculated from autoradiographic results of percent difference of DNA-labeled cells after varying short-term feeding times and after one generation time, when the cell population was assumed to have doubled, on the basis that $42 \%$ of the cells of the population enter DNA synthesis per hour. These experiments indicated a constant turnover time of the "late precursor" pool.

In all, the results suggest that between simple nucleotides and DNA a closed system of precursors exists which might be present in a more intricate structure than a mononucleotide or might be temporarily bound to a structure where they cannot readily equilibrate with the carrier. This closed system can be viewed also as a compartment with constant turnover time and a flow principally in one direction toward DNA.

The tritium released by the growing cells-into the culture medium was seen to be derived mainly from the acid-soluble pool, with increasing amounts appearing as tritiated water $(\approx 70 \%$ at $24 \mathrm{hr}$ after short-term feeding of the cells with $\mathrm{H}^{3}$ cytidine). The nonvolatile tritium fraction consisted of uridine, uridylic acid, cytidine, and cytidylic acid, in decreasing quantity. Experiments are under way to determine whether phosphorylation of the pyrimidine nucleosides had occurred outside or within the cell. 
RNA stability and late incorporation of precursors into DNA have also been verified for rabbit kidney cells in culture. Similar results were also obtained with ribose-1- $\mathrm{C}^{14}$ as the labeled precursor in HeLa cells.

2. RNA and DNA metabolism of hematopoietic tissue studied with tritiated cytidine, tritiated uridine, and tritiated thymidine. 0603. Drs. Bond, Feinendegen

In continuation of the experiments in tissue culture cells, aspects of nucleic acid metabolism were examined in bone marrow cells from the dog and the rat and from human beings. Suspensions of bone marrow cells were incubated in vitro with the $\mathrm{H}^{3}$-cytidine for different lengths of time, or the labeled precursor was administered intravenously in the rat, and bone marrow samples were obtained at different time intervals after the injection. The pattern of uptake and the label distribution was evaluated by the autoradiographic technique. By differential histochemical extraction of the nucleic acids, RNA labeling was distinguished from DNA labeling. $\mathrm{H}^{3}$-cytidine injected intravenously into the rat was cleared from the blood within the first $4 \mathrm{hr}$, when the circulating tritium activity reached a minimum. After this rapid fall, the circulating activity rose, reached a maximum at the third and fourth day, and then fell off slowly over a period of $>4 \mathrm{wk}$. Nearly all the serum tritium activity after the initial fall appeared as tritiated water; however, a small fraction of nonvolatile activity remained, which was rapidly cleared by the kidney. The appearance of this nonvolatile activity in the urine indicated a rather continuous supply of nucleic acid catabolites for $>2 \mathrm{wk}$ after the injection.

Bone marrow preparations from the rat were made at the fourth hour and the fourth day after a single injection of $\mathrm{H}^{3}$-cytidine, and the RNA was extracted to demonstrate DNA labeling. After RNA extraction $38 \%$ of the nucleated cells were labeled at the $4-\mathrm{hr}$ point, and $79 \%$ at the fourth day, while the nonextracted cells showed a total loss and redistribution of the incorporated tritium. These experiments suggest the reutilization or continued availability of $\mathrm{H}^{3}$-cytidine or its derivatives for DNA synthesis in the intact mammal after a single injection of the labeled precursor. These DNA precursors may be derived from the DNA-synthesizing cell itself, but the results are also consistent with an intercellular exchange of precursors as from a common pool. Further experiments are under way.
The in vitro incubation of hematopoietic tissue with $\mathrm{H}^{3}$-cytidine indicated that in general all nucleated cell types, regardless of their capacity to divide, can incorporate $\mathrm{H}^{3}$-cytidine, whereas no incorporation was observed in erythrocytes or platelets. Similar results were obtained with $\mathrm{H}^{3}$ uridine. The label first appeared scattered over the entire nucleus of the cell, and within $1 \mathrm{hr}$ over the cytoplasm also. In addition, nucleolar label was occasionally seen in the blast forms of the marrow. The mean grain count per cell type was found to be decreased by a factor of $\approx 0.5$ with each step of differentiation of the cell, except for promyelocytes, which had slightly more intense labeling than the preceding myeloblasts. These observations also support the hypothesis that the nucleus is necessary for RNA synthesis. The decrease of incorporation with differentiation of the cell might be due to a decrease of the metabolic activity or a decrease of the number of active sites for synthesis within the nucleus.

Quantitative RNA turnover studies were carried out on lymphosarcoma cells obtained by biopsy from patients. Again, a nearly exclusive nuclear labeling was first observed after 30-min exposure of the cells to $\mathrm{H}^{3}$-cytidine. After changing the incubation medium with addition of an abundance of carrier cytidine, an entire loss of nuclear label was demonstrated over a period of $24 \mathrm{hr}$, while lymphoblasts with relatively abundant cytoplasm exhibited strong cytoplasmic labeling with loss of nuclear labeling. Under these experimental conditions, therefore, nuclear RNA became lost from the lymphosarcoma cell and did not contribute to cytoplasmic RNA except for the lymphoblast. In the literature, loss of nuclear RNA is reported for nondividing cells, while rapidly proliferating cells exhibited a conservation of oncesynthesized RNA. It seems therefore that lymphosarcoma is not a rapidly proliferating tumor. Further experiments are projected to extend these findings.

In leukemia, the labeling of DNA with $\mathrm{H}^{3}$ cytidine was compared to that with $\mathrm{H}^{3}$-thymidine. The percent of labeled DNA cells was found to be equal with both precursors. This result supports the assumption that $\mathrm{H}^{3}$-thymidine is indeed incorporated into all cells that synthesize DNA.

3. Studies on incorporation of tritiated pyrimidines into mammalian cells in culture. 0603 . Drs. Drew, Painter

Experimental studies concerned with mammalian cell death and metabolism following incorporation 
of tritiated pyrimidines have been continued. The conditions for the use of $\mathrm{H}^{3}$-thymidine and $\mathrm{H}^{3}$ cytidine as biological tracers for the study of ribonucleic acid (RNA) and deoxyribonucleic acid (DNA) metabolism have been defined. Other experiments have been concerned with the toxic effects of carrier pyrimidines for mammalian cells in culture, since in many experiments it was necessary to use carrier in the culture medium. The importance of establishing an effective but nontoxic level of carrier was clearly brought out in these experiments. For example, high concentrations of cytidine carrier in the medium completely blocked cell metabolism and division.

A comparative study was made of the lethal action of $\mathrm{H}^{3}$-thymidine and $\mathrm{H}^{3}$-cytidine for HeLa S3 cells in culture. A discrepancy between the lethal action of the two radioactive pyrimidines was found. Growth inhibition and cell death by $\mathrm{H}^{3}$ cytidine was accomplished only by concentrations in the culture medium of the order of five times that of $\mathrm{H}^{3}$-thymidine at the same specific activity. The observed difference in lethal effect is believed to be an expression of the distribution of the radioactivity within the cell. In the case of $\mathrm{H}^{3}$-thymidine the radioactivity is concentrated within the nuclear DNA. $\mathrm{H}^{3}$-cytidine, on the other hand, goes into both DNA and RNA and, although there is early nuclear labeling, the radioactivity soon concentrates in the cell cytoplasm. Other factors which may be involved in this phenomenon are under consideration.

Further studies on DNA metabolism in HeLa $\mathrm{S} 3$ cells have been carried out with $\mathrm{H}^{3}$-thymidine as the tracer material. The experimental results have helped to clarify certain obscure points relative to the rate of DNA synthesis within the chromosomal complement. Cultured mammalian cells which are in active DNA synthesis incorporate $\mathrm{H}^{3}$-thymidine into their chromosomal complement in $<1 / 2$ min after the addition of the tracer to the medium. However, the onset and termination of synthesis was observed to vary among the individual chromosomes.

4. Studies of cell proliferation in human malignant disease using tritiated thymidine. 0609. Drs. Cronkite, Bond, Killmann, Fliedner, Rubini, Johnson

In 1958 the use of tritiated thymidine in the study of DNA synthesis and proliferation of cell populations was commenced in normal human beings and in patients with malignant disease. In the initial studies it was deduced that the genera- tion time of cells of both solid and diffuse tumors was longer than expected. There was no difficulty in labeling a glioblastoma multiforme, carcinoma of the breast, ovarian serous cystadenoma, and a spermatic cord leiomyoma. A small fraction of the tumor cells readily incorporated the tritiated thymidine, and either at biopsy, surgical removal, or autopsy it was possible to determine the ratio of labeled to unlabeled cells of a similar cytologic type. By determination of the fraction of tumor cells labeled, the generation or cell doubling times for the various populations were estimated. The doubling times in benign and malignant neoplasms were relatively similar and apparently of the order of months. This was in striking contrast to other studies carried out on hemopoietic tissues, which had generation times of 20 to $30 \mathrm{hr}$. A serious shortcoming of this study is the absence of serial biopsies or aspirations to determine the true generation time based on diminution in the intensity of label in the labeled tumor cells. In a case of multiple myeloma this has been shown to be $\approx 4$ days. The discrepancy in generation time determined by fraction of the population labeled and by diminution in grain count is significant. The implication is, at least in the case of the multiple myeloma, that only a small fraction of the population is proliferating. Hence all myeloma cells do not retain the capacity to multiply, and the tumorous tissue is maintained by a small proliferating compartment. Thus the growth is not truly wholly exponential; a certain fraction of the cells must be maturing and will remain as abnormal parasites with an exceptionally long life span. If this were true the generative fraction might be considered to consist of cells undergoing arithmetical multiplication with a long life span of the adult tumor progeny which act as parasites with abnormal metabolism and thus are deleterious to the host both by progressive encroachment upon marrow space and the production of abnormal proteins. Alternatively, the biological clock of the progeny may be seriously impaired, with a vast range in doubling times of the individual progeny varying from a few days to many months. These observations in myeloma are being extended to the leukemias and will be extended to appropriate solid tumors in the coming year.

5. Oral absorption of tritiated thymidine. 060102. Dr. Cronkite, Res. Col. Rubini

Although it is known that intravenous injection of tritiated thymidine labels proliferating tissue, 
the fate of oral thymidine, which bears upon the potential somatic and genetic hazard of the material, was conjectural. Preliminary studies in rats and guinea pigs given tritiated thymidine by gastric tube showed labeling of the intestinal mucosa, spleen, and bone marrow. Some of the tritiated thymidine had been catabolized to tritiated water, and small amounts were excreted as urinary nonvolatile tritium activity.

6. Local factors in the development of atheroscleroticlike lesions. 060102. Drs. Bond, Dahl, Spraragen

Autoradiograms from studies using tritiated thymidine to determine the role of hyperplasia in the development of atherosclerotic lesions in the aorta of the rabbit are being reviewed. At this point it may be stated that hyperplasia, indicated by the labeling of individual cells within the atherosclerotic lesion, does play a role in the pathogenesis of atherosclerosis in rabbits, but comment as to whether the hyperplasia is a secondary phenomenon as previously thought or whether hyperplasia plays a primary role will have to await completion of the microscopic study.

When study of the aorta is completed, autoradiograms will be prepared from rabbit heart tissue (obtained at the same time the aorta tissue was taken) to establish the role of hyperplasia in the atherosclerotic lesions found in the coronary vessels. This will also serve as a comparison of DNA synthesis patterns between the aorta and coronary vessels.

Previous attempts to label normal rabbit aorta tissue with $\mathrm{H}^{3} \mathrm{Th}$ in vitro failed. This experiment was repeated with finer strips of tissue, and minimal labeling similar to that found in vivo was obtained. Also, in vitro labeling of normal rabbit aorta tissue was obtained by using $\mathrm{H}^{3}$-cytidine as the tag. This labeling was found to be slightly more extensive than that obtained with thymidine.

To learn more about the possible role of hypervitaminosis $\mathrm{D}$ in the pathogenesis of atherosclerotic-like lesions in the aorta and coronary vessels, atherosclerotic rats were given $\mathrm{Ca}^{45}$ in the hope of demonstrating enhanced calcium deposition in the lesions by autoradiographic means. The tissues are currently being processed.

\section{Cellular aspects of antibody formation. 0605.} Drs. Cronkite, Stoner, Killmann

It is well established that some antibodies are formed in the lymphoid tissues, although opinions differ as to what type of cell (lymphocytes, plasma cells, transitional cells, etc.) actually is the site of antibody formation. There seems to be no disagreement, however, that antibody formation is associated with cell proliferation in the lymphoid tissues. Although this may be so, it certainly does not appear to be proved; the observed morphological changes might reflect only a changed functional state of undividing cells. This problem might be successfully approached wtih autoradiographic studies following injection of $\mathrm{H}^{3}$-TDR, which is known to be a specific label of DNA, combined with study of mitosis using the colchicine technique. The experimental phase was completed in fiscal 1960; study of the material collected is still in progress and is expected to be completed in fiscal 1961.

8. Mitotic index of erythroid and granulocytic series of human bone marrow. 0603. Drs. Cronkite, Killmann; Res. Col. Fliedner

In preliminary gross studies, the mitotic index of human bone marrow in normal subjects was determined to be $(9 \pm 1) / 1000$ mitoses. Increased mitosis has been found in various diseases. During fiscal 1960, in extensive studies made primarily by Dr. S.A. Killmann, the specific mitotic index has been determined for the erythroid and granulocytic series at each stage in which proliferation is taking place.

9. The mitotic index of human bone marrow in healthy individuals and irradiated human beings. 0605 . Drs. Cronkite, Bond, Fliedner; Res. Col. Rubini

The mitotic index of the bone marrow of seven healthy individuals was determined in Feulgenstained squash preparations to be $0.9 \%$ during the period 10 A.M. to 1 P.M. The method did not allow the distinction of mitoses of different cell lineages. On the basis of this mitotic index, the average turnover time of the red cell series is estimated to be of the order of 11 to $33 \mathrm{hr}$, and that of the white cell series, of the order of 25 to $75 \mathrm{hr}$. In serial studies the mitotic index of eight patients accidentally exposed to various doses of ionizing radiation was followed over a period of $4.5 \mathrm{mo}$. A dose dependence of the mitotic index was noticed on the fourth postirradiation day. After $4 \mathrm{wk}$, the number of mitotic figures was within normal limits. After $4.5 \mathrm{mo}$, the values were significantly higher than normal.

10. A radioautographic study of a human brain and glioblastoma multiforme after the in vivo uptake of 
tritiated thymidine. 0609. Drs. Cronkite, Bond, W.L. Hughes, Johnson, Rubini, Fliedner; Res. Col. Haymaker

The radioautographic findings in a human brain and glioblastoma multiforme after in vivo labeling with tritiated thymidine demonstrated a labeled nucleoside in neoplastic cells. From the percentage labeling, it is possible to compute a generation time of $1 \frac{1}{2}$ to 2 mo. Thus the cancer cells were dividing significantly more slowly than were nonneoplastic cells of bone marrow and ileum, and the time was of the same general order as that calculated from similar observations on various cystadenomata and breast carcinomata, and a leiomyoma of the spermatic cord.

11. Deoxyribonucleic acid synthesis in the developing mouse embryo studied with tritiated thymidine. 060102 . Drs. Bond, Cronkite; Res. Col. Atlas

Tritiated thymidine was injected into pregnant mice on days $6,7,8,9,10,11,14$, and 17 . The incorporation of the thymidine into the tissues of the embryo, uterus, and placenta was studied by the method of stripping-film autoradiography. Thymidine is incorporated into uterine cells at all stages. The greatest amount of uptake is effected by endothelial cells. Decidual cells show good uptake at the beginning, less later. Embryonic tissues do not show any noticeable uptake until the ninth day, and then only in the outer membrane tissues of the trophoblast cells, giant cells, and yolk sac cells. On the tenth day incorporation occurs mainly in the blood and mesenchyme cells. On succeeding days more incorporation is found in other embryonic tissue. The nervous system does not incorporate the thymidine noticeably until the fourteenth day.

12. Autoradiographic localization of tritiated thymidine in whole mount preparations of lens epithelium. 0605. Drs. W.L. Hughes, Bond; Res. Col. Harding A procedure was developed for the preparation of whole mounts of lens epithelium which allows the autoradiographic localization of tritium. In vitro incorporation of tritium-labeled thymidine into the nuclei of epithelial cells was demonstrated in the isolated lenses of rat, rabbit, and frog. Quantitative determinations indicate that the highest percent of radioactive nuclei appears in the germinative zone.

It is suggested that thymidine incorporation is related to cell division, and the percent of cells with radioactive nuclei is an indication of cellular proliferation. The technique may also be of use in following the migration of cells, since the labeled cells retain their radioactivity for considerable periods of time. It is planned to use this technique in the study of cellular proliferation and migration during the induction of cataracts, and following mechanical injury to the lens.

\section{CELL MIGRATION \\ (Radioactive Record of Various Cell Positions Within the Body)}

1. The origin of osteoclasts studied with tritiated thymidine. 0603. Drs. Cronkite, Tonna

The origin of osteoclasts has been an open question for about 100 years. Osteoclasts are skeletal cells important in resorption of bone, and hence in maintaining the balance between bone deposition and removal. Prior to the present experiments, osteoclasts were studied at the metaphyses. Because of the presence of several types of cells which could account for the origin of osteoclasts at the metaphyses, the results were inconclusive. In our experiments osteoclasts were studied in the perichondrial region of the distal femur. In this region, the only possible sources are two existing cell types, osteogenic cells or osteoblasts. Mice were labeled with tritiated thymidine, and autoradiographs were then prepared from the skeletal tissues. Initially no labeled osteoclasts were seen, whereas osteogenic cells and some osteoblasts were labeled. Numerous labeled osteoblasts were encountered $36 \mathrm{hr}$ after isotope administration, when the population of labeled osteoblasts which are derived from osteogenic cells increased. Since osteoclasts were never seen undergoing mitosis, the evidence shows that osteoclasts originate from the fusion of osteoblasts.

2. Tritiated thymidine study of the cellular contribution to fracture repair. 0603. Drs. Cronkite, Tonna

This study was undertaken to ascertain the contribution of various skeletal tissues to fracture repair and the way in which the process is altered as the animal ages. Mice in age groups from birth to old age had the right femur fractured. The animals were sacrificed $24 \mathrm{hr}, 1 \mathrm{wk}$, and $2 \mathrm{wk}$ after fracture. These mice received $0.5 \mu \mathrm{C}$ tritiated thymidine $1 \mathrm{hr}$ prior to sacrifice. This experiment is still in progress.

Another group of 6-wk-old mice were given tritiated thymidine immediately after fracture of the 
femur. These animals were serially sacrificed $1 \mathrm{hr}$ to 14 days after fracture. Autoradiographs and histological sections were prepared. Results show that no increase in isotope uptake takes place until $10 \mathrm{hr}$ after fracture. The labeled periosteal population was increased to $25 \%$ at $32 \mathrm{hr}$. It was interesting to note that the stimulation to the periosteum was not limited to the fracture site, as previously thought, but extended throughout the entire fractured femur. Also, contrary to previous belief, the endosteum was nonresponsive to trauma. The internal fracture callus was formed from newly differentiated osteoblasts found at the fracture site. Starting $32 \mathrm{hr}$ after fracture, there was a gradual decrease in the periosteal labeling index. This index decreased also about the fracture callus, but less rapidly. At 14 days postfracture, the labeling index of the fractured femur was still higher than that of the nonfractured control. The experiments are still in progress. A group of old animals are being studied for age comparison.

\section{Periosteal osteoclasts, skeletal development, and aging. 0603. Drs. Cronkite, Tonna}

Population studies were made from the left femora of 45 female mice of the Brookhaven National Laboratory strain of Swiss Albino. The right femur of each mouse was fractured by digital pressure applied to the midshaft under ether anaesthesia. The femora were fractured at 1, 5, 8, 26, and $52 \mathrm{wk}$ of age, and the mice were sacrificed 24 $\mathrm{hr}, 1 \mathrm{wk}$, and 2 wk postfracture. One hour before they were sacrificed, they received a subcutaneous injection of tritium-labeled thymidine in sterile aqueous solution $(0.5 \mu \mathrm{C} / \mathrm{g}$ body weight). Stripping-film autoradiographs were prepared from paraffin sections of whole decalcified femora. Additional sections were stained routinely with hematoxylin and eosin. Mononucleated cells, which in many instances resided in well-formed Howship's lacunae, exhibited an eosinophilic, foamy cytoplasm. The juxtanuclear vacuole seen in active osteoblasts was not observed in these cells.

The results showed that during the remodeling of the ends of the femur, the population of osteoclasts present in the periosteum fluctuated radically within short periods of time. Since active formation of periosteal osteoclasts was observed from the fusion of osteoblasts, and degenerating osteoclasts were not readily found, a reduction in population within $1 \mathrm{wk}$ is believed to have occurred as a result of the dissociation of osteoclasts into pre- cursor cells. It is possible that the population of osteoclasts migrated from one position to another. Autoradiographic results indicated that there was no uptake of tritium-labeled thymidine by periosteal osteoclasts, and hence there occurred neither deoxyribonucleic acid synthesis nor reproduction by mitotic division.

The observations indicate that periosteal osteoclasts originate in osteoblasts, and that their fate is to dissociate into precursor cells. It appears that with increasing age beyond the period of active bone remodeling, there is a decrease in the population of osteoclasts; however, changes in age in individual osteoclasts were not seen.

4. Autoradiographic studies on DNA-synthesizing cells in the peripheral blood. 0603. Drs. Bond, Cronkite, Fliedner, Rubini; Res. Col. Brecher

Tritiated thymidine, which is incorporated solely into DNA, was used in conjunction with stripping-film autoradiography to demonstrate that cells in the peripheral blood of normal human beings are capable of synthesizing DNA. Thus, these cells are presumably capable of division. Only large mononuclear cells were found to be labeled, and these could be divided into at least five categories on morphological grounds. The number of these cells, normally very small, was increased in the nonneoplastic diseases studied. Studies with parabiotic rats demonstrated that labeled cells circulate to the parabiont not given labeled thymidine. It is suggested that some of these cells may be part of a mobile pool of pluripotential cells that can respond on demand to undergo proliferation and maturation in areas of need, and that some act as macrophages.

\section{DIFFERENTIATION, TRANSFORMATION, AND MATURATION (Radioactive Proof of Identity of Differentiated, Transformed, or Matured Cells)}

1. Histochemical and autoradiographic studies on the effects of aging on the mucopolysaccharides of the periosteum. 0603. Drs. Cronkite, Tonna

An autoradiographic study was made using $\mathrm{S}^{35}$ sulfate for the localization, distribution, and variation in the mucopolysaccharide content of the femoral periosteum of rats from birth to old age. The mucopolysaccharides were also studied histochemically, by using toluidine blue $\mathrm{O}$, Rinehart and Abu'l-Haj's colloidal iron method, and the peri- 
odic acid-Schiff reaction, and after hyaluronidase treatment.

Autoradiograms revealed the uptake of $\mathrm{S}^{35}$ particularly in the vicinity of the preosseous zone and adjacent osteoblasts. This labeling was highest at the period of rapid bone growth. With increasing age, the $S^{35}$ uptake became progressively less. The preosseous zone showed gamma-metachromatic staining at all ages after treatment with toluidine blue. Active osteoblasts were mostly orthochromatic; however, beta-metachromasia was exhibited at a later date. Abundant amounts of intraand extracellular mucopolysaccharides of both the acid and neutral type were demonstrated in the periosteum.

$\mathrm{S}^{35}$ uptake and gamma-metachromasia show the presence of sulfated mucopolysaccharides, of which chondroitin sulfate predominates in the preosseous zone. Since $\mathrm{S}^{35}$ uptake is high in active osteoblasts, the failure to demonstrate metachromasia in osteoblasts may indicate either that chondroitin sulfate is liberated as fast as it is produced or that it is present within the cells in a precursor form not detectable by histochemical methods.

2. The aging cellular phase of the skeletal system studied with tritiated thymidine. 0603 . Drs. Cronkite, Tonna

The present investigation has been undertaken to obtain information concerning the kinetics of the cellular population responsible for bone formation, and to assess the contribution of kinetic changes to gross skeletal aging. Mice from 1 to 52 wk of age were given $0.5 \mu \mathrm{C}$ tritiated thymidine per gram body weight. The animals were sacrificed from $5 \mathrm{~min}$ to 25 days following isotope administration. The labeled population of epiphyseal and periosteal cells was observed and evaluated from autoradiographic preparaticns. Results have shown that the proliferative potential of the periosteum diminished rapidly from birth to $\approx 8 \mathrm{wk}$ of age, while that of the epiphysis maintained an initial high level of proliferation up to $5 \mathrm{wk}$ of age. The epiphysis then followed a course similar to that of the periosteum. These experiments have shown that the osteogenic layer of the periosteum is responsible for the supply of cells to the epiphyseal disk and epiphyseal head. Therefore, the periosteum is responsible for longitudinal growth of a long bone as well as for circumferential growth. The supply of periosteal cells for the epiphyseal disk appeared to be inadequate, since the prolif- erative potential of this tissue fell rapidly at an early age. However, epiphyseal cells apparently make up this deficiency by being able to undergo mitosis, and thus maintain the level of available active cells. A scheme accounting for skeletal aging based upon changes in the proliferative potential of skeletal tissues was developed. Work of this type is continuing in an attempt to obtain additional information concerning the origin, fate, and behavior of various cells responsible for bone growth, development, and aging of the skeletal system.

3. Studies on the fate and function of blood cells that can be labeled in vitro with tritiated thymidine. 0603. Drs. Bond, Cronkite, Usenik, Feinendegen

Several approaches have been pursued to determine the fate and function of cells in the blood capable of being labeled with $\mathrm{H}^{3}$-thymidine, and thus capable of DNA synthesis. Parabiotic rats were used, and while labeled cells apparently different from those found to be labeled in the peripheral blood were observed in the marrow of the recipient animals, these could not be identified as myeloid or erythropoid in nature. Temporary occlusion of the blood supply to a portion of the body, with administration of $\mathrm{H}^{3} \mathrm{Th}$ and later search for labeled cells in the occluded regions has been carried out, as have been direct transfusions of blood and of thoracic duct lymph from labeled donor rats. Labeled cells have been found in the bone marrow, spleen, and lymph nodes of recipient animals. The labeled cells found have been lymphocytes, "transitional" cells with some characteristics of both lymphocytes and plasma cells, and plasma cells. The plasma cells found have been confined to the bone marrow: none has been found in the spleen or in lymphoid tissue. Since plasma cell precursors apparently are present in the thoracic duct lymph, it cannot be stated that the finding of labeled plasma cells following lymph or blood transfusion represents cell transformation.

4. Radioactive isotopically labeled cells for predictions of life span, function, and progeny. 0602. Drs. Cronkite, Bond, Killmann, Fliedner, Reizenstein, Feinendegen, Bateman

Since 1958 material has been collected for the study of hematopoietic cell proliferation using tritiated thymidine labeling of DNA of the proliferative compartments in the study of cell turnover in patients without hematopoietic disorders. A large 
mass of material was collected on individuals with normal hematopoiesis. The tentative time parameters have been established for the generation time of the erythroid series of $\approx 20 \mathrm{hr}$, and the neutrophilic series of $\approx 20$ to $54 \mathrm{hr}$, depending upon the stage of granulocytopoiesis. The average stay of neutrophils in the peripheral blood is of the order of two days. The turnover time in a single patient of the megakaryocyte has been shown to be 10 days. Nothing can be said as yet about the distribution of turnover times in a population of normal human beings. The kinetics of normal blood cell production in leukemias and multiple myeloma has been essentially the same as in normal individuals as far as granulocytopoiesis is concerned. Erythropoiesis has not yet been studied. During 1960 two more patients with leukemia and one with multiple myeloma have been studied by performing serial aspirations of the bone marrow following intravenous injection of tritiated thymidine. This extensive amount of material has been prepared for study, and the work will be completed during fiscal 1961. The preliminary conclusions are that in chronic leukemia, multiple myeloma, and at least an occasional case of acute leukemia, the expanding mass of neoplasm is in part due to a longer life span of cells with no useful function. By a combined study of the sequence of the fraction of cells labeled and the grain count, it probably will be possible to determine what fraction of the leukemic population is responsible for the growth of the malignant tissue. Under the postulated conditions, the leukemic cell is apparently spending a smaller fraction of its life span in DNA synthesis or mitosis; hence, unless there is selective uptake in the neoplasm, chemical agents selected for mitosis or DNA synthesis will do more damage to the normal cells in the essential renewal systems than to the neoplasm. If this tentative conclusion is substantiated, additional and more extensive studies on the present rationale of cancer chemotherapy will be indicated.

5. Characterization of erythroid precursors. 0603. Drs. Bond, Feinendegen; Res. Col. Sondhaus

It has been well recognized that morphology does not constitute an adequate criterion for characterization of the various erythroid precursor forms. In this laboratory autoradiographic methods have been developed to indicate the degree of DNA synthesis within a cell. By differential extraction methods, it is possible to determine the degree of RNA synthesis in progress. Methods of quantifying the amount of nucleic acid and of hemoglobin within the single cell have been developed. Attempts to correlate these various quantitative indices wth the morphologic appearance of erythroid precursor cells are under way.

\section{Environmental Medicine and Radiation Effects}

\section{A. RADIOACTIVE OPERATIONAL HAZARDS AND CONTROL}

1. In vivo measurement of radioactive body burden in Brookhaven National Laboratory personnel. 0605. Drs. Love, Cohn

The body burdens of gamma emitters in 130 members of the Brookhaven National Laboratory staff have been measured in the whole-body counter. These persons were selected from among those working with high levels of radioactive isotopes, such as workers in the Reactor and Hot Laboratory Divisions who were reporting for routine annual physical examination. Levels of $\mathrm{K}^{40}, \mathrm{Cs}^{137}$, and in a number of cases $\mathrm{Zn}^{65}$ have been quantitated by comparison with a calibrated plastic phantom. These studies have been correlated with urinary excretion data and also with data from general physical and hematological examinations.

2. Protective effect of barium meals on acute radiation effects. 0605. Dr. Conard

The sensitivity of the gastrointestinal tract to gamma or $\mathrm{x}$-radiation is well recognized and in some cases of therapeutic radiation is the limiting factor in achieving the desired target dose. The possibility exists that barium meals might offer some degree of protection against radiation of the gut in such situations. To investigate this possibility rats are being given several oral intubations of a heavy barium meal several times before gamma irradiation with high lethal doses. Preliminary results indicate that there is some sparing effect on the gastrointestinal tract as evidenced by less diarrhea and longer survival times.

3. Control of radiation-induced hemorrhage with fresh platelets. 0605. Drs. Cronkite, Perman; Res. Col. Hiort

When irradiated dogs developed severe thrombocytopenia and purpura, the thoracic duct was cannulated, and the output of red cells per minute was counted to quantitate bleeding tendency. Fresh canine platelets disintegrated in a sonic os- 
cillator and infused into the dogs increased prothrombin consumption towards the normal range, but had no effect on bleeding tendency. Intact platelets, however, had an immediate and dramatic effect on bleeding tendency. It is concluded that a normal clotting system, including platelet factors, is not enough for normal hemostasis; the mechanical effect of intact platelets is also needed. Consequently, nonintact platelets or platelet substitutes cannot be expected to improve the bleeding tendency in thrombocytopenia.

\section{Analysis of data for estimating human lethal dose of radiation. 060601. Drs. Cronkite, Bond}

In addition to physical estimates, there appear to be many useful biologic indices of exposure to radiation. Of particular importance, because of the rapidity with which it can be done and the rate at which significant differences develop, is the mitotic index of bone marrow. Of the single blood determinations, a white blood cell count is probably the most useful if complete studies cannot be performed.

Data at present are inadequate for a realistic assessment of the $\mathrm{LD}_{50}$ for man. In discussing the $\mathrm{LD}_{50}$, the geometry of the exposure and the manner in which dose is expressed must be considered. The $\mathrm{LD}_{50}$ in terms of air dose may be quite different from an $\mathrm{LD}_{50}$ quoted in terms of tissue or absorbed dose. Obviously the lethal dose values for those who receive medical treatment following exposure and untreated individuals must not be confused. The $\mathrm{LD}_{50}$ for man probably approximates a $350-r$ tissue dose, under conditions of fairly uniform dose distribution throughout the body and at a fairly rapid dose rate. If a population is exposed to $\approx 200 \mathrm{r}$ or more, serious consequences may be expected. Many persons would be incapacitated for varying time intervals after such an exposure, and medical care and treatment would be needed. From the standpoint of practical military and civil defense planning, it appears that the current estimate of 400 to $450 \mathrm{r}$ for the $\mathrm{LD}_{50}$ for man should perhaps be lowered. At any rate the data are not adequate to indicate that it should be significantly increased. With lower dose rates, possibly $<1$ $\mathrm{r} / \mathrm{min}$ and in exponentially decaying fields, the $\mathrm{LD}_{50}$ may increase. However, the precise dose rate-effect relationship for man is not known.

5. Lyophilized platelets in control of thrombocytopenic hemorrhage. 0605. Drs. Cronkite, Bond, Fliedner, Sorensen
Eight dogs were rendered thrombocytopenic by the administration of 500 to $550 \mathrm{r}$ whole-body irradiation. After thrombocytopenia developed, the thoracic duct of each dog was cannulated, and large numbers of red blood cells were observed in the thoracic duct lymph. The hemostatic effectiveness of fresh and lyophilized platelets in reducing the output of red blood cells in the ly $\mathrm{mph}$ was compared.

Lyophilized dog platelets were infused into each dog in amounts calculated to increase the recipient's platelet level by $\approx 200,000 / \mathrm{mm}^{3}$. The circulating platelet levels of the recipients did not increase, and the output of red blood cells in the lymph did not decrease significantly.

Five of the dogs also received infusions of freshly separated, viable platelets. Fresh platelets were administered after the administration of lyophilized platelets in four of the animals, and in one the fresh platelets were administered initially. The circulating platelet levels of the recipients increased following infusions of fresh platelets, and the output of red blood cells in the lymph decreased strikingly.

6. Immune mechanisms in homologous and heterologous disease: Their significance in postradiation treatment. 0605. Drs. Stoner, Bond

Postirradiation transfusion of mouse and rat bone marrow protects recipient mice against lethal doses of whole-body radiation. Mice protected with homologous (same species) or heterologous (different species) marrow demonstrate recovery of the hematopoietic system followed by a secondary loss of weight and wasting, frequently resulting in death during the second month after irradiation. It has been postulated that the wasting disease and delayed deaths result from antibody production by the donor bone marrow against host tissues. We have previously demonstrated the ability of lymphoid tissues (spleen, lymph node, thymus, and Peyer's patch) to produce antibody when isologous (same strain) cell suspensions are transferred to irradiated mice. We have not been able to demonstrate antibody production by cell suspensions of these tissues when the cells are taken from homologous and heterologous donor mice and rats.

\section{B. LOW LEVEL RADIATION STUDIES}

1. In vivo measurement of Thorotrast. 060601. Drs. Cohn, Lippincoth, Fine 
The object of this study is to relate chronic low level radiation from Thorotrast with biological effects in human subjects. In order to define dose calculations, it is necessary to measure the body burden of Thorotrast in the body. As the major part of the thorium decay products remain in the body, the measurement of the body gamma activity and its origin in terms of individual daughter products should give an indication of the thorium burden.

To this end, the whole-body gamma spectrometer is being used for the measurement of gamma radiation from Thorotrast in several patients. The whole-body retention of $\mathrm{Ac}^{228}$ and $\mathrm{ThC}^{\prime \prime}$, two thorium daughters, was measured in the early period after administration of Thorotrast to three patients and in one patient who had received Thorotrast 21 years previously. From the ratio of the thorium daughters, an attempt was made to calculate the absolute levels of Thorotrast by comparison with a calibrated plastic phantom.

2. Distribution of technetium in animals. 060102. Dr. Shellabarger

Through the cooperation of the Hot Laboratory Division, technetium has become available for biological studies. This element is not stable; it occurs only in radioactive form and is produced by fission. There are technetium isotopes that have a half-life of many thousands of years; however, the isotope $\mathrm{Tc}^{99}$ has a half-life of $6 \mathrm{hr}$. Technetium is a member of Group VII of the periodic table. Since it had been reported that another member of this group, rhenium, was concentrated in hen eggs, $\mathrm{Tc}^{99}$ was given to 10 laying hens by the subcutaneous route. $\mathrm{Tc}^{99}$ radioactivity was detected in eggs laid by these hens. It has not yet been determined whether this is a process peculiar to these chemical elements or is part of a general metabolic process resident in egg production.

Iodine is concentrated by the thyroid gland and becomes part of the thyroid hormone. Other members of Group VII of the elements (manganese, rhenium, bromine, astatine) are concentrated by the thyroid gland, but are not utilized in the synthesis of thyroid hormone. $\mathrm{Tc}^{99}$ was studied and in all cases was found to be concentrated by the thyroid gland. In these experiments, $\mathrm{I}^{131}$ was found in the thyroid gland in larger amounts than $\mathrm{Tc}^{99}$, and these results are compatible with the hypothesis that, although it is concentrated by the gland, $\mathrm{Tc}^{99}$ is not utilized in the synthesis of thyroid hormone.

\section{INJURY EFFECTS OF RADIATION EXPOSURE}

1. Immune degradation of $1^{13}$-labeled serum. 0605 . Dr. Terres

The degradation of $I^{131}$-labeled immune rabbit gamma globulin (antibovine serum albumin) was followed in mice by whole-body measurement of retained radioactivity. The percent of labeled gamma globulin (antibody) degraded at an accelerated rate was studied as a function of the amount of antigen concomitantly injected. The percent of labeled gamma globulin specifically precipitated in vitro was also determined by using the same relative amounts of antigen and antibody. It was found that in antibody excess the percent of labeled gamma globulin degraded at an accelerated rate (first $24 \mathrm{hr}$ ) is the same as the percent precipitated. From equivalence into moderate antigen excess the percent degraded at an accelerated rate remains constant, while the percent precipitated decreases. The percent of gamma globulin degraded at an accelerated rate begins to decrease at $\approx 30$ times the amount of antigen necessary for maximum precipitation. At $\approx 1000$ times the amount needed for maximum precipitation, none of the globulin is degraded at an accelerated rate. These results indicate that antigenantibody complexes are formed in extreme antigen excess which are not degraded at an accelerated rate. Thus the complexes consisting of two antigen molecules per antibody molecule $\left(\mathrm{Ag}_{2} \mathrm{Ab}\right)$, the limiting antigen-antibody complex in antigen excess, are not degraded at an accelerated rate.

\section{Effects of radiation on bone growth of rats. 060101 . Dr. Conard}

Possible retardation of growth and development of children exposed to atomic bomb and fallout radiation has been reported. Studies are under way on the direct versus the indirect effects of $x$ radiation on tibial growth in the rat. Groups of rats were given various doses of radiation (1) with one leg shielded, and (2) with only one leg exposed (remainder of body shielded); a control group received no exposure. Tibial growth as measured from radiographs taken at intervals after exposure is compared with growth in the contralateral tibia of the same animal and with other groups of animals to determine the difference between direct and indirect effect, dose response, and recovery. Preliminary results indicate that an indirect effect on bone growth appears earlier and with lower doses (sublethal) than the direct effect and may 
be correlated with weight change. Shielding of the neck region (thyroid-parathyroid) seemed to have a sparing effect on growth retardation but not much sparing effect on body weight loss. Further experiments are in progress to elucidate the findings.

3. Comparative radiosensitivity of the primary and secondary antibody responses to $\mathrm{Co}^{60}$ gamma radiation. 0605. Dr. Stoner, Res. Col. Hale

Most literature indicating the inhibitory effect of ionizing radiation on antibody formation has dealt with the depressant effect of radiation on either the primary antibody response or the secondary antibody response, and it has been generally assumed that the primary and secondary antibody responses are equally sensitive to radiation. A comparison was made of the depressant effect of $\mathrm{Co}^{60}$ gamma-radiation on the primary and secondary tetanus antitoxin responses in mice. Animals were immunized with a single primary injection of either adsorbed tetanus toxoid or fluid toxoid. The secondary response (specific anamnestic response) was elicited with a single injection of fluid toxoid. Whole-body exposure to doses of $50,100,200$, and 300 rad increasingly suppressed the primary antibody response to fluid toxoid given $1 \mathrm{hr}$ after irradiation, whereas doses of 300 , 400 , and $600 \mathrm{rad}$ were needed to produce corresponding degrees of depression of the secondary response. A comparison of doses required to produce $50 \%$ depression indicated that the primary response was $\approx 3$ times more radiosensitive than the secondary response. Similar results were obtained when a primary injection of adsorbed toxoid was given $1 \mathrm{hr}$ after irradiation. An immediate radiosensitivity of the primary response was obtained when fluid toxoid was given 1, 3, and $6 \mathrm{hr}$ after exposure to $200 \mathrm{rad}$. Depression of the secondary response occurred only when the antigen was injected 6,12 , and $24 \mathrm{hr}$ after irradiation. The data suggest that the cells concerned with acceptance of the primary antigenic stimulus may be more radiosensitive than the cells involved in the secondary antibody response.

4. Early hemorrhage in the bone marrow of dogs following total-body exposure to radiation. 060101. Drs. Bond, Usenik; Res. Col. Fliedner

As indicated elsewhere in this report, extensive hemorrhage into the marrow parenchyma is found within hours after exposure of the rat to total-body radiation. It becomes of importance to know whether this phenomenon is limited to the rodent, or whether it is found also in the large animal. A search of previous studies on the pathology of total-body radiation injury has failed to reveal mention of early hemorrhage in small or large animals or in man.

Dogs were exposed to total-body radiation at different dose levels, and biopsies of rib and of larger bones were taken serially following exposure. Examination of the marrow revealed that, as in the rodent, hemorrhage into the marrow parenchyma is apparent within hours, at dose levels in the lethal range and above. By two days following exposure, the hemorrhage is widespread and extensive. These sections are being examined extensively to determine if the pattern of marrow destruction and regeneration is similar to that seen in the rodent.

5. The effect of tritiated thymidine on mouse spermatogonia. 060102. Drs. Cronkite, Johnson

The effect of tritiated thymidine on the development of mouse spermatogonia has been studied quantitatively. In this cellular system the biological effects of doses $<1 \mu \mathrm{C}$ per gram body weight are comparable to $<2 \mathrm{r}$ of gamma irradiation per day.

6. Effect of irradiation and theory of role of mitotic delay on the time course of labeling of HeLa S3 cells with tritiated thymidine. 0609. Drs. Robertson, Painter

The percentage of HeLa S3 cells in DNA synthesis at various times after administration of $500 \mathrm{r}$ of $\mathrm{x}$-irradiation has been determined by means of autoradiography with $\mathrm{H}^{3}$-thymidine. The percentage rises during the period of mitotic delay so that at 4 to $8 \mathrm{hr}$ after irradiation almost twice the proportion of cells are synthesizing DNA as are doing so in controls. In an attempt to explain these results on the basis of the build-up of cells in DNA synthesis occurring as a result of mitotic delay, the kinetics of the effects of irradiation on the numbers of cells in the various stages of the mitotic cycle have been determined. These kinetics are discussed with respect to their importance in the interpretation of data on the effects of irradiation on DNA synthesis, but they fail to account completely for the results reported here. Alternatively, the interpretation is that many cells in DNA synthesis at time of $\mathrm{x}$-irradiation remain in this stage for an abnormally long time, and there is no effect on the rate at which cells come into DNA synthesis. 
7. The effects of radiation on the structure of rodent bone marrow studied by histologic and autoradiographic methods. 0603. Drs. Bond, Cronkite, Fliedner

These studies were undertaken to investigate the interrelationships of structural, cytological, and biochemical changes in the bone marrow following total-body irradiation. Rats were exposed at three dose levels, 550,1000, and $1500 \mathrm{r}$, and serial sacrifices were carried out over the first few hours and on subsequent days. Each animal was injected with tritiated thymidine $1 / 2 \mathrm{hr}$ prior to sacrifice. Smears and bone marrow sections were prepared.

Cellularity decreased rapidly and markedly, with increasing severity at higher dose levels. At all dose levels, hemorrhage into the marrow parenchyma was apparent within $6 \mathrm{hr}$; definite hemorrhage within $1 \mathrm{hr}$ was noted in the $1500-\mathrm{r}$ group. In all groups, hemorrhage was widespread by two days following exposure. Cytologic changes could be divided into two categories, those associated with direct damage to cells, and those associated with abnormal mitosis.

Direct damage consisting of karyorrhexis, karyolysis, and pyknosis was observed within hours, and was essentially absent by 2 to 3 days. These changes were most evident in the erythroid precursors, to a less degree in the myeloid series. Mitotically connected abnormalities appeared in any number only after $24 \mathrm{hr}$ and continued to appear first in the bone marrow and then in the peripheral blood during the next several days. These changes consisted in obviously abnormal mitotic figures, bizarre-shaped nuclei, giant cells, binucleated cells, cells with small or "satellite" nuclei, and cells with multifragmented nuclei. The nuclear fragments were metabolically active as indicated by the fact that many incorporated tritiated thymidine. The number of labeled cells in the bone marrow decreased rapidly, with the greater effect at the higher dose levels. At these levels, the marrow was apparently completely depleted of myeloid and erythroid elements. In the 1000-r group, regeneration was evident along the endostium and along blood vessels, even though all animals at this dose level do not survive. The regeneration in the marrow was preceded by the appearance of large, blastlike cells that could not be identified. It appears obvious from these studies that extensive hemorrhage may contribute to the extensive degeneration of the marrow seen, and that it may be responsible in part for a delay in regeneration. Regeneration apparently does not begin until the marrow has been "cleaned up" and vascular channels have been re-established.

\section{CELLULAR RESPONSES TO RADIATION}

1. Tissue and tumor response to Pdi09. 0609. Dr. Robertson; Res. Col. Ariel

The treatment of tumors by direct infiltration with radioisotopes such as $\mathrm{Au}^{197}, \mathrm{P}^{32}$, and $\mathrm{Y}^{90}$ is well established, but the optimal combination of half-life and energy of the radioisotope to be so used is not established. As part of the search for alternative radioisotopes, the use of $\mathrm{Pd}^{109}$ is being explored. The isotope is prepared by activating palladium metal in the Graphite Research Reactor, dissolving the activated metal in aqua regia, and neutralizing the solution with sodium hydroxide. Preliminary to its use in patients, $\mathrm{Pd}^{109}$ has been injected intramuscularly into a series of rabbits in quantities of up to $200 \mathrm{mC}$ each. The results of these trials support the expectation that $\mathrm{Pd}^{109}$ infiltrated into tumors will be of use in producing extensive local radiative tissue reactions without serious systemic effects. After further studies in animals, the technique will be applied in the treatment of selected patients for comparison with other modes of tumor irradiation.

\section{Action of tritiated thymidine on the clonal growth of mammalian cells. 0603. Drs. Drew, Painter}

The effect of intracellular incorporation of tritiated thymidine ( $\left.\mathrm{H}^{3} \mathrm{TDR}\right)$ on mammalian cell cytology and survival has been investigated by the single-cell plating technique. A survival curve of HeLa S3 cells grown in medium containing $\mathrm{H}^{3} \mathrm{TDR}$ has been constructed which demonstrates the lethal action of the radioisotope. At concentrations of $0.1 \mu \mathrm{C} / \mathrm{ml}$ or greater, very few cells survive and continue to divide to form macroscopic colonies in the plate culture. The lethal action of $\mathrm{H}^{3} \mathrm{TDR}$ has been shown to be a function of both the dose and the specific activity. The cytological appearance of the cells is changed as a result of exposure to $\mathrm{H}^{3} \mathrm{TDR}$. Giant cell formation, loosely packed cells, and abortive colonial growth all indicate a radiation effect. No reversal of the killing effect could be demonstrated when $H^{3} T D R$ treated cells were grown over nonmultiplying, $\mathrm{x}$ irradiated "feeder" cells. 
3. Effects of radiation on incorporation of tritiated thymidine in the bone marrow cells. 0603. Drs. Bond, Tsuya, Fliedner

Tritiated thymidine and autoradiographic techniques have been used to study DNA synthesis in the individual bone marrow cells of the irradiated rat and dog. Both total and partialbody irradiation have been used. In the rat, total cellularity of the marrow was estimated by means of the Sandkuhler ocular.

Doses in the lethal range resulted in a rapid decrease in the number of erythropoietic cells, as well as a drop in the grain count. A study of the change in the total number of labeled and unlabeled cells indicated that the number of labeled cells began to fall before the drop in unlabeled cells was detectable. These findings, coupled with the fact that the decrease in grain counts occurred in a time period considerably shorter than the total DNA synthesis time, indicate that there is an early, and perhaps selective, effect on cells in DNA synthesis. Since the mitotic index is decreased to virtually zero, followed by the appearance only of abnormal mitoses, a portion of the apparent effect on labeled cells may result from the failure of cells to complete normal mitosis and again enter the period of DNA synthesis. A study of bone marrow sections indicated that normally the greater proportion of labeled cells is found near the endostium, and near the central sinus of the marrow. This pattern was not changed detectably following irradiation.

\section{Intranuclear irradiation with tritium. 0603. Drs.} Cronkite, Johnson, Killmann

Initial studies of the influence of tritiated thymidine upon spermatogenesis using the Oakberg technique for measuring depletion of spermatocytes have been completed and published. The effect on spermatogonia of an injected dose of 1 $\mu \mathrm{C} / \mathrm{g}$ body weight of tritiated thymidine is comparable to that of $2 \mathrm{r}$ per day. The study of intranuclear irradiation with tritiated thymidine has been extended to lymphocytic tissue by utilizing the Trowell technique of pyknosis of small lymphocytes. The radiosensitivity of lymphocytes has been found to be similar to that of spermatogonia, and the relative effect on this tissue is approximately the same as in the testes; $20 \mu \mathrm{C} / \mathrm{g}$ tritiated thymidine gives an effect approximately equal to $75 \mathrm{r}$ of external $\mathrm{x}$-ray.

5. Radiation effects on mammalian lipids and sterols. 0603. Drs. Schwartz, Debons; Res. Col. Gidez
A limited number of methods for extraction and analysis of lipids have been set up and used in experiments to study effects of whole-body radiation $(1000 \mathrm{r})$ on blood and adipose tissue in rats and dogs. Lipids from blood sampled during these experiments have been extracted, rectified, frozen, and stored pending satisfactory collaborative arrangements for final fractionation of the extracts by salicylic acid and gas chromatography. All rats not sacrificed on the day of irradiation were given an intraperitoneal injection of acetate-1-C $\mathrm{C}^{14} 3 \mathrm{hr}$ before sacrifice on the second or third postirradiation day. In vivo incorporation of acetate into adipose and hepatic fatty acids and particularly into hepatic cholesterol was found to be greatly increased in the irradiated as compared to the control animals.

\section{E. RADIATION-INDUCED NEOPLASIA}

1. Carcinogenesis in rats following sublethal $x$-or gamma-ray exposure. 0609. Drs. Cronkite, Bond, Shellabarger, Lippincott, Conard; Res. Col. Aponte

It has been established that $400 \mathrm{r}$ of $250-\mathrm{kvp}$ $\mathrm{x}$-rays administered as a single total-body dose on the 40th day of age to female Sprague-Dawley rats produced the maximum neoplastic response of mammary tissues. The effect of fractionation and protraction of the 400-r exposure was studied by administering either $22.2 \mathrm{r}$ on 18 consecutive days or $80 \mathrm{r}$ on 5 consecutive days. The neoplastic response of the mammary tissue was not different when $400 \mathrm{r}$ was given as a single exposure or when the exposure was divided as indicated above. These results are interpreted to mean that the neoplastic response of rat mammary tissue to totalbody irradiation is independent of the time over which radiation was administered within the limits of the dosage schedules studied.

The interaction of an exposure of $400 \mathrm{r}$ of totalbody irradiation and pregnancy was investigated. Pregnancy did not change the incidence of mammary neoplasms following exposure to radiation as compared to radiation alone in the nonpregnant rat. However, the growth rate of mammary neoplasms of the adenocarcinomatic type was strongly influenced by pregnancy. During pregnancy adenocarcinomas grew rapidly; following parturition, regardless of whether lactation was permitted, the adenocarcinomas regressed. No effects of pregnancy were noted on the growth rates of adenofibroma or fibroadenoma. 
Neither hypothyroidism, produced by administered propylthiouracil, nor hyperthyroidism, produced by triiodothyronine injections, influenced the neoplastic response of mammary tissue to radiation exposure. The administration of a synthetic estrogen, diethylstilbestrol, reduced the neoplastic response to radiation exposure and depressed ovarian hormone secretion, which suggests that in the absence of a normal hormonal pattern of both estrogen and progesterone as provided by the estrus cycle and the anterior pituitary, the carcinogenic potential of ionizing irradiation on breast tissue is reduced.

During the past two years, male and female rats of the Long-Evans strain have been followed after a total-body dose of $400 \mathrm{r}$ of x-rays. Although more mammary neoplasms were found in both male and female rats exposed to radiation than in nonexposed animals of this strain, the incidence of mammary neoplasms was considerably less than that noted in Sprague-Dawley rats following a similar radiation exposure. These results are interpreted to mean that there is a strain difference in the neoplastic response of mammary tissue of the rat to total-body irradiation.

An experiment was begun to test the relationship of the neoplastic response of the rat breast to the dose of total-body radiation, since previous reports from this laboratory suggested that, between the limits of 25 and $400 \mathrm{r}$ of $250-\mathrm{kvp} \mathrm{x}$-rays, doubling the dose doubled the neoplastic response. Although the current experiment will not be completed for another year, present results are consistent with the hypothesis that the neoplastic response of the rat breast is related to the dose of radiation in a linear, nonthreshold fashion.

Another experiment was begun to expand the study on the neoplastic response of the rat breast to fractionated and protracted total-body radiation exposure. Again, the experiment is not completed, but within the limits of $500 \mathrm{r}$ given over a few minutes to $500 \mathrm{r}$ given over 2 mo the neoplastic response of the breast is not changed. However, when $500 \mathrm{r}$ was given over $4 \mathrm{mo}$, the neoplastic response observed to date has been very much reduced.

2. The role of the ovary in the neoplastic response of breast tissue to total or partial-body x-irradiation. 0609. Drs. Cronkite, Shellabarger, Bond, Lippincott

Total-body exposure of 40-day-old female Sprague-Dawley rats to $400 \mathrm{r}$ of 250-kvp x-rays delivered in a single dose was followed by a $79 \%$ tumor incidence, with one or more neoplasms of the breast at the end of 10 mo postexposure. The incidence of breast neoplasms in nonexposed rats of the same age was $2 \%$. The over-all incidence of nonbreast tissue neoplasms was $2 \%$ in all groups with and without radiation exposure.

Exteriorizing and shielding the ovaries, transplanting nonexposed ovaries into ovariectomized irradiated rats, or shielding the head did not reduce the incidence of breast neoplasms below $69 \%$. Shielding the ovarian area reduced the incidence slightly to $40 \%$. Removal of the ovaries before or after total-body radiation reduced, but did not eliminate, neoplasia of the breast in 19 to $23 \%$. A further reduction to $25 \%$ occurred when the day of exposure was delayed to 120 days of age, although this group was studied for only 6 mo postexposure. Exposure of the ovaries alone or ovariectomy did not induce neoplasia of the breast.

These results were interpreted to mean that total-body radiation or exposure of the entire animal except the ovaries or the head induces neoplasia of the breast. The presence of functioning ovary is required for the maximum neoplastic response of the breast to radiation. Reasons were presented for believing that $400 \mathrm{r}$ of total-body radiation both hastens the onset of neoplasia of the breast and induces a higher incidence of neoplasia of the breast than would be expected to occur if the nonexposed rats were allowed to live out their life span.

The histological types of neoplasms of the breast were, in decreasing order of occurrence, adenofibroma, adenocarcinoma, fibroadenoma, and fibrosarcoma. When multiple neoplasms were found in the same animal, the neoplasms were usually of the same type. Although the adenocarcinomas were noted to appear somewhat earlier and the adenofibromas somewhat later, no further correlation of histological type with any radiation, shielding, or surgical treatment was found.

The relatively short period of time between exposure and development of a high incidence of breast neoplasms suggests that the young female SpragueDawley rat offers many advantages in studies of neoplasia induction by total-body radiation.

3. The response of castrated and intact male rats to $400 \mathrm{r}$ of total-body irradiation. 0609. Drs. Cronkite, Shellabarger, Bond, Lippincott

Male Sprague-Dawley rats, both castrated and intact, had a 50\% incidence of breast neoplasms 16 


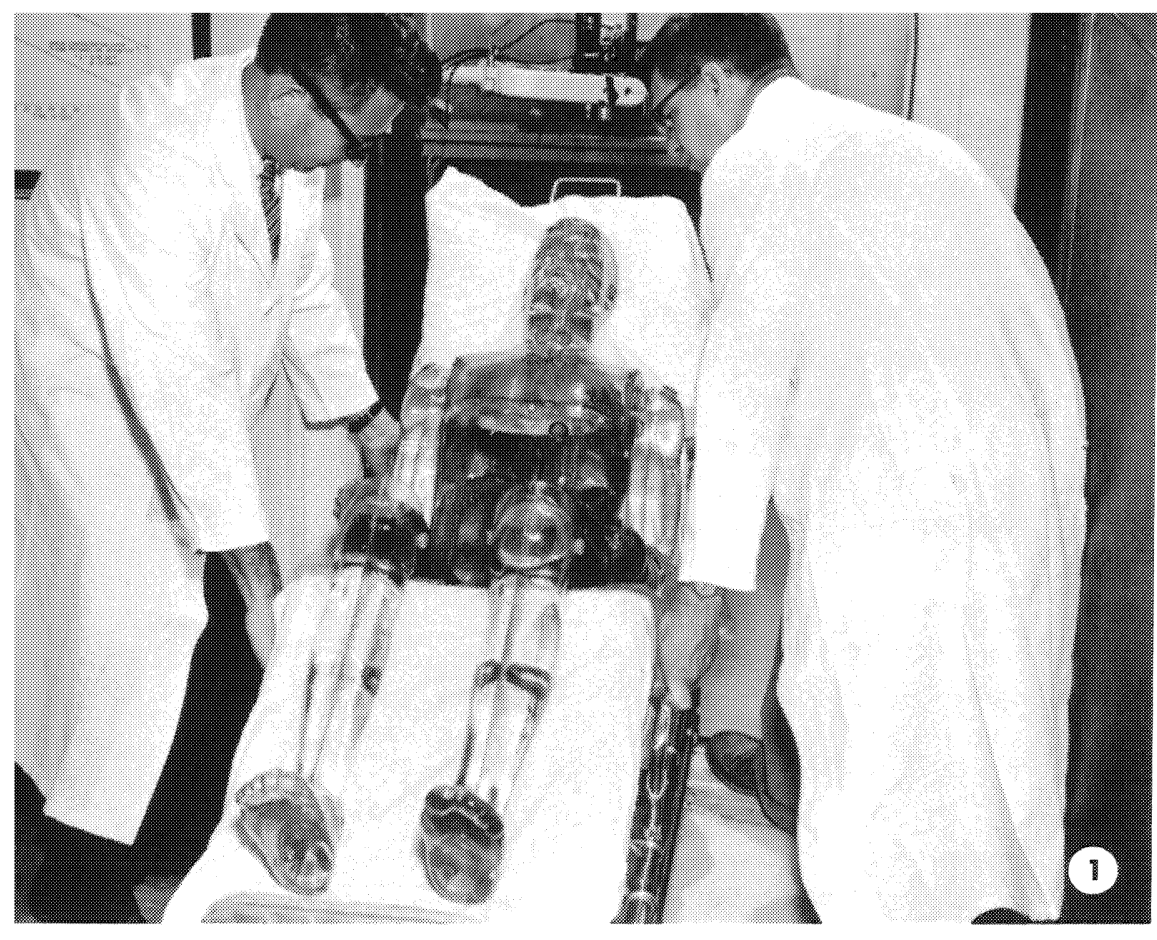

1. Plastic phantom of standard man, fllled with radioactive solution, is carried into whole-body counter. Measurements on phantoms provide dara for calibration and comparison of dara obtained from patients.

1. Plastic phantom, placed in standard measuring position, is positioned under a detecting crystal of thallium-activated sodium iodide.

1. Brookhaven employee, seated in whole-body counter for standard measurement during a survey of employees, receives instructions on the use of the two-way intercommunication system.

1. Crystal detector is positioned over a patient from the Industrial Medicine Clinic who may have been exposed to internal radioactive contamination. By whole-body measurement, the presence and extent of such contamination can be defermined.

Personnel operating 100-channel analyzer and print-out equipment during measurement of patient in whole-body counter.

Defector crystal is positioned over a patient who has received neutron capture therapy in treatment of brain cancer. A count of the neutron-induced gamma activity will provide a measure of the intensily of neutron exposure.

Patient seated in whole-body counter for measurement of radioactive sodium in sfudy of management of hypertension.

Use of the whole-body counter in the study of protein metabolism in cancer. An iodine-labeled protein fraction has been given to this petient with multiple myeloma; its disappearance can be followed accurately over a period of weeks.

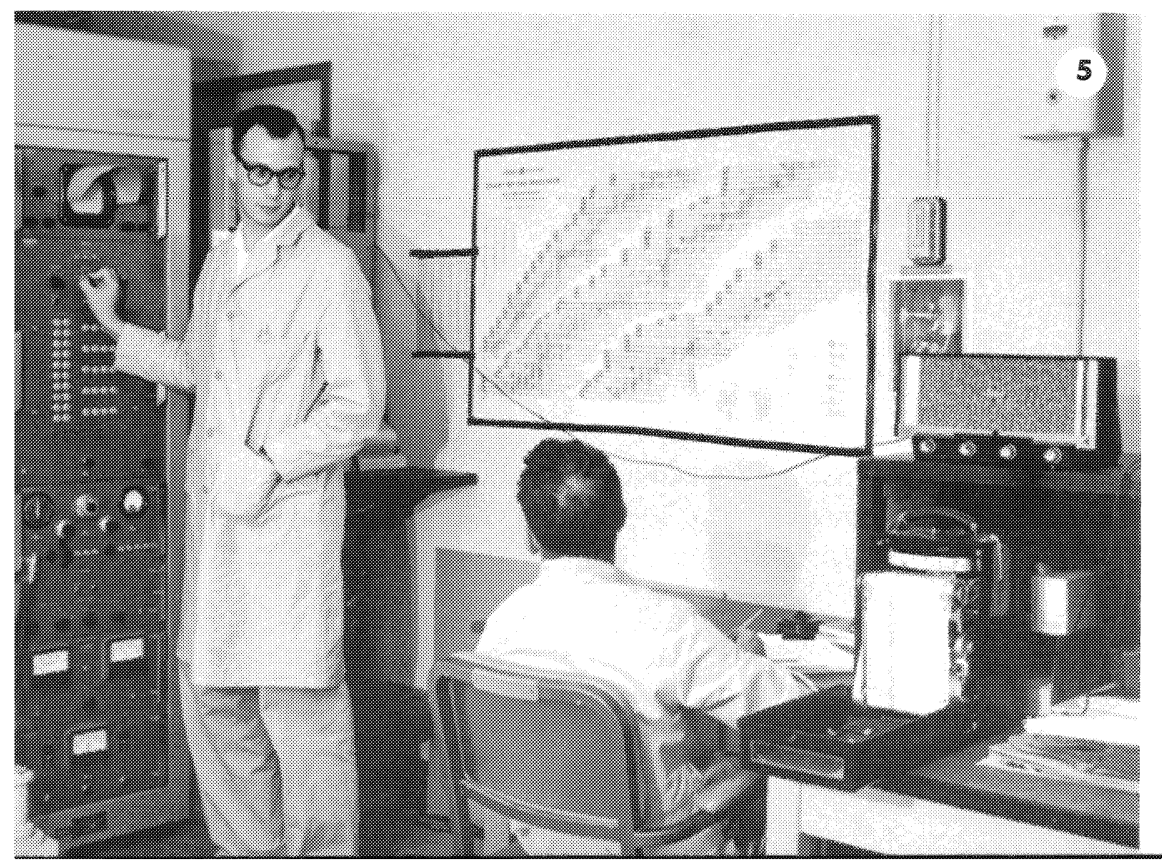

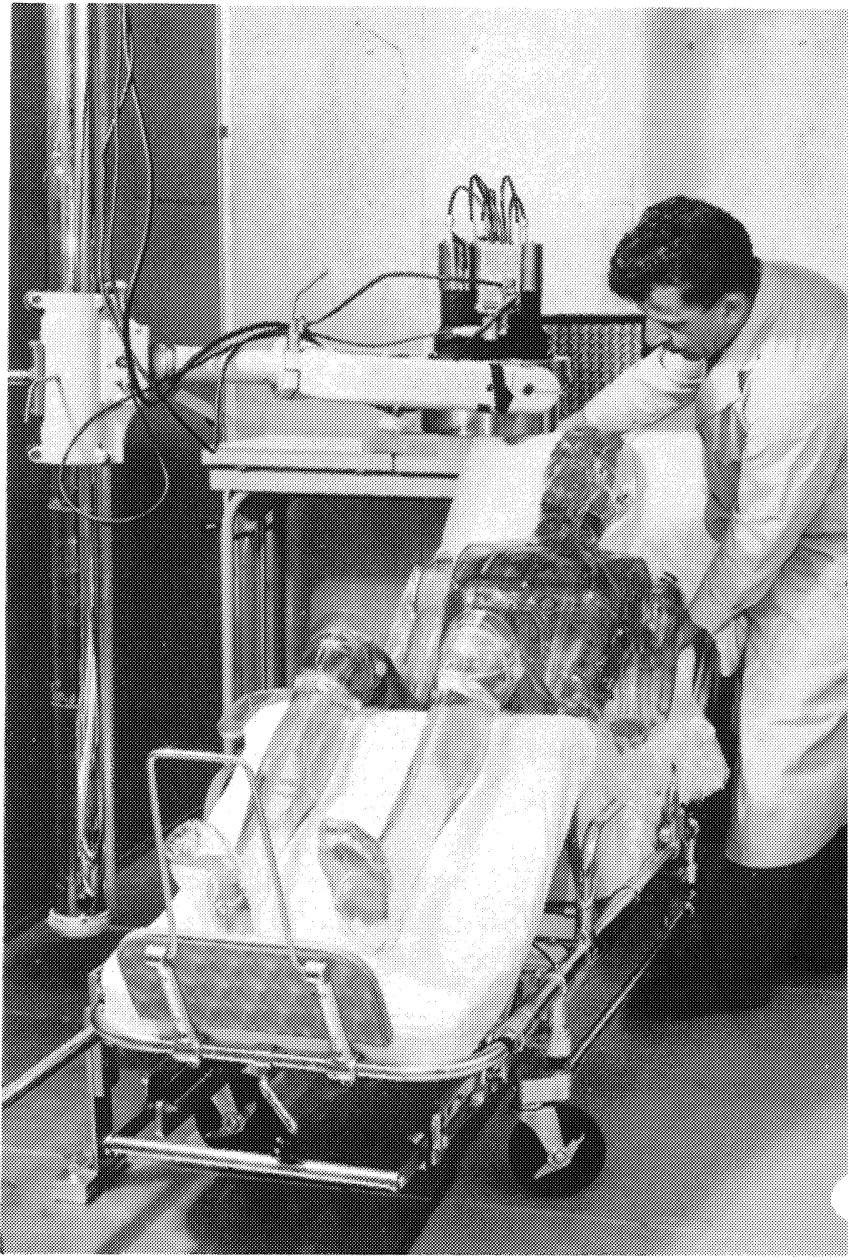

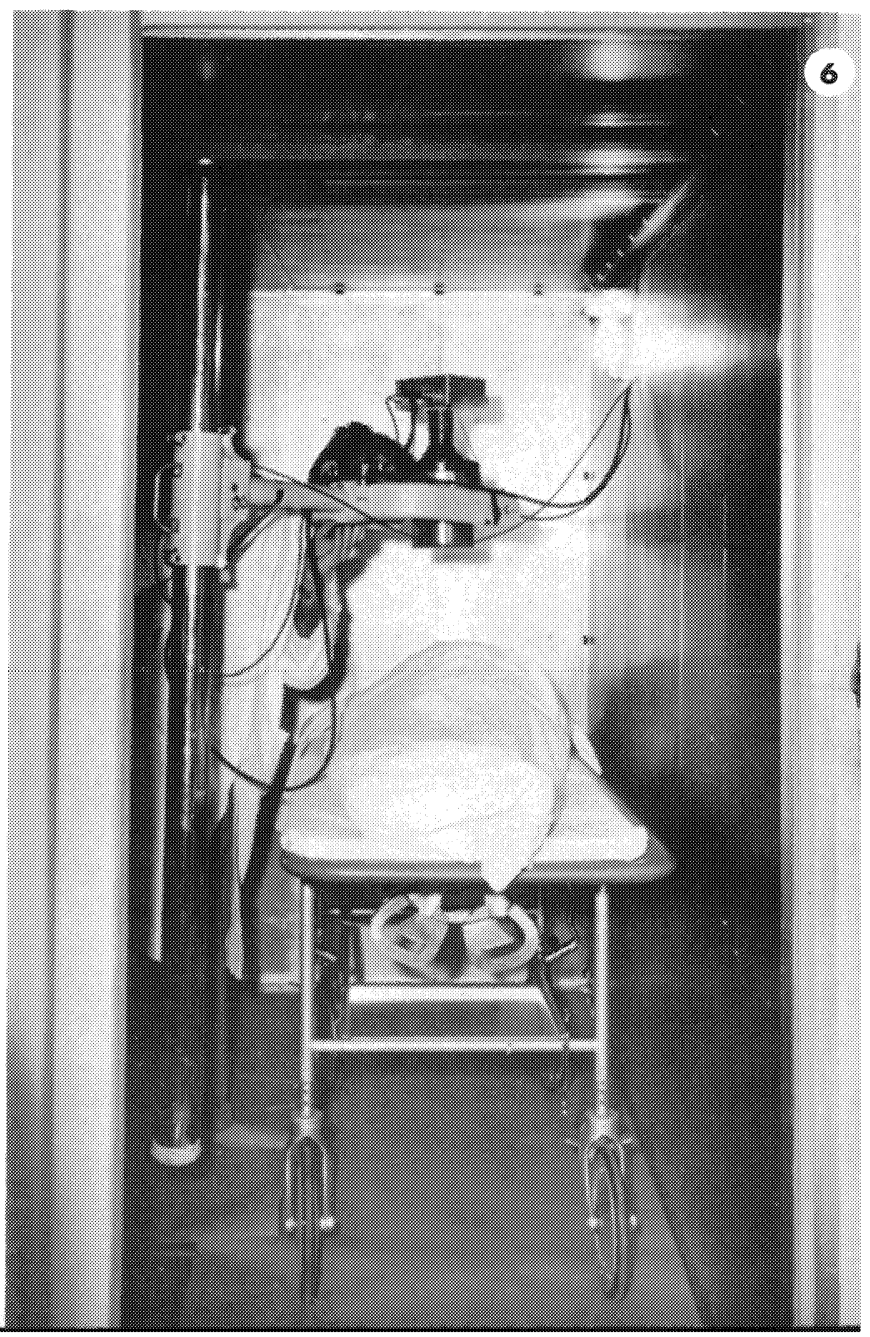

